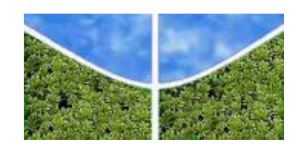

UNIVERSIDADE DE BRASÍLIA INSTITUTO DE CIÊNCIAS BIOLÓGICAS

DEPARTAMENTO DE BOTÂNICA PROGRAMA DE PÓS-GRADUAÇÃO EM BOTÂNICA

COMPOSIÇÃO, ESTRUTURA E DIVERSIDADE DA VEGETAÇÃO HERBÁCEOARBUSTIVA EM VEREDAS NO JALAPÃO, TOCANTINS

DIOGO PEREIRA DA SILVA

BRASÍLIA - DF

Julho de 2016 


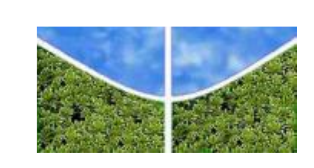

UNIVERSIDADE DE BRASÍLIA INSTITUTO DE CIÊNCIAS BIOLÓGICAS

DEPARTAMENTO DE BOTÂNICA

PROGRAMA DE PÓS-GRADUAÇÃO EM BOTÂNICA

\section{COMPOSIÇÃO, ESTRUTURA E DIVERSIDADE DA VEGETAÇÃO HERBÁCEO- ARBUSTIVA EM VEREDAS NO JALAPÃO, TOCANTINS}

Dissertação apresentada ao Programa de Pós-Graduação em Botânica como requisito parcial para a obtenção do título de mestre em Botânica na Universidade de Brasília (UnB).

ORIENTADORA: Prof. Dra. Cássia Beatriz R. Munhoz Diogo Pereira da Silva

BRASÍLIA - DF

Julho de 2016 


\section{COMPOSIÇÃO, ESTRUTURA E DIVERSIDADE DA VEGETAÇÃO HERBÁCEO- ARBUSTIVA EM VEREDAS NO JALAPÃO, TOCANTINS}

Trabalho realizado junto ao Programa de Pós-Graduação em Botânica da Universidade de Brasília como requisito parcial para obtenção do título de mestre em Botânica.

Banca examinadora:

Profa. Dra. Cássia Beatriz Rodrigues Munhoz

Orientadora - UnB

Profa. Dra. Carolyn Elinore Barnes Proença

Membro Titular - UnB

Prof. Dr. Luciano Coelho Milhomens

Membro Titular - UCB

Prof. Dr. José Roberto Rodrigues Pinto

Membro Suplente - UnB 
"E eis que vou hoje pelo caminho de toda a terra; $e$ vós bem sabeis, com todo o vosso coração, e com toda a vossa alma, que nem uma só palavra falhou de todas as boas coisas que falou de vós o Senhor vosso Deus; todas vos sobrevieram, nenhuma delas falhou." (Josué 23:14).

Ebenézer; Até aqui nos ajudou o Senhor. 


\section{AGRADECIMENTOS}

Por tudo o que tens feito, por tudo o que vais fazer, por tuas promessas e tudo que és, eu quero te agradecer, com todo meu ser! Te agradeço, meu Senhor!

À professora Cássia Munhoz, agradeço por entender todas as minhas necessidades e anseios, por ser como uma rocha firme e me juntar cada vez que caia em pedaços. Eu lhe aplaudiria até que o eco lhe aplaudisse de volta!

Ao Professor Octávio L. Franco, agradeço por me apresentar o mundo científico, com toda sua excelência e generosidade.

À amiga Natália Bijos, pelos bons momentos e pelos difíceis também. Por cada picada de abelha no belíssimo Jalapão, por me ouvir e procurar me compreender todas as vezes.

À amiga Caroline Teixeira, por compreender a minha ausência e por degustar a minha presença, por estar ao meu lado, seja como for.

Ao pastor Jouber Almeida, por me aceitar como eu sou aos olhos de Deus, por me impulsionar ao que eu posso ser de melhor, pela amizade e pela cumplicidade. (“O moço, porém, nada percebeu; só Jônatas e Davi sabiam do negócio.” - 1 Samuel 20.39)

Aos meus companheiros de vida, fé, jejum e oração Jadson Leonardo e Rodrigo Luis.

Aos vários especialistas que forneceram preciosas identificações: Marccus V. S. Alves (Cyperaceae), Regina C. Oliveira (Poaceae), João B. Bringel (Asteraceae), Anadria S. Silva (Poaceae), Daniel V. Segarra (várias famílias), Jair J. E. Q. Faria Junior (várias famílias), Maria Rosa V. Zanatta (Fabaceae), Vanessa L. Rivera (Asteraceae), Carolyn E. B. Proença (várias famílias), Adriana L. R. Oliveira (Eriocaulaceae). 
Aos professores do Departamento de Botânica por contribuírem com minha formação, compartilhando seu conhecimento de forma generosa.

À Professora Carolyn por me lembrar, mesmo sem saber, que a Universidade está de portas abertas a quem possa interessar.

Agradeço ao PNUD pelo apoio financeiro que permitiu viabilizar toda logística e infraestrutura necessária para execução deste estudo;

ICMBio pelo apoio e auxílio no trabalho de campo. Ubiratam, sempre com sorriso no rosto, carregando meu solo, contanto piadas, nos fazendo leves.

À CAPES pela bolsa de mestrado concedida a mim concedida.

À minha mãe Denise, por toda sua chatice, sem o qual eu não encontraria a ponte que me guia à vida, pelo apoio incondicional, compreensão e exemplo.

À minha irmã Joyce, por me apoiar com seus olhares de orgulho, que me aquecem o coração.

Ao Jalapão, que tive a grata oportunidade de conhecer e me maravilhar, um lugar onde o capim é dourado.

Por fim, agradeço aos meus futuros alunos, para quem hoje me preparo, pelo amor à docência e a pesquisa. 


\section{RESUMO GERAL}

A Vereda é uma fitofisionomia savânica do Bioma Cerrado onde a variação sazonal na drenagem do solo pode influenciar a ocorrência e a distribuição das espécies, determinando sua composição florística. A riqueza florística e a diversidade do estrato herbáceo-arbustivo das Veredas são pouco conhecidas, embora este seja o maior componente na vegetação do Cerrado. Assim, o presente trabalho teve por objetivo realizar o levantamento florístico da camada herbáceo-arbustiva de cinco Veredas, e a comparação de suas floras com outras do Brasil Central, e também com outras fitofisionomias, e ainda o estudo fitossociologico de quatro Veredas na região do Jalapão, Tocantins (Estação Ecológica Serra Geral do Tocantins), que, juntamente com o Parque Estadual do Jalapão constituem a maior área contínua de Cerrado preservado sob regime de proteção integral no Brasil. Os solos no Jalapão são do tipo Neossolo Quartizarênico, distróficos e álicos. O clima da região é caracterizado por forte sazonalidade, onde $90 \%$ das chuvas ocorrem de outubro a abril. A temperatura média na região é de $27^{\circ} \mathrm{C}$ e a precipitação anual média é de $1.700 \mathrm{~mm}$. Os estudos quali-quantitativos da vegetação foram realizados em expedições no período chuvoso quando os espécimes que se encontravam em estágio reprodutivo foram coletados e prensados. Através do método de linha, a projeção das espécies foi anotada para cálculos das cobertura e frequência. A identificação das espécies foi feita por meio de análises morfológicas, utilizando-se chaves analíticas, consultas a especialistas de várias famílias e comparação com exsicatas depositadas no herbário do Instituto Brasileiro de Geografia e Estatística e da Universidade de Brasília, onde foram depositados. Registraram-se 218 espécies distribuídas em 114 gêneros e 51 famílias, sendo que as famílias com maior número de espécies foram Poaceae (40 espécies), Cyperaceae (32), Xyridaceae (23) e Eriocaulaceae (18). Apenas 35\% das espécies ocorreram nas cinco áreas inventariadas, e 14,5\% foram compartilhadas com outras fitofisionomias. Foram registradas 78 novas ocorrências para o estado do Tocantins. Para análise fitossociológica foram registradas 123 espécies em 69 gêneros e 33 famílias. 
Analises das variáveis ambientais, de agrupamento e ordenação, refletem a homogeneidade florística entre as áreas comparadas, o que está relacionado à baixa variação ambiental entre as mesmas. A riqueza florística das Veredas no Jalapão foi elevada e com registro de novas espécies, tendo se mostrado dentro dos limites normalmente encontrados para outras Veredas no Brasil Central.

(CAPES, ICMBio, PNUD)

Palavras-chave: Cerrado, Poaceae, riqueza de espécies. 


\section{SUMÁRIO}

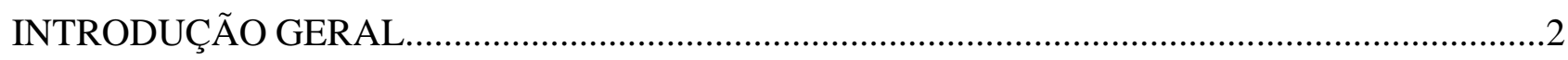

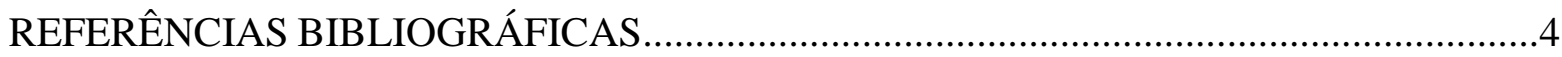

CAPÍTULO 1. A VEREDA É UMA FITOFISIONOMIA SAVÂNICA DISTINGUÍVEL? COMPOSIÇÃO FLORÍSTICA DA VEGETAÇÃO HERBÁCEO-ARBUSTIVA EM VEREDAS NO BRASIL CENTRAL

RESUMO

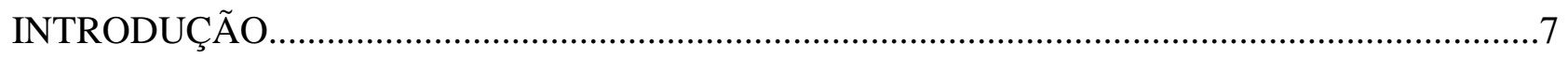

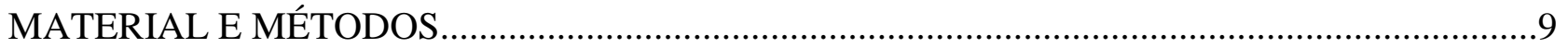

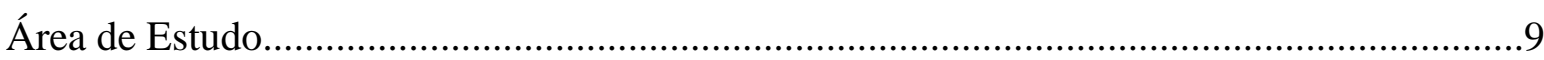

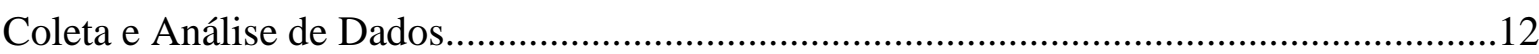

RESULTADOS

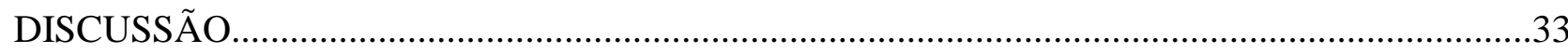

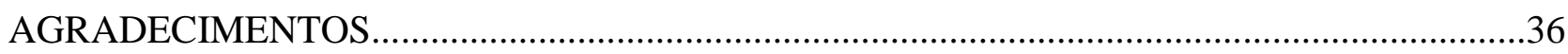

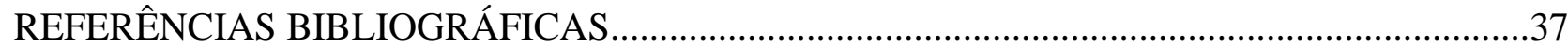

CAPÍTULO 2. ESTRUTURA FITOSSOCIOLÓGICA EM VEREDAS NA ESTAÇÃO ECOLÓGICA SERRA GERAL DO TOCANTINS NO JALAPÃO, TOCANTINS

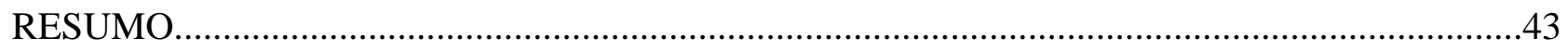

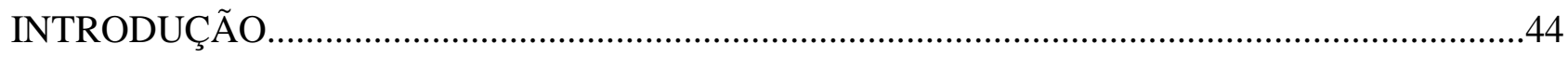

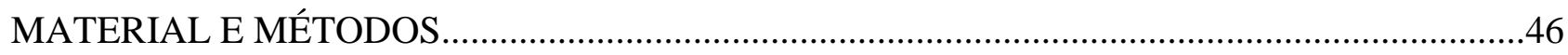

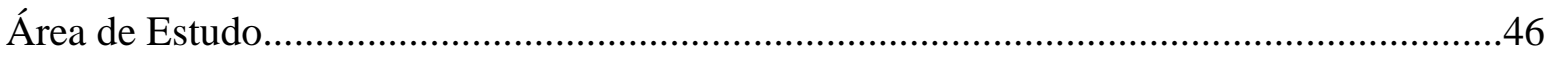

Amostragem da Vegetação............................................................................................4

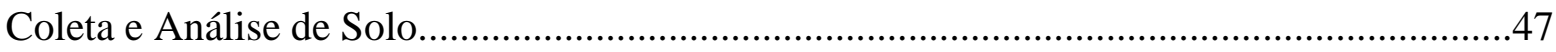


Análise dos Dados

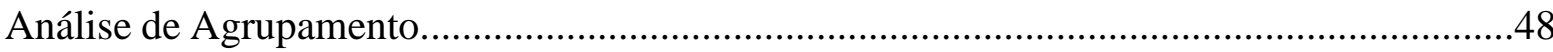

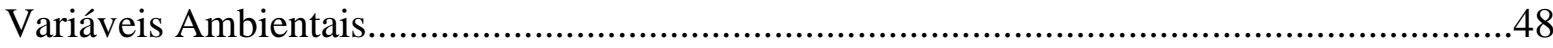

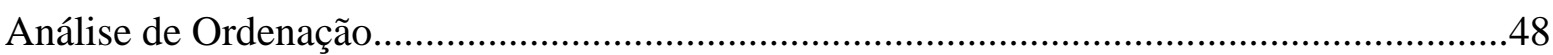

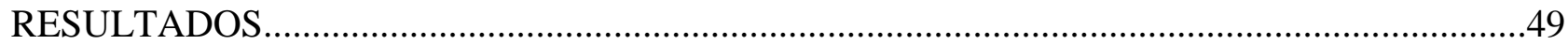

DISCUSSÃO

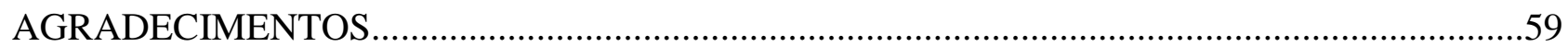

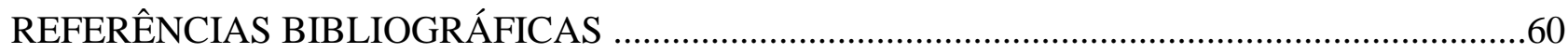




\section{LISTA DE ILUSTRAÇÕES}

\section{CAPÍTULO 1}

Figura 1: Localização das áreas estudadas na Estação Ecológica Serra Geral do Tocantins, Brasil, e demais localidades de Cerrado, onde CSS = Cerrado sensu stricto, $\mathrm{CS}=$ Campo sujo, $\mathrm{CLU}=\mathrm{Campo}$ Limpo Úmido e V1, 2, 3, 4 e 5 = Veredas 1, 2, 3, 4 e 5.

Figura 2. Áreas de estudo. A - Vereda próxima ao rio Balsas $\mathrm{V}_{-} 1$; B - Vereda na margem direita do rio Novo V_2; C- Vereda na margem esquerda do rio Novo V_3; D- Vereda próxima ao rio Preto V_4; E- Vereda próxima à Lagoa Espraiada V_5.

Figura 3: Ranque das dez famílias que apresentam maior número de espécies no levantamento florístico na Estação Ecológica Serra Geral do Tocantins, TO e nas veredas comparadas.

Figura 4: Ranque das famílias que apresentam maior número de espécies no levantamento florístico na Estação Ecológica Serra Geral do Tocantins, TO, nas veredas comparadas e nas fitofisionomias comparadas.

Figura 5: Ranque dos dez gêneros que apresentam maior número de espécies no levantamento florístico na Estação Ecológica Serra Geral do Tocantins, TO e nas veredas comparadas.

Figura 6: Ranque dos gêneros que apresentam maior número de espécies no levantamento florístico na Estação Ecológica Serra Geral do Tocantins, TO, nas veredas comparadas e nas fitofisionomias comparadas.

Figura 7: Porcentagem de distribuição de espécies de acordo com o hábito no estudo florístico na Estação Ecológica Serra Geral do Tocantins, TO, e nas veredas comparadas. 
Figura 8: Posicionamento por eixos de ordenação (DCA) dos componentes herbáceos-arbustivos de 13 áreas de Veredas a nível específico (A) e genérico (B). MS_2, Vereda m Mato Grosso do Sul, GO_1, 2 e 3, Veredas em Goiás, TM_1, 2, 3 e 4, Veredas em Minas Gerais e TO_1, 2, 3, 4 e 5 = Veredas na EESGTO.

Figura 9: Posicionamento por eixos de ordenação (DCA) dos componentes herbáceos-arbustivos de 24 áreas em diferentes fitofisionomias de Cerrado a nível específico (A) e genérico (B). CSS_DF_, CSS_SP_1, 2 e 3 = Cerrado Sensu Stricto, CS_SP, CS_DF = Campo Sujo, CLU_DF, CLU_SP,

CLU_GO, CLU_PI, V_MS_1 = Campo Limpo Úmido, V_MS_2, V_GO_1, 2 e 3, V_TM_1, 2, 3 e 4, V_TO_1, 2, 3, 4 e 5 = Veredas.

\section{CAPÍtUlO 2.}

Figura 1. Localização das quatro Veredas estudadas na Estação Ecológica Serra Geral do Tocantins, Brasil.

Figura 2. Dendrograma gerado a partir do índice de Sorensen (Bray-Curtis) entre as 60 linhas das quatro Veredas Estação Ecológica Serra Geral do Tocantins. V_1 = Vereda 1, V_2 = Vereda 2, V_3 = Vereda 3 e V_4 = Vereda 4. Três grupos foram evidenciados por diferentes colorações.

Figura 3. Análise de redundância (RDA) para as 60 linhas e variáveis ambientais nas Veredas da Estação Ecológica Serra Geral do Tocantins. 


\section{LISTA DE TABELAS}

\section{CAPÍTULO 1}

Tabela 1: Fitofisionomias de Cerrado comparados com o presente estudo. Cod. - código dos sítios, Prec. - Precipitação média anual $(\mathrm{mm} / \mathrm{ano}), \mathrm{T}$ - temperatura média anual $\left({ }^{\circ} \mathrm{C}\right), \mathrm{N}=$ número de espécies utilizadas na matriz de comparação.

Tabela 2: Famílias e espécies da flora amostradas em cinco veredas na Estação Ecológica Serra Geral do Tocantins (EESGTO), TO, e suas ocorrências em Veredas no estados de Goiás (GO), Mato Grosso do Sul (MS) e Minas Gerais (MG) e em áreas de Cerrado sensu stricto (CSS), Campo sujo (CS) e Campo Limpo Úmido (CLU). Onde: $*=$ nova ocorrência para o estado do Tocantins; $* *$ nova ocorrência para o Cerrado; Hábito e N= Número de coletor Silva D.P.

Tabela 3: Ocorrência de espécies e gêneros do presente estudo em comparação com outras fitofisionomias de Cerrado. Onde $\mathrm{N}^{\circ}=$ Número, EESGTO = Estação Ecológica Serra Geral do Tocantins, CSS = Cerrado sensu stricto, CS = Campo Sujo e CLU = Campo Limpo Úmido.

\section{CAPÍTULO 2}

Tabela 1. Espécies com maior cobertura absoluta potencial em quatro Veredas (V_1, V_2, V_3 e V_4) na Estação Ecológica Serra Geral do Tocantins, onde CA= Cobertura Absoluta, CR= Cobertura Relativa, FA= Frequência Absoluta e FR= Frequência Relativa. Em negrito os valores de CA, CR, FA e FR acima de $10 \%$. 


\section{INTRODUÇÃO GERAL}

Os ecossistemas tem sido explorados ao longo da história da humanidade, e o que se pretende é proporcionar a exploração racional, que só pode ser planejada a partir do conhecimento de suas dinâmicas biológicas (Pereira et al. 2001). Os estudos da composição florística e fitossociologica são elementos que contribuem para este planejamento (Marangon et al. 2003) orientando a facção de medidas de manejo para preservação e conservação dos ambientes, e ainda promovendo o conhecimento básico para programas de recomposição da vegetação (Vilela et al. 1994). Os levantamentos florísticos e fitossociológicos permitem conhecer os parâmetros qualitativos e quantitativos das veredas, bem como de outras fitofisionomias, evidenciando assim sua riqueza, diversidade e similaridade entre e dentro das áreas em questão. Assim, é possível comparar as variações florísticas e estruturais das veredas identificando as diferenças que possam existir entre as áreas analisadas.

O Cerrado é o segundo maior bioma da América do Sul (Klink \& Machado 2005) e inclui grande parte do Brasil Central e é considerada a mais rica e ameaçada savana do mundo (Silva \& Bates 2002). O Cerrado é caracterizado por duas estações bem definidas, com invernos secos e verões chuvosos normalmente, de outubro a março (Ribeiro \& Walter 2008). Assim, o clima predominante é o Aw no sistema Köppen desenvolvido a partir de um estudo intensivo dos limites climáticos dos principais tipos de vegetação do mundo (Tivy 1971).

A vegetação do bioma apresenta fisionomias que vão desde formações florestais que apresentam predominância do hábito arbóreo com formação de dossel fechado, passando pelas savânicas que compreendem árvores, arbustos e subarbustos sobre um estrato predominante graminoso até campestres com predominância de herbáceas e algumas espécies arbustivas (Ribeiro \& Walter 2008). Dentre as formações savânicas, as veredas são comunidades vegetais que ocorrem em áreas de nascentes na região do Brasil Central, tendo ao seu redor vegetação de cerrado, e em alguns locais matas de galeria (Eiten 1983, 1994). A principal característica destes ambientes é a 
presença da palmeira arbórea Mauritia flexuosa L.f. (buriti) que ocorre em geral, na porção mais alagada da vereda, uma vez que as veredas podem ser também caracterizadas por seu gradiente de umidade. A maior parte desse ambiente é ocupada por uma densa vegetação herbácea (Ramos et al. 2006, Ribeiro \& Walter 2008).

Nas Veredas se encontram espécies de plantas utilizadas pela população local para pastoreio do gado, com a utilização de escapos florais do capim dourado Syngonanthus nitens (Bong.) Ruhland (Eriocaulaceae) para produção de artesanato. O buriti Mauritia flexuosa L.f. (Arecaceae), largamente utilizado na dieta humana, artesanato e construção, tal uso é comum no estado do Tocantins, na região do Jalapão, situada ao leste do estado, onde se encontra a Estação Ecológica Serra Geral do Tocantins (EESGTO) (Schmidt 2011).

Neste sentido, o objetivo deste trabalho foi estudar a composição florística de veredas na Estação Ecológica Serra Geral do Tocantins, bem como realizar o estudo fitossociologico das mesmas, evidenciando informações sobre sua biodiversidade.

O texto da tese está dividido em dois capítulos, cujo títulos e objetivos são:

Capítulo 1: A Vereda é Uma Fitofisionomia Savânica Distinguível? Composição florística da vegetação herbáceo-arbustiva em Veredas no Brasil Central

- Realizar o levantamento florístico em Veredas na Estação Ecológica Serra Geral do Tocantins, TO, e comparar sua flora com a de outras Veredas no Brasil Central.

Capítulo 2: Estrutura fitossociologica em Veredas na "Estação Ecológica Serra Geral do Tocantins" no Jalapão, Tocantins

- Realizar o estudo fitossociologico, para o conhecimento da composição e diversidade em Veredas na Estação Ecológica Serra Geral do Tocantins, TO 


\section{REFERÊNCIAS BIBLIOGRÁFICAS}

Eiten, G. 1983. Classificação da vegetação do Brasil. In Classificação da vegetação do Brasil. CNPq.

Eiten, G. 1984. Vegetation of Brasilia. Phytocoenologia, p. 271-292.

Klink, C.A., Machado, R.B. 2005. Conservation of the Brazilian Cerrado. Conservation biology 19: $707-713$.

Marangon, L. C., Soares, J. J., Feciano, A. L. P. 2003. Florística arbórea da mata da pedreira: município de Viçosa, Minas Gerais. Revista Árvore, Viçosa, 27: 207-215.

Pereira, I. M.; Andrade, L. A.; Costa, J. R.; Dias, J. S. 2001. Regeneração natural em um remanescente de caatinga sob diferentes níveis de perturbação, no Agreste Paraibano. Acta Botânica Brasilica, Brasília, 15: 413-426.

Ramos, M.V.V., Curi, N., Motta, P.E.F., Vitorino, A.C.T., Ferreira, M.M., Silva, M.L.N. 2006. Veredas do Triângulo Mineiro: solos, água e uso. Ciência e Agrotecnologia Lavras, 30: 283293.

Ribeiro, J.F., Walter, B.M.T. 2008. As Principais Fitofisionomias do Bioma Cerrado. In Cerrado: Ecologia e Flora (S.M. Sano \& S.P. de Almeida, eds.). EMBRAPA, Planaltina, p. 153-212

Schmidt, I.B. 2011. Effects of local ecological knowledge, harvest and fire on Golden-grass (Syngonanthus nitens, Eriocaulaceae), a non-timber forest product (NTFP) species from Brazilian savanna. Tese (Doutorado em Botânica, Ecologia, Evolução e Biologia da Conservação). University of Hawai'I at Manoa. p. 186.

Silva, J.M.C, Bates, J.M. 2002. Biogeographic Patterns and Conservation in the South American Cerrado: A Tropical Savanna Hotspot. BioScience, 52: 225-234.

Tivy, J. 1971. Biogeography. A study of plants in the ecosphere. Edinburgh, UK, Oliver and Boyd. 
Vilela, E. A., Oliveira-Filho, A. T., Carvalho, D. A., Gavilanes, M. L. 1994. Fitossociologia e fisionomia de mata semidecídua margeando o reservatório de Camargos em Itutinga, MG. Ciências e práticas, Lavras, 18: 415-424. 


\section{CAPÍTULO 1}

\section{A VEREDA É UMA FITOFISIONOMIA SAVÂNICA DISTINGUÍVEL? COMPOSIÇÃO FLORÍSTICA DA VEGETAÇÃO HERBÁCEO-ARBUSTIVA EM VEREDAS NO BRASIL CENTRAL}

\section{RESUMO}

A Vereda é uma fitofisionomia savânica do Bioma Cerrado que ocorre sobre solos úmidos em áreas de nascentes na região do Brasil Central, a drenagem no solo nesses ambientes determina a ocorrência e a distribuição das espécies, o que reflete na sua composição florística. A riqueza florística do estrato herbáceo-arbustivo de Veredas é pouco conhecida. Assim, o objetivo deste trabalho foi realizar o levantamento florístico da camada herbáceo-arbustiva de Veredas no Jalapão/TO (Estação Ecológica Serra Geral do Tocantins - EESGTO) e comparar esta flora entre Veredas de outras localidades no Brasil Central, e ainda com outras fitofisionomias campestres e savânicas. Afim de avaliar o compartilhamento da flora, em nível específico e genérico, entre as Veredas e ambientes savânicos em solo bem drenado e ambientes campestres, com solos úmidos e bem drenados para determinar quão distinta é a fora de Veredas em relação a outras fitofisionomias. Foi realizada coleta do material botânico em Veredas na região do Jalapão, seguida de comparação com a flora de outros sítios de Vereda, disponível em estudos publicados, bem como áreas de Cerrado sensu stricto, Campo Sujo e Campo limpo úmido. Para comparação entre as áreas analisadas foi medido o índice de Jaccard para determinar a similaridade e DCA (Análise de Correspondência Retificada) para as relações florísticas das áreas. Nas veredas da EESGTO foram registradas 215 espécies distribuídas em 111 gêneros e 51 famílias, sendo cinco espécies novas ocorrências para o Cerrado e 78 para o Tocantins. Considerando todos os sítios analisados, temos que as Veredas na EESGTO representam 29,7\% do total de espécies. O total de $47 \%$ de espécies ocorreram somente em Veredas. Logo, concluímos que as Veredas no Brasil Central podem ser consideradas uma unidade florística distinguível de outras fitofisionomias.

(CAPES, ICMBio, PNUD)

Palavras-chave: Cerrado, herbácea, Similaridade. 


\section{INTRODUÇÃO}

O Cerrado é a savana com maior diversidade de plantas no mundo, sendo composto por um mosaico de formações que contemplam desde campos, passando por formações savânicas, até florestas de vários tipos (Ribeiro \& Walter 2008). Sua flora possui alto nível de endemismo (Mendonça et al. 2008), que pode estar relacionada à sua extensão que compreende cerca de 2 milhões $\mathrm{km}^{2}$, ocorrendo principalmente na região Centro-Oeste do Brasil, abrangendo grandes variações altitudinais, climáticas e edáficas em um gradiente de $20^{\circ}$ de latitude (Oliveira-Filho et al. 1989; Silva \& Bates 2002; Klink \& Machado 2005).

Entre as formações savânicas do Cerrado a Vereda é um fitofisionomia que ocorre sobre solo úmido, sendo uma paisagem caracterizada por um estrato herbáceo-subarbustivo dominante com a presença da palmeira arbórea Mauritia flexuosa L.f. (buriti). A Vereda apresenta elevada riqueza e diversidade florística, que está relacionada à sua heterogeneidade ambiental, condicionada por variações na drenagem e texturas ao longo do perfil do solo (Guimarães et al. 2002, Resende et al. 2013). Apresenta zonas que vão desde permanentemente alagadas até zonas bem drenadas na estação seca (Ramos et al. 2006, Ribeiro \& Walter 2008). As Veredas são muito comuns ao leste do estado do Tocantins, especialmente na região do Jalapão (Villela \& Nogueira 2011).

O Jalapão apresenta uma grande extensão de áreas protegidas contínuas, composta por cinco unidades de conservação. Sendo três de proteção integral que somam cerca de 2 milhões de hectares e duas de uso sustentável que abrangem 500 mil hectares. Entre as áreas de proteção integral está a Estação Ecológica Serra Geral do Tocantins (EESGTO), onde encontram-se grande áreas de veredas, utilizadas até a criação da estação para colheita de escapos florais do capim dourado - Syngonanthus nitens (Bong.) Ruhlnad (Eriocaulaceae) e do pecíolo de buriti - Mauritia flexuosa L. (Arecaceae), que são matéria para o artesanato, comercializado em todo Brasil (Schmidt et al. 2007). Mesmo o Jalapão contendo áreas extensas de proteção no Brasil, sua flora, assim como grande parte da flora 
do Cerrado, ainda carece de estudos florísticos (Proença et al. 2007), estudos recentes tem revelado novas descobertas de espécies na região (Borges \& Antar 2016).

A região do Jalapão ainda é bem preservada, resultado principalmente de seu solo arenoso, impróprio para o estabelecimento da agricultura, e ainda por conter uma baixa densidade demográfica (Schmidt et al. 2007). Suas atividades econômicas estão baseadas no extrativismo, agricultura e pecuária de subsistência (Seplam 2003a,b, Schmidt et al. 2011). No entanto, na última década, houve um grande estímulo à expansão agrícola nas áreas de Cerrado do Tocantins (Cifuentes 2014). O recente decreto ( $\mathrm{N}^{\circ} 8.447$ do 6 de maio de 2015) de criação do MATOPIBA, visa promover e coordenar políticas públicas voltadas ao aumento da produção agrícola e pecuária nos estados da Bahia, Maranhão, Piauí e Tocantins (Brasil 2015b, p. 1). A expansão do agronegócio promove o aumento nas taxas de desmatamento, com a remoção de espécies da vegetação nativa, o que torna urgente a coleta para o conhecimento das mesmas (Ferreira et al. 2009).

O Cerrado de modo geral, possui uma grande diversidade de espécies vegetais (Mendonça et al. 2008; Forzza et al. 2012). O registro de um táxon em uma localidade em um determinado período de tempo é a informação biológica mais primaria, sendo crucial para manutenção e conservação da biodiversidade (Boulinier et al. 1998; Sousa-Baena et al. 2014). Durante as últimas décadas vários estudos tem sintetizado o conhecimento disponível para o Cerrado (Rizzini 1963; Castro et al. 1999; Oliveira-Filho \& Ratter 2002; Ratter et al. 2003). Comparações florísticas entre sítios de uma mesma fitofisionomia encontraram floras distintas entre os mesmos (Felfili \& Silva 1993, Kurtz et al. 2015). Assim como entre diferentes fitofisionomias (Munhoz \& Felfili 2007). Porém, avaliações da exclusividade da flora de veredas em relação a outras fitofisionomias ainda não foram realizadas.

Apesar da importância das Veredas para manutenção da diversidade florística e dos recursos hídricos no Cerrado (e.g. Araújo et al. 2002, Oliveira et al. 2009; Moreira et al. 2015), essas áreas úmidas carecem de estudos que embasem políticas públicas para sua conservação (Rosolen et al. 2014). Neste estudo nós buscamos sintetizar o conhecimento florístico de Veredas no Brasil Central. 
Nossos objetivos foram: (1) realizar o levantamento da flora herbáceo-arbustiva das Veredas na EESGTO; (2) sintetizar a informação sobre a composição florística das Veredas no Brasil Central, e (3) avaliar o compartilhamento em nível específico e genérico entre Veredas e fitofisionomias campestres e savânicas no Bioma Cerrado. Nós buscamos responder a seguinte questão: Quão exclusiva é a flora herbáceo-arbustiva dessa savana úmida?

\section{MATERIAL E MÉTODOS}

\section{Área de Estudo}

O estudo foi conduzido na Estação Ecológica Serra Geral do Tocantins (EESGTO). Localizada no leste do Estado do Tocantins e extremo oeste da Bahia ( $10^{\circ} 25^{\prime}$ a $11^{\circ} 21^{\prime}$ ' S e $47^{\circ} 13^{\prime}$ a $\left.45^{\circ} 50^{\prime} \mathrm{W}\right)$, a EESGTO possui uma área de aproximadamente 716.343 ha (Villela \& Nogueira 2011). A região é composta por um conjunto de depressões e planaltos adjacentes, formando as serras do tipo mesa e morros testemunhos (Villela \& Nogueira 2011). Os solos são principalmente do tipo Neossolo Quartzarênico, distróficos e álicos (Embrapa 1999, Mamede et al. 2002). De acordo com a classificação de Köppen, o clima no Cerrado é predominantemente Aw (tropical chuvoso), caracterizado pela presença de invernos secos e verões chuvosos, sendo que a precipitação anual varia de $750 \mathrm{~mm}$ a $2.000 \mathrm{~mm}$ (Adámoli et al. 1987). A temperatura média na região é de $27^{\circ} \mathrm{C}$ e $90 \%$ das chuvas ocorrem de Outubro a Abril (Seplam 2003b).

Foram realizadas coletas botânicas em cinco Veredas (Figura 1). A primeira ocorre ao sul da

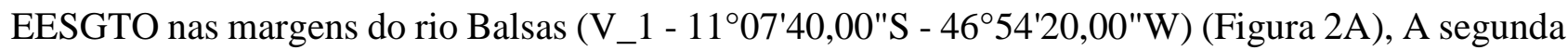
(V_4 - 1052'03,00"S- 46³6'55,40"W) (Figura 2B), na margem direita do rio Novo. A terceira ocorre na margem esquerda do rio Novo (V_3 - 1051'49,30"S - 46³6'54,30"W) (Figura 2C). A quarta área está situada na região norte da EESGTO, na margem do rio Preto (V_5 - 10³6'48,70"S $\left.46^{\circ} 31^{\prime} 41,50^{\prime \prime} \mathrm{W}\right)$ (Figura 2D), e a quinta (V_2 - 1057'09,00"S - 46² $\left.42^{\prime} 13,00^{\prime \prime W}\right)$ (Figura 2E) está situada na região conhecida como Lagoa Espraiada. 


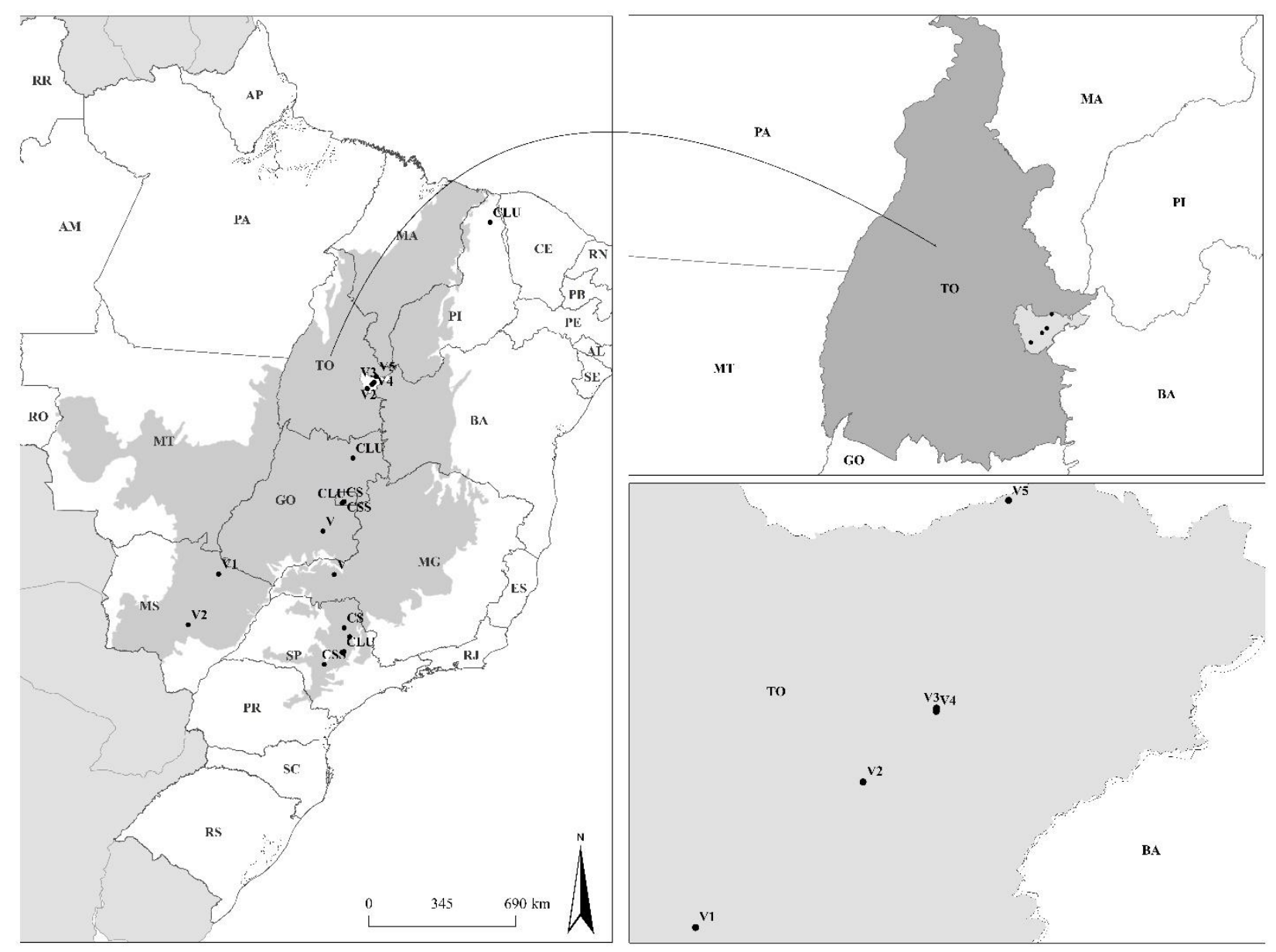

Figura 1: Localização das áreas estudadas na Estação Ecológica Serra Geral do Tocantins, Brasil, e demais localidades de Cerrado, onde CSS = Cerrado sensu stricto, CS = Campo sujo, CLU = Campo Limpo Úmido e V1, 2, 3, 4 e 5 = Veredas 1, 2, 3, 4 e 5. 

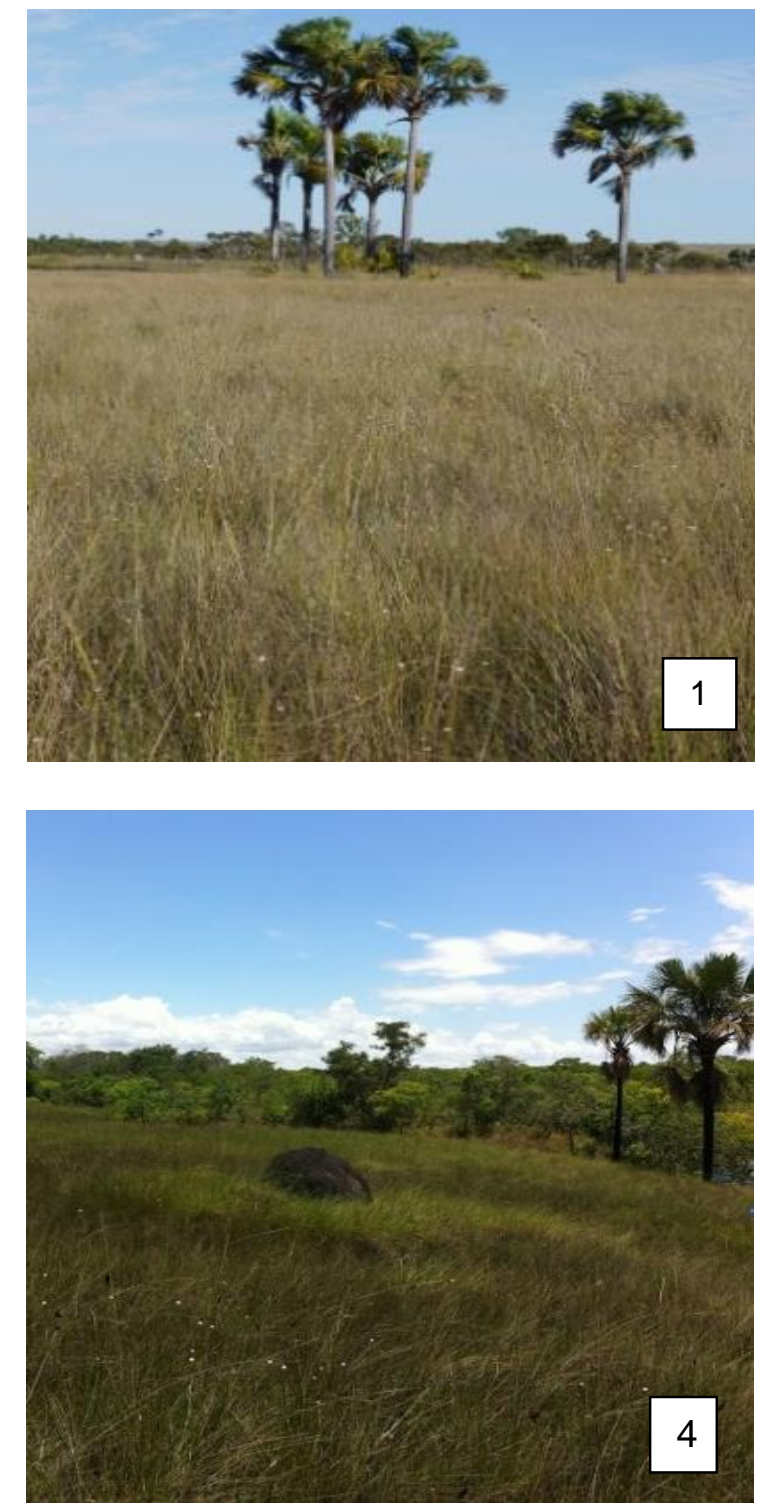
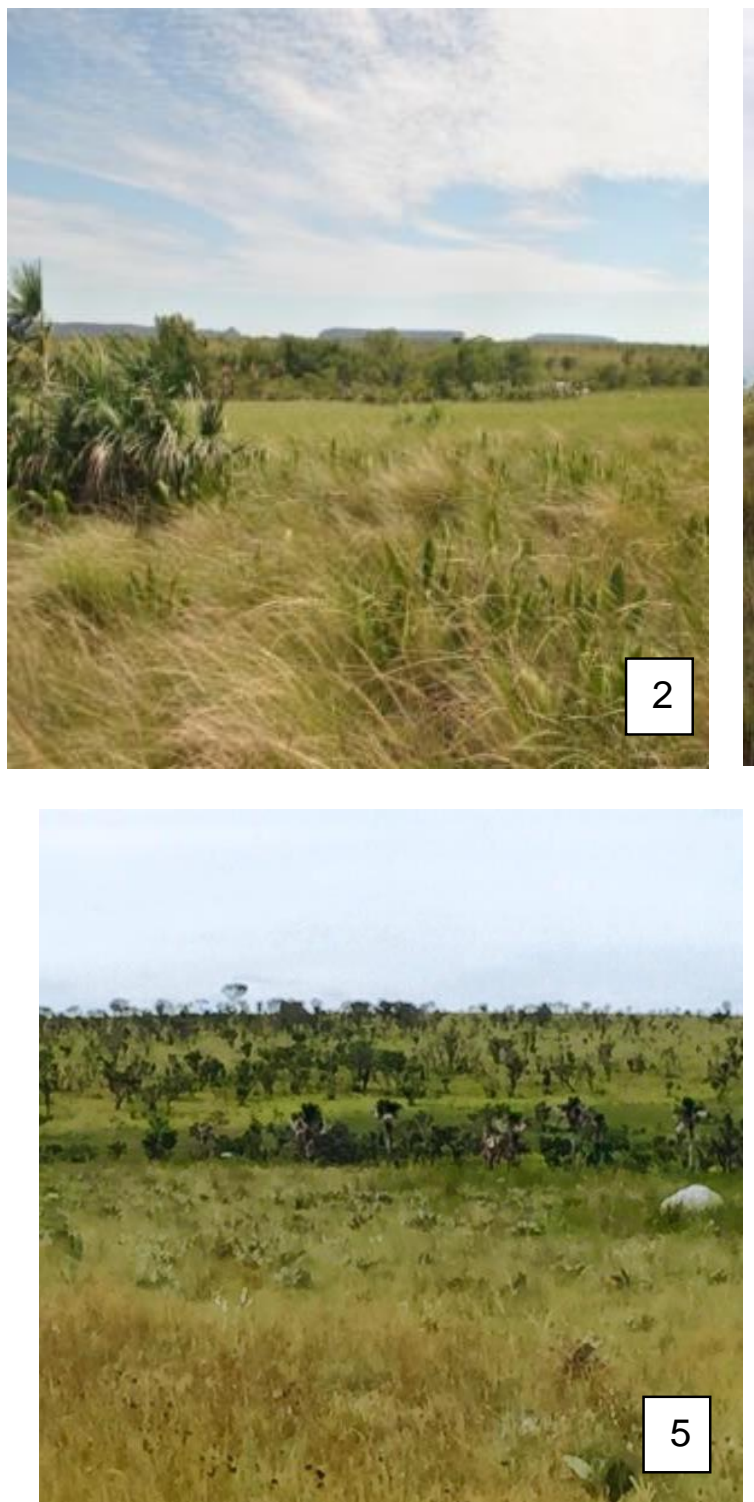

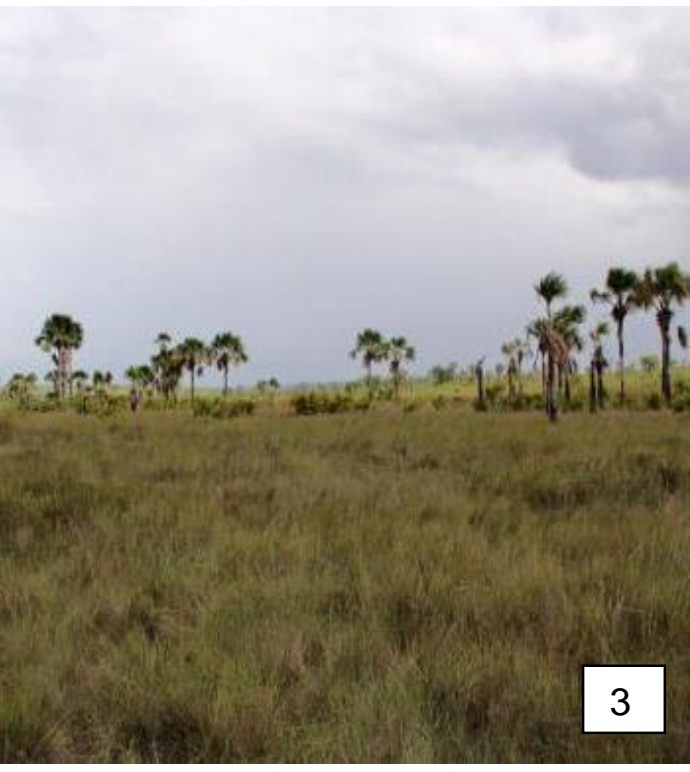

Figura 2: Áreas de estudo. 1 - Vereda próxima ao rio Balsas V_1; 2 - Vereda na margem direita do rio Novo V_2; 3- Vereda na margem esquerda do rio Novo V_3; 4- Vereda próxima ao rio Preto V_4; 5Vereda próxima à Lagoa Espraiada V_5. 


\section{Coleta e análise dos dados}

Realizamos o levantamento florístico em expedições de coleta no início (NovembroDezembro/2014) e no fim do período chuvoso (Maio/2015), quando há maior número de espécies herbáceo-arbustivas florescendo em ambientes úmidos (Munhoz \& Felfili 2005). Registramos as espécies por meio de caminhamento (Filgueiras et al. 1994), onde toda extensão das Veredas era percorrida e os espécimes que se encontravam em estágio reprodutivo foram coletados e prensados.

A identificação das espécies foi realizada pelos autores e revisada, em alguns casos, por especialistas nos grupos taxonômicos, literatura especializada, comparação com exsicatas depositadas no herbário do Instituto Brasileiro de Geografia e Estatística (IBGE) e da Universidade de Brasília (UB), onde foram depositadas. Para determinação da nomenclatura botânica das famílias e espécies, seguiu-se a classificação do Angiosperm Phylogeny Group APG IV (Byng et al. 2016).

Foi elaborada uma listagem contendo as famílias, espécies, hábito, área de ocorrência e o número de coleta. O registro de novas ocorrências de espécies para o Cerrado e para o estado de Tocantins foi verificado através de consultas ao site flora do Brasil (Flora do Brasil 2020 em construção; http://floradobrasil.jbrj.gov.br/).

A flora encontrada nas Veredas da EESGTO foi comparada com a flora de estudos que contemplam o estrato herbáceo-arbustivo de Veredas nos estados de Goiás (Resende et al. 2013), Mato Grosso do Sul, somando a floras das seis áreas com buriti, devido ao seu menor número de espécies em cada sítio de coleta, quando comparado ao das outras áreas (Moreira et al. 2015) e Minas Gerais (Araújo et al. 2002), totalizando 13 áreas (Tabela 1). Foram incluídas espécies herbáceas, subarbustivas, arbustivas, a palmeira arbórea buriti e trepadeiras. Espécies identificadas somente até o nível de gênero ou somente até o nível de família e espécies com necessidade de 
confirmação de identificação (cf.) foram excluídas, bem como espécies que apareciam apenas uma área (McCune et al. 2002). Fizeram parte da composição da matriz inicial 786 espécies, e após as exclusões 456 espécies.

Nos comparamos a flora das Veredas da EESGTO e demais Veredas no Brasil Central e ainda de Cerrado sensu stricto, Campo Sujo e Campo Limpo úmido, sumarizando ao todo 24 áreas que contempla a variabilidade latitudinal do bioma (Tabela 1). Fizeram parte da composição da matriz de presença e ausência inicial 1347 espécies, e após as exclusões das unicatas 722 espécies. Os sítios de Vereda sem buritis do Mato Grosso do Sul (Moreira et al. 2015) foram considerados aqui como Campo Limpo úmido, segundo Ribeiro \& Walter (2008). As relações florísticas entre as áreas foi avaliada através da Análise de Correspondência Retificada (DCA), no programa R, pacote vegan, versão 2.3-1, (Oksanen 2015). A similaridade entre as áreas foi medida pelo índice de Jaccard. Para evitar o falso aumento das espécies e a falsa diferença florística entre as áreas, devido à incorreção no uso de nomes, as sinonímias e grafia dos taxa foram conferidas através do pacote flora, versão 0.2.7 (Carvalho 2015) no programa R (version 3.0.3; R Development Core Team 2015). 
Tabela 1: Fitofisionomias de Cerrado comparados com o presente estudo. Cod. - código dos sítios, Prec. - Precipitação média anual (mm/ano), T - temperatura média anual $\left({ }^{\circ} \mathrm{C}\right), \mathrm{N}=$ número de espécies de plantas herbáceas vasculares utilizadas na matriz de comparação.

\begin{tabular}{|c|c|c|c|c|c|c|c|c|c|}
\hline Cod. & Sítios & Fitofisionomia & Prec. & $\mathrm{T}$. & latitude (S) & longitude $(\mathrm{W})$ & Altitude (m) & Referências & $\mathrm{N}$ \\
\hline CSS_DF & Reserva Ecológica do IBGE, DF & $\begin{array}{l}\text { Cerrado sensu } \\
\text { stricto } \\
\text { Cerrado sensu }\end{array}$ & 1.500 & 21 & $15^{\circ} 55^{\prime} 00.00^{\prime \prime}$ & $47^{\circ} 53^{\prime} 00.00^{\prime \prime}$ & 1178 & Silva \& Nogueira 1999 & 144 \\
\hline CSS_SP_1 & Reserva Pé-de-Gigante, SP & $\begin{array}{l}\text { stricto } \\
\text { Cerrado Sensu }\end{array}$ & 1.400 & 20 & $21^{\circ} 38^{\prime} 00.00^{\prime \prime}$ & $47^{\circ} 39^{\prime} 00.00^{\prime \prime}$ & 720 & Batalha \& Mantovani 2001 & 181 \\
\hline CSS_SP_2 e 3 & Pratânia, SP 1; Pratânia, SP 2 & Stricto & 1.453 & 20.8 & $22^{\circ} 48^{\prime} 00.00^{\prime \prime}$ & $48^{\circ} 44^{\prime} 00.00^{\prime \prime}$ & 725 & Ishara \& Maimori-Rodela 2012 & 121 \\
\hline CS_SP & Itirapina, SP & Campo Sujo & 1.523 & 20 & $22^{\circ} 15^{\prime} 00.00^{\prime \prime}$ & $47^{\circ} 53^{\prime} 00.00^{\prime \prime}$ & 700 & Tannus \& Assis 2004 & 177 \\
\hline CS_DF & Fazenda Água Limpa, DF & $\begin{array}{l}\text { Campo Sujo } \\
\text { Campo Limpo }\end{array}$ & 1.500 & 21 & $15^{\circ} 56^{\prime} 00.00^{\prime \prime}$ & $47^{\circ} 55^{\prime} 00.00^{\prime \prime}$ & 1178 & Munhoz \& Felfili 2004 & 224 \\
\hline CLU_DF & Fazenda Água Limpa, DF & $\begin{array}{l}\text { Úmido } \\
\text { Campo Limpo }\end{array}$ & 1.500 & 21 & $15^{\circ} 59^{\prime} 00.00^{\prime \prime}$ & $47^{\circ} 58^{\prime} 00.00^{\prime \prime}$ & 1178 & Munhoz \& Felfili 2007 & 224 \\
\hline CLU_SP & Itirapina, SP & $\begin{array}{c}\text { Úmido } \\
\text { Campo Limpo }\end{array}$ & 1.523 & 20 & $22^{\circ} 15^{\prime} 43.00^{\prime \prime}$ & $47^{\circ} 54^{\prime} 00.00^{\prime \prime}$ & 700 & Tannus \& Assis 2004 & 105 \\
\hline CLU_GO & Alto Paraíso de Goiás, GO & $\begin{array}{l}\text { Úmido } \\
\text { Campo Limpo }\end{array}$ & 1.300 & 23 & $14^{\circ} 04^{\prime} 08,83^{\prime \prime}$ & $47^{\circ} 30^{\prime} 33,01^{\prime \prime}$ & 992 & Munhoz \& Felfili 2006 & 207 \\
\hline CLU_PI & Parque Nacional Sete Cidades Park & Úmido & 1.650 & 26.7 & $04^{\circ} 05^{\prime} 55.26^{\prime \prime}$ & $41^{\circ} 42^{\prime} 09.83^{\prime \prime}$ & 290 & Mendes et al. 2014 & 92 \\
\hline V_MS_1 & $\begin{array}{l}\text { Camapuã, Aquidauana, Bonito, Sidrolândia, } \\
\text { Maracajú, Coxim }\end{array}$ & $\begin{array}{l}\text { Campo Limpo } \\
\text { Úmido/Vereda }\end{array}$ & 2.000 & 25 & $18^{\circ} 58^{\prime} 52.34^{\prime \prime}$ & $53^{\circ} 11^{\prime} 36.86^{\prime \prime}$ & 510 & Moreira et al. 2015 & 183 \\
\hline V_MS_2 & $\begin{array}{l}\text { Anhanduí, Ribas do Rio Pardo, Fátima do } \\
\text { Sul, Costa Rica, Chapadão do Sul, } \\
\text { Brasilândia }\end{array}$ & Vereda & 2.000 & 25 & $21^{\circ} 07^{\prime} 26.25^{\prime \prime}$ & $54^{\circ} 28^{\prime} 52.15^{\prime \prime}$ & 453 & Moreira et al. 2015 & 174 \\
\hline V_GO_1, 2 e 3 & $\begin{array}{l}\text { Rio Peixe/GO, Rio Corumbá/GO, Rio } \\
\text { Paranaíba/GO }\end{array}$ & Vereda & 2.000 & 24 & $17^{\circ} 00^{\prime} 63.00^{\prime \prime}$ & $48^{\circ} 47^{\prime} 33.00^{\prime \prime}$ & 899 & Resende et al. 2013 & $\begin{array}{l}152 \\
157 \\
154\end{array}$ \\
\hline $\begin{array}{l}\text { V_TM_1 } \\
4\end{array}$ & $\begin{array}{l}\text { Clube Caça e Pesca Itororó/MG, Campo } \\
\text { Florido/MG, Estação Ecológica do } \\
\text { Panga/MG } 1 \text { e } 2\end{array}$ & Vereda & 1.900 & 26 & $18^{\circ} 59^{\prime} 59.00^{\prime \prime}$ & $48^{\circ} 18^{\prime} 00.00^{\prime \prime}$ & 860 & Araújo et al.2002 & $\begin{array}{l}246 \\
216 \\
183 \\
203\end{array}$ \\
\hline $\begin{array}{l}\text { V_TO_1, 2, 3, } 4 \\
\text { e } 5\end{array}$ & $\begin{array}{l}\text { Rio Balsas/TO, Rio Novo margem } \\
\text { direita/TO, Rio Novo margem esquerda/TO, } \\
\text { Rio Preto/TO e Lagoa Espraiada/TO }\end{array}$ & Vereda & 1.700 & 27 & $11^{\circ} 07^{\prime} 40,00^{\prime \prime}$ & $46^{\circ} 54^{\prime} 20,00^{\prime \prime}$ & 490 & Presente Estudo & $\begin{array}{c}127 \\
128 \\
125 \\
133 \text { e } \\
127\end{array}$ \\
\hline
\end{tabular}




\section{RESULTADOS}

Um total de 646 espécimes foram coletados nas cinco Veredas na EESGTO, resultando em 213 espécies distribuídas em 109 gêneros e 49 famílias (Tabela 2). Entre as espécies coletadas 35\% ocorreram em todas as Veredas da EESGTO. Do total de espécies, 19 foram identificadas apenas ao nível de gênero, incluindo o gênero Bisboeckelera que, juntamente com as espécies, Chelonanthus alatus (Aubl.) Pulle, Paepalanthus polytrichoides Kunth, Xyris egleri L.B.Sm. \& Downs e Xyris brevifolia Michx. foram novas ocorrências para o Cerrado. As quatro primeiras até então registradas para região amazônica e a quinta para Mata Atlântica. Registramos 78 novas ocorrências de espécies para o estado do Tocantins.

As dez famílias que se destacaram em riqueza nas Veredas estudadas no Tocantins englobaram 62,8\% do total de espécies. Poaceae (40 espécies), Cyperaceae (32), Xyridaceae (23) e Eriocaulaceae (18) apresentam riqueza elevada na EESGTO, padrão semelhante em todas as Veredas, assim como para as demais fitofisionomias (Figura 3, 4). O gênero Rhynchospora foi o mais comum nas Veredas e demais fitofisionomias analisadas (Figura 5, 6). O hábito herbáceo foi predominante na EESGTO (61\%), assim como nas outras Veredas situadas nas várias regiões do Brasil Central (Figura 7). Considerando todas as espécies identificadas nos 24 sítios analisados, as encontradas nas Veredas na EESGTO representam 5,3\% do total, sendo que 70 não ocorreram nas demais Veredas (Tabela 3).

As Veredas da EESGTO apresentaram similaridade florística em torno de 60\%, apesar de $41 \%$ das espécies ocorreram em apenas um dos cinco sítios, sendo a Vereda 2 mais diferente floristicamente. Apenas seis espécies foram registradas em todos os 13 sítios de Veredas, (Andropogon bicornis L., Anthaenantia lanata (Kunth) Benth., Ascolepis brasiliensis (Kunth) Benth. ex C.B.Clarke, Ludwigia nervosa (Poir.) H.Hara, Mauritia flexuosa L.f. e Rhynchospora globosa (Kunth) Roem. \& Schult.). 
Considerando todas as espécies registradas nas 13 Veredas, e nas demais fitofisionomias comparadas, um total de $47 \%$ das espécies ocorreram somente em Veredas. Somente $14,3 \%$ das espécies registradas em sítios de Cerrado sensu stricto ocorrem também em Veredas, 19,6\% coincidiram com a flora de Campo Sujo e 53\% com a de Campo Limpo Úmido. A similaridade florística medida pelo índice de Jaccard entre as diferentes fitofisionomias, foi maior entre a flora de áreas de mesma localidade e fisionomia. As Veredas da EESGTO apresentaram similaridade acima de $60 \%$, porém quando comparadas à Veredas de outras regiões a similaridade foi em torno de $22 \%$. Sítios de Cerrado sensu stricto e Campo Sujo no Distrito Federal, apresentam cerca de 33\% de similaridade, enquanto os Campos limpos úmidos do estado de Goiás e Distrito Federal apresentaram $25 \%$ de similaridade.

A ordenação por DCA, realizada ao nível específico para a flora das Veredas (Figura 8A) reuniu sítios próximos entre si, sendo que a nível genérico há uma maior proximidade da flora do sudeste de Goiás e do Triangulo Mineiro (Figura 8B). A ordenação das Veredas com as demais fitofisionomias, ao nível específico e genérico (Figura 9A, B), mostrou no primeiro eixo uma separação em resposta à umidade no solo, com as áreas úmidas à esquerda e as sob solo bem drenado à direita. $\mathrm{O}$ eixo 2 da ordenação separou as áreas úmidas em resposta à distância geográfica, com as veredas da EESGTO, situadas ao norte do Cerrado, na parte inferior do gráfico as áreas úmidas do mato Grosso do Sul, localizadas na porção sudoeste do Cerrado, no extremo superior do gráfico. 
Tabela 2: Famílias e espécies da flora amostradas em cinco veredas na Estação Ecológica Serra Geral do Tocantins (EESGTO), TO, e suas ocorrências em Veredas no estados de Goiás (GO), Mato Grosso do Sul (MS) e Minas Gerais (MG) e em áreas de Cerrado sensu stricto (CSS), Campo sujo (CS) e Campo Limpo Úmido (CLU). Onde: * = nova ocorrência para o estado do Tocantins; ** = nova ocorrência para o Cerrado; Hábito e N= Número de coletor Silva D.P.

\begin{tabular}{|c|c|c|c|c|c|c|c|c|c|}
\hline FAMÍLIA/ESPÉCIE & EESGTO & GO & MS & TM & CSS & $\mathrm{CS}$ & CLU & Hábito & $\mathrm{N}$ \\
\hline \multicolumn{10}{|l|}{ ACANTHACEAE } \\
\hline Justicia sericographis V.A.W.Graham. & $\mathrm{V} 1, \mathrm{~V} 3, \mathrm{~V} 4$ & & & & & & & subarbusto & 484 \\
\hline \multicolumn{10}{|l|}{ AMARANTHACEAE } \\
\hline Pfaffia jubata Mart. & V5 & & & $\mathrm{x}$ & & $\mathrm{x}$ & $\mathrm{x}$ & subarbusto & 607 \\
\hline \multicolumn{10}{|l|}{ APOCYNACEAE } \\
\hline Blepharodon bicolor Decne. & V3 & & & $\mathrm{x}$ & $\mathrm{x}$ & $\mathrm{x}$ & & trepadeira & 429 \\
\hline Nephradenia acerosa Decne. & $\mathrm{V} 1, \mathrm{~V} 2, \mathrm{~V} 3, \mathrm{~V} 4, \mathrm{~V} 5$ & & & & & & & subarbusto & 6 \\
\hline Odontadenia lutea (Vell.) Markgr. & V5 & & & $\mathrm{x}$ & $\mathrm{x}$ & & & trepadeira & 638 \\
\hline \multicolumn{10}{|l|}{ ARACEAE } \\
\hline Philodendron dardanianum Мауо* & V1, V2, V3, V4 & & & & & & & arbusto & 10 \\
\hline Urospatha sagittifolia (Rudge) Schott & $\mathrm{V} 1, \mathrm{~V} 2, \mathrm{~V} 3, \mathrm{~V} 4, \mathrm{~V} 5$ & $\mathrm{x}$ & $\mathrm{x}$ & & & & & arbusto & 511 \\
\hline \multicolumn{10}{|l|}{ ARECACEAE } \\
\hline Mauritia flexuosa L.f. & $\mathrm{V} 1, \mathrm{~V} 2, \mathrm{~V} 3, \mathrm{~V} 4, \mathrm{~V} 5$ & $\mathrm{x}$ & $\mathrm{x}$ & $\mathrm{x}$ & & & & palmeira & avistada \\
\hline Mauritiella armata (Mart.) Burret & $\mathrm{V} 1, \mathrm{~V} 2, \mathrm{~V} 3, \mathrm{~V} 4, \mathrm{~V} 5$ & $\mathrm{x}$ & $\mathrm{x}$ & $\mathrm{x}$ & & & & palmeira & avistada \\
\hline \multicolumn{10}{|l|}{ ASTERACEAE } \\
\hline Calea purpurea G.M.Barroso & V1 & & & & & & & arbusto & 561 \\
\hline Clibadium armani (Balb.) Sch.Bip. ex O.E.Schulz & $\mathrm{V} 3, \mathrm{~V} 4$ & & $\mathrm{x}$ & & & & & arbusto & 482 \\
\hline Chrysolaena desertorum (Mart. ex DC.) Dematt.* & $\mathrm{V} 1, \mathrm{~V} 2, \mathrm{~V} 3, \mathrm{~V} 4, \mathrm{~V} 5$ & & & & & & $\mathrm{x}$ & subarbusto & 323 \\
\hline Erechtites hieracifolius (L.) Raf. ex DC.* & $\mathrm{V} 1, \mathrm{~V} 3, \mathrm{~V} 4, \mathrm{~V} 5$ & $\mathrm{x}$ & $\mathrm{x}$ & $\mathrm{x}$ & & & & subarbusto & 11 \\
\hline Lepidaploa nitens (Gardner) H.Rob. & V5 & & & & & $\mathrm{x}$ & $\mathrm{x}$ & arbusto & 721 \\
\hline Mikania officinalis Mart.* & $\mathrm{V} 1, \mathrm{~V} 2, \mathrm{~V} 3, \mathrm{~V} 4, \mathrm{~V} 5$ & $\mathrm{x}$ & & $\mathrm{x}$ & & $\mathrm{x}$ & & subarbusto & 31 \\
\hline Porophyllum ruderale (Jacq.) Cass.* & $\mathrm{V} 3$ & $\mathrm{x}$ & & & & & & subarbusto & 533 \\
\hline
\end{tabular}




\begin{tabular}{|c|c|c|c|c|c|c|c|c|c|}
\hline FAMÍLIA/ESPÉCIE & EESGTO & GO & MS & $\mathrm{TM}$ & CSS & $\mathrm{CS}$ & $\mathrm{CLU}$ & Hábito & $\mathrm{N}$ \\
\hline \multicolumn{10}{|l|}{ BLECHNACEAE } \\
\hline Blechnum serrulatum Rich.* & $\mathrm{V} 2, \mathrm{~V} 3, \mathrm{~V} 4$ & & & & & & & arbusto & 133 \\
\hline \multicolumn{10}{|l|}{ BURMANNIACEAE } \\
\hline Burmannia capitata (Walter ex J.F.Gmel.) Mart. & $\mathrm{V} 1, \mathrm{~V} 3$ & $\mathrm{x}$ & $\mathrm{x}$ & & & & $\mathrm{x}$ & erva & 446 \\
\hline Burmannia flava Mart.* & $\mathrm{V} 1, \mathrm{~V} 2, \mathrm{~V} 3, \mathrm{~V} 4, \mathrm{~V} 5$ & $\mathrm{x}$ & $\mathrm{x}$ & $\mathrm{x}$ & & & $\mathrm{x}$ & subarbusto & 523 \\
\hline \multicolumn{10}{|l|}{ CABOMBACEAE } \\
\hline Cabomba aquatica Aubl.* & $\mathrm{V} 3$ & & & & & & & erva & 419 \\
\hline \multicolumn{10}{|l|}{ CARYOPHYLLACEAE } \\
\hline Polycarpaea corymbosa (L.) Lam. & $\mathrm{V} 2$ & & & & $\mathrm{x}$ & $\mathrm{x}$ & & subarbusto & 600 \\
\hline \multicolumn{10}{|l|}{ CONVOLVULACEAE } \\
\hline Aniseia martinicensis (Jacq.) Choisy & $\mathrm{V} 2$ & & & & & & & trepadeira & 619 \\
\hline \multicolumn{10}{|l|}{ COSTACEAE } \\
\hline Costus spiralis (Jacq.) Roscoe & $\mathrm{V} 1, \mathrm{~V} 2, \mathrm{~V} 3, \mathrm{~V} 4, \mathrm{~V} 5$ & & & & & & & subarbusto & 20 \\
\hline \multicolumn{10}{|l|}{ CYPERACEAE } \\
\hline Ascolepis brasiliensis (Kunth) Benth. ex C.B.Clarke & $\mathrm{V} 1, \mathrm{~V} 2, \mathrm{~V} 3, \mathrm{~V} 4, \mathrm{~V} 5$ & $\mathrm{x}$ & $\mathrm{x}$ & $\mathrm{x}$ & & & $\mathrm{x}$ & erva & 27 \\
\hline Calyptrocarya glomerulata (Brongn.) Urb. & $\mathrm{V} 1$ & $\mathrm{x}$ & $\mathrm{x}$ & $\mathrm{x}$ & & & & erva & 161 \\
\hline Cyperus haspan $\mathrm{L}$. & $\mathrm{V} 2, \mathrm{~V} 3, \mathrm{~V} 4, \mathrm{~V} 5$ & & & & & & $\mathrm{x}$ & erva & 158 \\
\hline Cyperus rotundus $\mathrm{L}$. & $\mathrm{V} 2$ & & $\mathrm{x}$ & & & & & erva & 616 \\
\hline Bisboeckelera sp. $1^{* *}$ & V5 & & & & & & & erva & 80 \\
\hline Bulbostylis conifera (Kunth) C.B.Clarke & V4 & & & & & & $\mathrm{x}$ & erva & 121 \\
\hline Bulbostylis consanguinea (Kunth) C.B.Clarke & $\mathrm{V} 1, \mathrm{~V} 2, \mathrm{~V} 3, \mathrm{~V} 4, \mathrm{~V} 5$ & & & & & & & erva & 162 \\
\hline Bulbostylis emmerichiae T.Koyama* & $\mathrm{V} 1, \mathrm{~V} 2, \mathrm{~V} 3, \mathrm{~V} 4, \mathrm{~V} 5$ & & & & & & & erva & 378 \\
\hline Bulbostylis junciformis (Kunth) C.B.Clarke & $\mathrm{V} 1, \mathrm{~V} 2, \mathrm{~V} 3, \mathrm{~V} 4, \mathrm{~V} 5$ & & & $\mathrm{x}$ & $\mathrm{x}$ & $\mathrm{x}$ & $\mathrm{x}$ & erva & 78 \\
\hline Bulbostylis sellowiana (Kunth) Palla & $\mathrm{V} 1, \mathrm{~V} 2, \mathrm{~V} 3, \mathrm{~V} 4, \mathrm{~V} 5$ & $\mathrm{x}$ & & $\mathrm{x}$ & & & $\mathrm{x}$ & erva & 66 \\
\hline Cryptangium verticillatum (Spreng.) Vitta & $\mathrm{V} 3, \mathrm{~V} 4, \mathrm{~V} 5$ & & & & & & & erva & 305 \\
\hline Exochogyne amazonica C.B.Clarke & V5 & & $\mathrm{x}$ & $\mathrm{x}$ & & & $\mathrm{x}$ & erva & 75 \\
\hline Lagenocarpus rigidus Nees & $\mathrm{V} 1, \mathrm{~V} 2, \mathrm{~V} 3, \mathrm{~V} 4, \mathrm{~V} 5$ & & & & & & $\mathrm{x}$ & erva & 1 \\
\hline Rhynchospora albiceps Kunth & $\mathrm{V} 2, \mathrm{~V} 5$ & & $\mathrm{x}$ & $\mathrm{x}$ & & & $\mathrm{x}$ & erva & 696 \\
\hline
\end{tabular}




\begin{tabular}{|c|c|c|c|c|c|c|c|c|c|}
\hline FAMÍLIA/ESPÉCIE & EESGTO & GO & MS & $\mathrm{TM}$ & CSS & $\mathrm{CS}$ & $\mathrm{CLU}$ & Hábito & $\mathrm{N}$ \\
\hline Rhynchospora asperula (Nees) Steud.* & V4, V5 & & & & & & & erva & 129 \\
\hline Rhynchospora barbata (Vahl) Kunth & $\mathrm{V} 1$ & & & & & & $\mathrm{x}$ & erva & 44 \\
\hline Rhynchospora brasiliensis Boeckeler* & $\mathrm{V} 1, \mathrm{~V} 2, \mathrm{~V} 3, \mathrm{~V} 4, \mathrm{~V} 5$ & $\mathrm{x}$ & & & & & $\mathrm{x}$ & erva & 713 \\
\hline Rhynchospora brevirostris Griseb. & $\mathrm{V} 1, \mathrm{~V} 2, \mathrm{~V} 3, \mathrm{~V} 4, \mathrm{~V} 5$ & & & & & & $\mathrm{x}$ & erva & 420 \\
\hline Rhynchospora consanguinea (Kunth) Boeckeler & $\mathrm{V} 1, \mathrm{~V} 2, \mathrm{~V} 3, \mathrm{~V} 4, \mathrm{~V} 5$ & $\mathrm{x}$ & & $\mathrm{x}$ & $\mathrm{x}$ & $\mathrm{x}$ & $\mathrm{x}$ & erva & 60 \\
\hline Rhynchospora elatior Kunth* & $\mathrm{V} 1, \mathrm{~V} 2, \mathrm{~V} 3, \mathrm{~V} 4, \mathrm{~V} 5$ & & & & & & & erva & 82 \\
\hline Rhynchospora emaciata (Nees) Boeckeler & V1, V2, V4, V5 & $\mathrm{x}$ & $\mathrm{x}$ & & & & $\mathrm{x}$ & erva & 76 \\
\hline Rhynchospora globosa (Kunth) Roem. \& Schult. & $\mathrm{V} 1, \mathrm{~V} 2, \mathrm{~V} 3, \mathrm{~V} 4, \mathrm{~V} 5$ & $\mathrm{x}$ & $\mathrm{x}$ & $\mathrm{x}$ & & & $\mathrm{x}$ & erva & 182 \\
\hline Rhynchospora hirta (Nees) Boeckeler & $\mathrm{V} 1, \mathrm{~V} 2, \mathrm{~V} 3, \mathrm{~V} 4, \mathrm{~V} 5$ & & & & & & $\mathrm{x}$ & erva & 36 \\
\hline Rhynchospora marisculus Lindl. \& Nees & $\mathrm{V} 1, \mathrm{~V} 3, \mathrm{~V} 5$ & $\mathrm{x}$ & $\mathrm{x}$ & & & & $\mathrm{x}$ & erva & 302 \\
\hline Rhynchospora rugosa (Vahl) Gale & V1 & $\mathrm{x}$ & $\mathrm{x}$ & $\mathrm{x}$ & & & $\mathrm{x}$ & erva & 49 \\
\hline Rhynchospora spruceana C.B.Clarke* & V3, V5 & & & & & & & erva & 648 \\
\hline Rhynchospora sp.1 & $\mathrm{V} 1, \mathrm{~V} 2, \mathrm{~V} 5$ & & & & & & & erva & 45 \\
\hline Rhynchospora sp.2 & $\mathrm{V} 2, \mathrm{~V} 4, \mathrm{~V} 5$ & & & & & & & erva & 97 \\
\hline Rhynchospora sp.3 & $\mathrm{V} 1, \mathrm{~V} 2, \mathrm{~V} 5$ & & & & & & & erva & 377 \\
\hline Rhynchospora sp.4 & V1, V5 & & & & & & & erva & 380 \\
\hline Rhynchospora sp.5 & $\mathrm{V} 1, \mathrm{~V} 2, \mathrm{~V} 5$ & & & & & & & erva & 25 \\
\hline Scleria hirtella Sw. & $\mathrm{V} 1, \mathrm{~V} 2, \mathrm{~V} 4$ & $\mathrm{x}$ & & $\mathrm{x}$ & & $\mathrm{x}$ & $\mathrm{x}$ & erva & 15 \\
\hline \multicolumn{10}{|l|}{ DIOSCOREACEAE } \\
\hline Dioscorea ceratandra R.Knuth & $\mathrm{V} 1, \mathrm{~V} 3$ & & & & & & & trepadeira & 408 \\
\hline \multicolumn{10}{|l|}{ DROSERACEAE } \\
\hline Drosera communis A.St.-Hil.* & $\mathrm{V} 1, \mathrm{~V} 2, \mathrm{~V} 3, \mathrm{~V} 4, \mathrm{~V} 5$ & $\mathrm{x}$ & $\mathrm{x}$ & $\mathrm{x}$ & & & $\mathrm{x}$ & erva & 77 \\
\hline \multicolumn{10}{|l|}{ ERIOCAULACEAE } \\
\hline Actinocephalus bongardii (A.St.-Hil.) Sano & V2 & & & $\mathrm{x}$ & & & & subarbusto & 613 \\
\hline Comanthera xeranthemoides (Bong.) L.R.Parra \& Giul. & $\mathrm{V} 1, \mathrm{~V} 2, \mathrm{~V} 3, \mathrm{~V} 4, \mathrm{~V} 5$ & & $\mathrm{x}$ & & & & & erva & 718 \\
\hline Eriocaulon humboldtii Kunth* & $\mathrm{V} 2, \mathrm{~V} 3, \mathrm{~V} 4$ & $\mathrm{x}$ & & & & & & erva & 404 \\
\hline Leiothrix flavescens (Bong.) Ruhland & V2 & & & & & & & erva & 666 \\
\hline Paepalanthus chiquitensis Herzog & $\mathrm{V} 2$ & & & $\mathrm{x}$ & & $\mathrm{x}$ & $\mathrm{x}$ & subarbusto & 725 \\
\hline
\end{tabular}




\begin{tabular}{|c|c|c|c|c|c|c|c|c|c|}
\hline FAMÍLIA/ESPÉCIE & EESGTO & GO & MS & $\mathrm{TM}$ & CSS & $\mathrm{CS}$ & $\mathrm{CLU}$ & Hábito & $\mathrm{N}$ \\
\hline Paepalanthus elongatus (Bong.) Körn.* & $\mathrm{V} 1, \mathrm{~V} 2, \mathrm{~V} 5$ & & & & & & & subarbusto & 33 \\
\hline Paepalanthus polytrichoides Kunth** & $\mathrm{V} 2, \mathrm{~V} 5$ & & & & & & & erva & 601 \\
\hline Syngonanthus anthemiflorus (Bong.) Ruhland* & $\mathrm{V} 2, \mathrm{~V} 3, \mathrm{~V} 4, \mathrm{~V} 5$ & $\mathrm{x}$ & & & & & & erva & 649 \\
\hline Syngonanthus bisumbellatus (Steud.) Ruhland & $\mathrm{V} 1, \mathrm{~V} 4$ & & & & & & & erva & 502 \\
\hline Syngonanthus caulescens (Poir.) Ruhland & $\mathrm{V} 2, \mathrm{~V} 4$ & $\mathrm{x}$ & $\mathrm{x}$ & $\mathrm{x}$ & & & $\mathrm{x}$ & erva & 549 \\
\hline Syngonanthus densiflorus (Körn.) Ruhland & $\mathrm{V} 1, \mathrm{~V} 2, \mathrm{~V} 3, \mathrm{~V} 4, \mathrm{~V} 5$ & $\mathrm{x}$ & & $\mathrm{x}$ & & & $\mathrm{x}$ & subarbusto & 543 \\
\hline Syngonanthus fischerianus (Bong.) Ruhland* & $\mathrm{V} 4$ & & & & & & & erva & 128 \\
\hline Syngonanthus gracilis (Bong.) Ruhland* & $\mathrm{V} 2$ & $\mathrm{x}$ & $\mathrm{x}$ & $\mathrm{x}$ & & & $\mathrm{x}$ & erva & 662 \\
\hline Syngonanthus helminthorrhizus (Mart. ex Körn.) Ruhland* & V1, V2, V4, V5 & & $\mathrm{x}$ & & & & & erva & 478 \\
\hline Syngonanthus humboldtii (Kunth) Ruhland & $\mathrm{V} 1, \mathrm{~V} 2, \mathrm{~V} 3, \mathrm{~V} 4, \mathrm{~V} 5$ & & & & & & & erva & 505 \\
\hline Syngonanthus nitens Ruhland & $\mathrm{V} 1, \mathrm{~V} 2, \mathrm{~V} 3, \mathrm{~V} 4, \mathrm{~V} 5$ & $\mathrm{x}$ & & $\mathrm{x}$ & & & $\mathrm{x}$ & erva & 510 \\
\hline Syngonanthus verticillatus (Bong.) Ruhland* & $\mathrm{V} 1, \mathrm{~V} 2, \mathrm{~V} 3, \mathrm{~V} 4, \mathrm{~V} 5$ & & & & & & & erva & 645 \\
\hline Syngonanthus widgrenianus (Körn.) Ruhland* & $\mathrm{V} 1, \mathrm{~V} 2, \mathrm{~V} 3$ & & & $\mathrm{x}$ & & & & erva & 425 \\
\hline \multicolumn{10}{|l|}{ EUPHORBIACEAE } \\
\hline Microstachys bidentata (Mart.\& Zucc.) Esser & V3, V5 & & & & & & $\mathrm{x}$ & subarbusto & 101 \\
\hline Euphorbia sp.1 & $\mathrm{V} 1, \mathrm{~V} 2, \mathrm{~V} 5$ & & & & & & & arbusto & 443 \\
\hline \multicolumn{10}{|l|}{ FABACEAE } \\
\hline Aeschynomene paniculata Willd. ex Vogel & $\mathrm{V} 1, \mathrm{~V} 2, \mathrm{~V} 3$ & $\mathrm{x}$ & & $\mathrm{x}$ & & & & arbusto & 22 \\
\hline Chamaecrista desvauxii (Collad.) Killip & $\mathrm{V} 1, \mathrm{~V} 2, \mathrm{~V} 3, \mathrm{~V} 4, \mathrm{~V} 5$ & & & & $\mathrm{x}$ & $\mathrm{x}$ & $\mathrm{x}$ & arbusto & 138 \\
\hline Chamaecrista sp.1 & $\mathrm{V} 2, \mathrm{~V} 3$ & & & & & & & arbusto & 184 \\
\hline Eriosema campestre Benth. & V1 & & & & & $\mathrm{x}$ & $\mathrm{x}$ & arbusto & 17 \\
\hline Galactia martii DC.* & $\mathrm{V} 1, \mathrm{~V} 2, \mathrm{~V} 5$ & & & & $\mathrm{x}$ & $\mathrm{x}$ & $\mathrm{x}$ & arbusto & 486 \\
\hline Stylosanthes sp.1 & $\mathrm{V} 1, \mathrm{~V} 2, \mathrm{~V} 3, \mathrm{~V} 4, \mathrm{~V} 5$ & & & & & & & arbusto & 37 \\
\hline Stylosanthes sp.2 & $\mathrm{V} 1, \mathrm{~V} 4$ & & & & & & & arbusto & 52 \\
\hline \multicolumn{10}{|l|}{ GENTIANACEAE } \\
\hline Chelonanthus alatus (Aubl.) Pulle** & $\mathrm{V} 2, \mathrm{~V} 5$ & & & & & & & arbusto & 711 \\
\hline Chelonanthus purpurascens (Aubl.) Struwe et al.* & $\mathrm{V} 2, \mathrm{~V} 5$ & & & & & & & arbusto & 705 \\
\hline Chelonanthus viridiflorus (Mart.) Gilg & $\mathrm{V} 1, \mathrm{~V} 2, \mathrm{~V} 3, \mathrm{~V} 4, \mathrm{~V} 5$ & & & & & & & arbusto & 439 \\
\hline
\end{tabular}




\begin{tabular}{|c|c|c|c|c|c|c|c|c|c|}
\hline FAMÍLIA/ESPÉCIE & EESGTO & GO & MS & $\mathrm{TM}$ & CSS & $\mathrm{CS}$ & CLU & Hábito & $\mathrm{N}$ \\
\hline Curtia tenuifolia (Aubl.) Knobl.* & $\mathrm{V} 1, \mathrm{~V} 2, \mathrm{~V} 3, \mathrm{~V} 4, \mathrm{~V} 5$ & $\mathrm{x}$ & & $\mathrm{x}$ & & & $\mathrm{x}$ & subarbusto & 550 \\
\hline Deianira chiquitana Herzog & $\mathrm{V} 1, \mathrm{~V} 2, \mathrm{~V} 3, \mathrm{~V} 4, \mathrm{~V} 5$ & & & & & $\mathrm{x}$ & $\mathrm{x}$ & arbusto & 723 \\
\hline Schultesia heterophylla Miq.* & $\mathrm{V} 3, \mathrm{~V} 4$ & & & $\mathrm{x}$ & & & & erva & 311 \\
\hline Sinningia elatior (Kunth) Chautems & V5 & $\mathrm{x}$ & $\mathrm{x}$ & $\mathrm{x}$ & & & $\mathrm{x}$ & erva & 722 \\
\hline \multicolumn{10}{|l|}{ HAEMODORACEAE } \\
\hline Schiekia orinocensis (Kunth) Meisn. & $\mathrm{V} 1, \mathrm{~V} 2, \mathrm{~V} 3, \mathrm{~V} 4, \mathrm{~V} 5$ & & & & & & & arbusto & 694 \\
\hline \multicolumn{10}{|l|}{ IRIDACEAE } \\
\hline Cipura paludosa Aubl. & $\mathrm{V} 2$ & $\mathrm{x}$ & & $\mathrm{x}$ & & & $\mathrm{x}$ & erva & 650 \\
\hline Sisyrinchium vaginatum Spreng.* & V3, V5 & $\mathrm{x}$ & & $\mathrm{x}$ & & $\mathrm{x}$ & $\mathrm{x}$ & erva & 202 \\
\hline Trimezia cathartica (Klatt) Niederl.* & V5 & & & & & & $\mathrm{x}$ & erva & 548 \\
\hline Trimezia juncifolia (Klatt) Benth. \& Hook.* & $\mathrm{V} 1, \mathrm{~V} 2, \mathrm{~V} 3, \mathrm{~V} 4, \mathrm{~V} 5$ & & & $\mathrm{x}$ & $\mathrm{x}$ & & & subarbusto & 313 \\
\hline \multicolumn{10}{|l|}{ JUNCACEAE } \\
\hline Juncus effusus L.* & V4 & & & & & & & erva & 134 \\
\hline \multicolumn{10}{|l|}{ LAMIACEAE } \\
\hline Hyptis fallax Harley* & V4 & & & & & & & subarbusto & 471 \\
\hline Hyptis linarioides Pohl ex Benth. & $\mathrm{V} 1, \mathrm{~V} 2, \mathrm{~V} 3, \mathrm{~V} 4, \mathrm{~V} 5$ & & & $\mathrm{x}$ & & & $\mathrm{x}$ & arbusto & 14 \\
\hline \multicolumn{10}{|l|}{ LAURACEAE } \\
\hline Cassytha filiformis L. & $\mathrm{V} 1, \mathrm{~V} 2, \mathrm{~V} 3, \mathrm{~V} 4, \mathrm{~V} 5$ & & & & $\mathrm{x}$ & & & trepadeira & 401 \\
\hline \multicolumn{10}{|l|}{ LENTIBULARIACEAE } \\
\hline Utricularia amethystina Salzm. ex A.St.-Hil. \& Girard & $\mathrm{V} 2, \mathrm{~V} 3$ & $\mathrm{x}$ & $\mathrm{x}$ & $\mathrm{x}$ & & & $\mathrm{x}$ & erva & 422 \\
\hline Utricularia juncea Vahl* & V3 & & & & & & & erva & 381 \\
\hline \multicolumn{10}{|l|}{ LYCOPODIACEAE } \\
\hline Lycopodiella alopecuroides (L.) Cranfill & $\mathrm{V} 1, \mathrm{~V} 4, \mathrm{~V} 5$ & $\mathrm{x}$ & $\mathrm{x}$ & $\mathrm{x}$ & & & $\mathrm{x}$ & erva & 169 \\
\hline Palhinhaea cernua (L.) Franco \& Vasc. & $\mathrm{V} 1, \mathrm{~V} 4, \mathrm{~V} 5$ & $\mathrm{x}$ & & $\mathrm{x}$ & & & $\mathrm{x}$ & erva & 91 \\
\hline \multicolumn{10}{|l|}{ LYTHRACEAE } \\
\hline Cuphea antisyphilitica Kunth & $\mathrm{V} 1, \mathrm{~V} 2, \mathrm{~V} 3, \mathrm{~V} 4, \mathrm{~V} 5$ & & & & & & & arbusto & 5 \\
\hline \multicolumn{10}{|l|}{ MALPIGHIACEAE } \\
\hline Byrsonima umbellata Mart. ex A.Juss. & $\mathrm{V} 1, \mathrm{~V} 2, \mathrm{~V} 3, \mathrm{~V} 4, \mathrm{~V} 5$ & & & & & & & arbusto & 145 \\
\hline
\end{tabular}




\begin{tabular}{|c|c|c|c|c|c|c|c|c|c|}
\hline FAMÍLIA/ESPÉCIE & EESGTO & $\mathrm{GO}$ & MS & $\mathrm{TM}$ & CSS & $\mathrm{CS}$ & CLU & Hábito & $\mathrm{N}$ \\
\hline Byrsonima subterranea Brade \& Markgr. & $\mathrm{V} 1, \mathrm{~V} 3, \mathrm{~V} 4, \mathrm{~V} 5$ & & & & & $\mathrm{x}$ & & arbusto & 427 \\
\hline \multicolumn{10}{|l|}{ MALVACEAE } \\
\hline Melochia graminifolia A.St.-Hil. & V3 & & & & & & & arbusto & 720 \\
\hline Waltheria albicans Turcz.* & V5 & & & & $\mathrm{x}$ & $\mathrm{x}$ & & arbusto & 652 \\
\hline \multicolumn{10}{|l|}{ MELASTOMATACEAE } \\
\hline Cambessedesia hilariana (Kunth) DC. & V2 & & & $\mathrm{x}$ & & $\mathrm{x}$ & & subarbusto & $699 a$ \\
\hline Desmoscelis villosa (Aubl.) Naudin & $\mathrm{V} 1, \mathrm{~V} 2, \mathrm{~V} 3, \mathrm{~V} 4, \mathrm{~V} 5$ & $\mathrm{x}$ & $\mathrm{x}$ & $\mathrm{x}$ & & $\mathrm{x}$ & $\mathrm{x}$ & arbusto & avistado \\
\hline Miconia chamissois Naudin & $\mathrm{V} 1, \mathrm{~V} 2, \mathrm{~V} 3, \mathrm{~V} 4, \mathrm{~V} 5$ & $\mathrm{x}$ & $\mathrm{x}$ & $\mathrm{x}$ & & $\mathrm{x}$ & & arbusto & 440 \\
\hline Microlicia viminalis (DC.) Triana* & $\mathrm{V} 1, \mathrm{~V} 2, \mathrm{~V} 3, \mathrm{~V} 4, \mathrm{~V} 5$ & & & & & & $\mathrm{x}$ & arbusto & 96 \\
\hline Pterolepis repanda (DC.) Triana* & $\mathrm{V} 1, \mathrm{~V} 2, \mathrm{~V} 3, \mathrm{~V} 4, \mathrm{~V} 5$ & & & & & & & erva & 13 \\
\hline Tococa nitens (Benth.) Triana & $\mathrm{V} 1, \mathrm{~V} 2, \mathrm{~V} 3, \mathrm{~V} 4, \mathrm{~V} 5$ & & & & & & & arbusto & 2 \\
\hline \multicolumn{10}{|l|}{ MENISPERMACEAE } \\
\hline Cissampelos ovalifolia DC. & $\mathrm{V} 1, \mathrm{~V} 2$ & & & & $\mathrm{x}$ & $\mathrm{x}$ & $\mathrm{x}$ & subarbusto & 351 \\
\hline \multicolumn{10}{|l|}{ MYRTACEAE } \\
\hline Eugenia angustissima O.Berg & V1 & & & & & & & arbusto & 42 \\
\hline Eugenia sprengelii DC.* & V1 & & & & & & & arbusto & 41 \\
\hline \multicolumn{10}{|l|}{ OCHNACEAE } \\
\hline Sauvagesia linearifolia A.St.-Hil. & $\mathrm{V} 1, \mathrm{~V} 2, \mathrm{~V} 3, \mathrm{~V} 4, \mathrm{~V} 5$ & & & $\mathrm{x}$ & & & $\mathrm{x}$ & subarbusto & 7 \\
\hline Sauvagesia ramosa (Gleason) Sastre & V4 & $\mathrm{x}$ & $\mathrm{x}$ & $\mathrm{x}$ & & & $\mathrm{x}$ & subarbusto & 165 \\
\hline \multicolumn{10}{|l|}{ ONAGRACEAE } \\
\hline Ludwigia nervosa (Poir.) H.Hara & $\mathrm{V} 1, \mathrm{~V} 2, \mathrm{~V} 3, \mathrm{~V} 4, \mathrm{~V} 5$ & $\mathrm{x}$ & $\mathrm{x}$ & $\mathrm{x}$ & & & $\mathrm{x}$ & arbusto & 21 \\
\hline \multicolumn{10}{|l|}{ ORCHIDACEAE } \\
\hline Cleistes metallina (Barb.Rodr.) Schltr.* & $\mathrm{V} 1, \mathrm{~V} 3, \mathrm{~V} 4$ & & & & & & & erva & 70 \\
\hline Cyrtopodium flavum Link \& Otto ex Rchb.f.* & V1 & & & & & & & erva & 454 \\
\hline Cyrtopodium fowliei L.C.Menezes* & V1 & & & & & & & erva & 28 \\
\hline Habenaria schwackei Barb.Rodr. & V3, V4 & & & & & & $\mathrm{x}$ & erva & 168 \\
\hline Veyretia simplex (Griseb.) Szlach. & $\mathrm{V} 2, \mathrm{~V} 4, \mathrm{~V} 5$ & & & & & & & erva & 331 \\
\hline OROBANCHACEAE & & & & & & & & & \\
\hline
\end{tabular}




\begin{tabular}{|c|c|c|c|c|c|c|c|c|c|}
\hline FAMÍLIA/ESPÉCIE & EESGTO & GO & MS & $\mathrm{TM}$ & CSS & $\mathrm{CS}$ & $\mathrm{CLU}$ & Hábito & $\mathrm{N}$ \\
\hline Buchnera juncea Cham. \& Schltdl. & $\mathrm{V} 1, \mathrm{~V} 3$ & & & $\mathrm{x}$ & & & $\mathrm{x}$ & arbusto & 310 \\
\hline Buchnera lavandulacea Cham. \& Schltdl. & $\mathrm{V} 1, \mathrm{~V} 2, \mathrm{~V} 3, \mathrm{~V} 4, \mathrm{~V} 5$ & & & & $\mathrm{x}$ & $\mathrm{x}$ & $\mathrm{x}$ & arbusto & 469 \\
\hline Esterhazya splendida J.C.Mikan* & V5 & & & $\mathrm{x}$ & & $\mathrm{x}$ & $\mathrm{x}$ & arbusto & 729 \\
\hline \multicolumn{10}{|l|}{ PASSIFLORACEAE } \\
\hline Passiflora mansoi (Mart.) Mast.* & $\mathrm{V} 2$ & & & & & & & trepadeira & 355 \\
\hline \multicolumn{10}{|l|}{ PHYLLANTHACEAE } \\
\hline Phyllanthus niruri L. & $\mathrm{V} 1, \mathrm{~V} 2, \mathrm{~V} 3, \mathrm{~V} 4, \mathrm{~V} 5$ & & & & & & & erva & 164 \\
\hline \multicolumn{10}{|l|}{ PIPERACEAE } \\
\hline Piper fuligineum Kunth & V1 & $\mathrm{x}$ & $\mathrm{x}$ & & & & & subarbusto & 19 \\
\hline \multicolumn{10}{|l|}{ POACEAE } \\
\hline Agenium villosum (Nees) Pilg. & $\mathrm{V} 1, \mathrm{~V} 2, \mathrm{~V} 3$ & & & & & & & erva & 319 \\
\hline Andropogon angustatus (J. Presl) Steud.* & V1 & & & & & & & erva & 141 \\
\hline Andropogon carinatus Nees* & $\mathrm{V} 1, \mathrm{~V} 2, \mathrm{~V} 3, \mathrm{~V} 4, \mathrm{~V} 5$ & & & $\mathrm{x}$ & & & & erva & 366 \\
\hline Andropogon bicornis $\mathrm{L}$. & $\mathrm{V} 1, \mathrm{~V} 2, \mathrm{~V} 3, \mathrm{~V} 4, \mathrm{~V} 5$ & $\mathrm{x}$ & $\mathrm{x}$ & $\mathrm{x}$ & & & & erva & 321 \\
\hline Andropogon lateralis Nees* & $\mathrm{V} 1, \mathrm{~V} 2, \mathrm{~V} 3, \mathrm{~V} 4, \mathrm{~V} 5$ & $\mathrm{x}$ & $\mathrm{x}$ & $\mathrm{x}$ & & & $\mathrm{x}$ & erva & 3 \\
\hline Andropogon leucostachyus Kunth & $\mathrm{V} 3, \mathrm{~V} 4, \mathrm{~V} 5$ & $\mathrm{x}$ & $\mathrm{x}$ & $\mathrm{x}$ & $\mathrm{x}$ & & & erva & 303 \\
\hline Andropogon selloanus (Hack.) Hack. & $\mathrm{V} 1, \mathrm{~V} 2, \mathrm{~V} 3, \mathrm{~V} 4, \mathrm{~V} 5$ & & & $\mathrm{x}$ & & & $\mathrm{x}$ & erva & 320 \\
\hline Andropogon virgatus Desv. & $\mathrm{V} 1, \mathrm{~V} 2, \mathrm{~V} 3, \mathrm{~V} 4, \mathrm{~V} 5$ & $\mathrm{x}$ & & $\mathrm{x}$ & & $\mathrm{x}$ & $\mathrm{x}$ & erva & 151 \\
\hline Anthaenantia lanata (Kunth) Benth. & $\mathrm{V} 1, \mathrm{~V} 2, \mathrm{~V} 3, \mathrm{~V} 4, \mathrm{~V} 5$ & $\mathrm{x}$ & $\mathrm{x}$ & $\mathrm{x}$ & & $\mathrm{x}$ & & erva & 367 \\
\hline Axonopus brasiliensis (Spreng.) Kuhlm.* & $\mathrm{V} 1, \mathrm{~V} 2, \mathrm{~V} 3, \mathrm{~V} 4, \mathrm{~V} 5$ & $\mathrm{x}$ & $\mathrm{x}$ & $\mathrm{x}$ & & $\mathrm{x}$ & $\mathrm{x}$ & erva & 349 \\
\hline Axonopus comans (Trin. ex Döll) Kuhlm.* & $\mathrm{V} 1, \mathrm{~V} 2, \mathrm{~V} 3, \mathrm{~V} 4, \mathrm{~V} 5$ & $\mathrm{x}$ & $\mathrm{x}$ & & & & $\mathrm{x}$ & erva & 179 \\
\hline Axonopus fastigiatus (Nees ex Trin.) Kuhlm.* & $\mathrm{V} 1, \mathrm{~V} 2, \mathrm{~V} 3, \mathrm{~V} 4, \mathrm{~V} 5$ & & & & & & $\mathrm{x}$ & erva & 62 \\
\hline Axonopus sp. 1 & $\mathrm{~V} 4$ & & & & & & & erva & 304 \\
\hline Echinolaena inflexa (Poir.) Chase & $\mathrm{V} 1, \mathrm{~V} 2, \mathrm{~V} 3, \mathrm{~V} 4, \mathrm{~V} 5$ & $\mathrm{x}$ & & $\mathrm{x}$ & $\mathrm{x}$ & $\mathrm{x}$ & $\mathrm{x}$ & erva & 86 \\
\hline Eriochrysis cayennensis P. Beauv.* & $\mathrm{V} 1, \mathrm{~V} 2$ & $\mathrm{x}$ & $\mathrm{x}$ & $\mathrm{x}$ & & & $\mathrm{x}$ & erva & 34 \\
\hline Eriochrysis holcoides (Nees) Kuhlm.* & $\mathrm{V} 2, \mathrm{~V} 3$ & $\mathrm{x}$ & $\mathrm{x}$ & & & & & erva & 365 \\
\hline Gymnopogon foliosus (Willd.) Nees & V5 & & & & $\mathrm{x}$ & $\mathrm{x}$ & $\mathrm{x}$ & erva & 89 \\
\hline Ichnanthus procurrens (Nees ex Trin.) Swallen & $\mathrm{V} 1, \mathrm{~V} 2, \mathrm{~V} 3, \mathrm{~V} 4, \mathrm{~V} 5$ & $\mathrm{x}$ & $\mathrm{x}$ & $\mathrm{x}$ & $\mathrm{x}$ & & $\mathrm{x}$ & erva & 193 \\
\hline
\end{tabular}




\begin{tabular}{|c|c|c|c|c|c|c|c|c|c|}
\hline FAMÍLIA/ESPÉCIE & EESGTO & $\mathrm{GO}$ & MS & TM & CSS & $\mathrm{CS}$ & CLU & Hábito & $\mathrm{N}$ \\
\hline Mesosetum penicillatum $\mathrm{Mez}$ & $\mathrm{V} 1, \mathrm{~V} 2, \mathrm{~V} 3, \mathrm{~V} 4, \mathrm{~V} 5$ & & & & & & & erva & 329 \\
\hline Panicum campestre Nees ex Trin. & $\mathrm{V} 1, \mathrm{~V} 4, \mathrm{~V} 5$ & & & & & & & erva & 307 \\
\hline Paspalum ammodes Trin. & $\mathrm{V} 1, \mathrm{~V} 2, \mathrm{~V} 4$ & & & & & $x$ & & erva & 181 \\
\hline Paspalum approximatum Döll & V1 & & & & & & & erva & 47 \\
\hline Paspalum carinatum Humb. \& Bonpl. ex Flüggé & $\mathrm{V} 2$ & & & & & & $\mathrm{x}$ & erva & 714 \\
\hline Paspalum dedeccae Quarí* & $\mathrm{V} 1, \mathrm{~V} 2, \mathrm{~V} 3, \mathrm{~V} 4, \mathrm{~V} 5$ & & $\mathrm{x}$ & & & & $\mathrm{x}$ & erva & 200 \\
\hline Paspalum ellipticum Döll* & V5 & & & & & $\mathrm{x}$ & $\mathrm{x}$ & erva & 597 \\
\hline Paspalum glaziovii (A.G.Burm.) S.Denham* & V4 & & & & & & & erva & 348 \\
\hline Paspalum guttatum Trin.* & $\mathrm{V} 2$ & & & & & & & erva & 572 \\
\hline Paspalum hyalinum Nees ex Trin. & $\mathrm{V} 1, \mathrm{~V} 2, \mathrm{~V} 3, \mathrm{~V} 4, \mathrm{~V} 5$ & & & $\mathrm{x}$ & & & $\mathrm{x}$ & erva & 431 \\
\hline Paspalum lanciflorum Nees ex Steud. & $\mathrm{V} 2, \mathrm{~V} 3, \mathrm{~V} 5$ & & & & & & & erva & 192 \\
\hline Paspalum lineare Trin. & $\mathrm{V} 1, \mathrm{~V} 2, \mathrm{~V} 3, \mathrm{~V} 4, \mathrm{~V} 5$ & & & $\mathrm{x}$ & & & $\mathrm{x}$ & erva & 344 \\
\hline Paspalum maculosum Trin. & $\mathrm{V} 1, \mathrm{~V} 3, \mathrm{~V} 4$ & $\mathrm{x}$ & $\mathrm{x}$ & & & $\mathrm{x}$ & $\mathrm{x}$ & erva & 187 \\
\hline Paspalum pectinatum Nees ex Trin.* & V2, V5 & & & $\mathrm{x}$ & & $\mathrm{x}$ & $\mathrm{x}$ & erva & 708 \\
\hline Paspalum polyphyllum Nees* & $\mathrm{V} 4$ & & & & $\mathrm{x}$ & $\mathrm{x}$ & $\mathrm{x}$ & erva & 397 \\
\hline Paspalum stellatum Humb. \& Bonpl. ex Flüggé & $\mathrm{V} 1, \mathrm{~V} 2, \mathrm{~V} 3, \mathrm{~V} 4, \mathrm{~V} 5$ & $\mathrm{x}$ & $\mathrm{x}$ & & & $\mathrm{x}$ & $\mathrm{x}$ & erva & 608 \\
\hline Saccharum asperum (Nees) Steud.* & $\mathrm{V} 3, \mathrm{~V} 4, \mathrm{~V} 5$ & $\mathrm{x}$ & $\mathrm{x}$ & $\mathrm{x}$ & & & & erva & 417 \\
\hline Saccharum villosum Steud.* & V3 & & $\mathrm{x}$ & & & & & erva & 441 \\
\hline Sacciolepis angustissima (Hochst. ex Steud.) Kuhlm.* & V5 & & & & & & & erva & 569 \\
\hline Sacciolepis myuros (Lam.) Chase* & $\mathrm{V} 1$ & & & & & & $\mathrm{x}$ & erva & 453 \\
\hline Trachypogon spicatus (L.f.) Kuntze & $\mathrm{V} 1, \mathrm{~V} 2, \mathrm{~V} 3, \mathrm{~V} 4, \mathrm{~V} 5$ & & & $\mathrm{x}$ & $\mathrm{x}$ & $\mathrm{x}$ & $\mathrm{x}$ & erva & 9 \\
\hline $\begin{array}{l}\text { Trichanthecium cyanescens (Nees ex Trin.) Zuloaga \& Morrone } \\
\text { POLYGALACEAE }\end{array}$ & $\mathrm{V} 2, \mathrm{~V} 3, \mathrm{~V} 4$ & & & & & $\mathrm{x}$ & $\mathrm{x}$ & erva & 137 \\
\hline Polygala abreui Marques \& J.F.B.Pastore* & V4 & & & & & & & subarbusto & 447 \\
\hline Polygala adenophora DC. & $\mathrm{V} 1, \mathrm{~V} 2, \mathrm{~V} 3, \mathrm{~V} 4, \mathrm{~V} 5$ & & & & & & & subarbusto & 4 \\
\hline Polygala celosioides Mart. ex A.W.Benn. & $\mathrm{V} 1, \mathrm{~V} 2, \mathrm{~V} 3, \mathrm{~V} 4, \mathrm{~V} 5$ & & & & & & $\mathrm{x}$ & subarbusto & 43 \\
\hline Polygala gracilis Kunth & $\mathrm{V} 1, \mathrm{~V} 2, \mathrm{~V} 3, \mathrm{~V} 4, \mathrm{~V} 5$ & & & & & & $\mathrm{x}$ & subarbusto & 356 \\
\hline Polygala longicaulis Kunth & $\mathrm{V} 1, \mathrm{~V} 2, \mathrm{~V} 3, \mathrm{~V} 4, \mathrm{~V} 5$ & $\mathrm{x}$ & $\mathrm{x}$ & $\mathrm{x}$ & & $\mathrm{x}$ & $\mathrm{x}$ & subarbusto & 8 \\
\hline
\end{tabular}




\begin{tabular}{|c|c|c|c|c|c|c|c|c|c|}
\hline FAMÍLIA/ESPÉCIE & EESGTO & $\mathrm{GO}$ & MS & TM & CSS & $\mathrm{CS}$ & CLU & Hábito & $\mathrm{N}$ \\
\hline Polygala moquiniana A.St.-Hil. \& Moq.* & V4 & & & & & & & subarbusto & 391 \\
\hline Polygala sellowiana A.St.-Hil. \& Moq. & V2, V3 & & & & & & & subarbusto & 691 \\
\hline Polygala tenuis DC. & $\mathrm{V} 1, \mathrm{~V} 2, \mathrm{~V} 3$ & $\mathrm{x}$ & & & & $\mathrm{x}$ & $\mathrm{x}$ & subarbusto & 689 \\
\hline Polygala timoutou Aubl. & V3, V4 & & & $\mathrm{x}$ & & & $\mathrm{x}$ & subarbusto & 492 \\
\hline \multicolumn{10}{|l|}{ RAPATEACEAE } \\
\hline Cephalostemon angustatus Malme & $\mathrm{V} 1, \mathrm{~V} 4$ & & $\mathrm{x}$ & $\mathrm{x}$ & & & & erva & 475 \\
\hline Cephalostemon microglochin Sandwith & $\mathrm{V} 1$ & & & & & & & erva & 152 \\
\hline Cephalostemon riedelianus Körn. & $\mathrm{V} 1, \mathrm{~V} 2, \mathrm{~V} 3, \mathrm{~V} 4, \mathrm{~V} 5$ & & & & & & $\mathrm{x}$ & erva & 81 \\
\hline \multicolumn{10}{|l|}{ RUBIACEAE } \\
\hline Borreria tenella (Kunth) Cham. \& Schltdl. & V5 & & & & & & & arbusto & 690 \\
\hline Diodia sp.1 & V5 & & & & & & & subarbusto & 92 \\
\hline Perama hirsuta Aubl. & $\mathrm{V} 1, \mathrm{~V} 2, \mathrm{~V} 3, \mathrm{~V} 4, \mathrm{~V} 5$ & & & $\mathrm{x}$ & & & & subarbusto & 69 \\
\hline Perama galioides (Kunth) Poir.* & V5 & & & & & & & subarbusto & 678 \\
\hline Staelia virgata (Link ex Roem. \& Schult.) K.Schum. & $\mathrm{V} 2$ & & & & & & $\mathrm{x}$ & subarbusto & 605 \\
\hline \multicolumn{10}{|l|}{ SANTALANACEAE } \\
\hline Thesium aphyllum Mart. ex A. DC. & V4 & & & & & & & subarbusto & 599 \\
\hline \multicolumn{10}{|l|}{ SCROPHULARIACEAE } \\
\hline Buddleja stachyoides Cham. \& Schltdl.* & $\mathrm{V} 2$ & & & & & & & arbusto & 663 \\
\hline \multicolumn{10}{|l|}{ STYRACACEAE } \\
\hline Styrax ferrugineus Nees \& Mart. & $\mathrm{V} 3, \mathrm{~V} 4, \mathrm{~V} 5$ & & & & & & & arbusto & 146 \\
\hline \multicolumn{10}{|l|}{ URTICACEAE } \\
\hline Cecropia pachystachya Trécul & $\mathrm{V} 2, \mathrm{~V} 4$ & $\mathrm{x}$ & $\mathrm{x}$ & $\mathrm{x}$ & & & & árvore & avistada \\
\hline \multicolumn{10}{|l|}{ VERBENACEAE } \\
\hline Lippia sp.1 & $\mathrm{V} 2$ & & & & & & & erva & 624 \\
\hline \multicolumn{10}{|l|}{ VOCHYSIACEAE } \\
\hline Vochysia rufa Mart. & V3 & & & & & & & árvore & 437 \\
\hline \multicolumn{10}{|l|}{ XYRIDACEAE } \\
\hline Abolboda pulchella Humb. & $\mathrm{V} 1, \mathrm{~V} 2, \mathrm{~V} 3, \mathrm{~V} 4, \mathrm{~V} 5$ & & & $\mathrm{x}$ & & & $\mathrm{x}$ & erva & 98 \\
\hline
\end{tabular}




\begin{tabular}{|c|c|c|c|c|c|c|c|c|c|}
\hline FAMÍLIA/ESPÉCIE & EESGTO & $\mathrm{GO}$ & MS & $\mathrm{TM}$ & CSS & $\mathrm{CS}$ & CLU & Hábito & $\mathrm{N}$ \\
\hline Abolboda poarchon Seub. & $\mathrm{V} 1, \mathrm{~V} 2, \mathrm{~V} 3, \mathrm{~V} 4, \mathrm{~V} 5$ & $\mathrm{x}$ & $\mathrm{x}$ & & & & $\mathrm{x}$ & erva & 32 \\
\hline Xyris almae Kral \& Wand.* & V3 & & & & & & & erva & 527 \\
\hline Xyris blanchetiana Malme* & $\mathrm{V} 3, \mathrm{~V} 4, \mathrm{~V} 5$ & & & & & & $\mathrm{x}$ & erva & 529 \\
\hline Xyris brevifolia Michx.** & V5 & & & & & & & erva & 526 \\
\hline Xyris dawsonii L.B.Sm. \& Downs* & $\mathrm{V} 3, \mathrm{~V} 4, \mathrm{~V} 5$ & & & & & & $\mathrm{x}$ & erva & 120 \\
\hline Xyris egleri L.B.Sm. \& Downs** & V1, V3 & & & & & & & erva & 389 \\
\hline Xyris fallax Malme & $\mathrm{V} 1, \mathrm{~V} 2, \mathrm{~V} 3, \mathrm{~V} 4, \mathrm{~V} 5$ & & & & & & $\mathrm{x}$ & erva & 148 \\
\hline Xyris hymenachne Mart. & $\mathrm{V} 1, \mathrm{~V} 2, \mathrm{~V} 3, \mathrm{~V} 4, \mathrm{~V} 5$ & & & & & & $\mathrm{x}$ & erva & 674 \\
\hline Xyris macrocephala Vahl & $\mathrm{V} 1, \mathrm{~V} 2, \mathrm{~V} 3, \mathrm{~V} 4, \mathrm{~V} 5$ & $\mathrm{x}$ & $\mathrm{x}$ & & & & $\mathrm{x}$ & erva & 135 \\
\hline Xyris paradisiaca Wand.* & V5 & & & & & & $\mathrm{x}$ & erva & 103 \\
\hline Xyris paraensis Poepp. ex Kunth* & $\mathrm{V} 1, \mathrm{~V} 2, \mathrm{~V} 3, \mathrm{~V} 4, \mathrm{~V} 5$ & & & & & & $\mathrm{x}$ & erva & 24 \\
\hline Xyris pterygoblephara Steud.* & V3, V4, V5 & & & & & & & erva & 306 \\
\hline Xyris savanensis Miq. & $\mathrm{V} 3, \mathrm{~V} 4, \mathrm{~V} 5$ & $\mathrm{x}$ & $\mathrm{x}$ & $\mathrm{x}$ & & & $\mathrm{x}$ & erva & 71 \\
\hline Xyris seubertii L.A.Nilsson* & V4, V5 & & & & & & $\mathrm{x}$ & erva & 139 \\
\hline Xyris spinulosa Kral \& L.B.Sm.* & $\mathrm{V} 3, \mathrm{~V} 5$ & & $\mathrm{x}$ & & & & & erva & 564 \\
\hline Xyris tortula Mart.* & $\mathrm{V} 1, \mathrm{~V} 2, \mathrm{~V} 3, \mathrm{~V} 4, \mathrm{~V} 5$ & $\mathrm{x}$ & $\mathrm{x}$ & $\mathrm{x}$ & & & $\mathrm{x}$ & erva & 189 \\
\hline Xyris sp.1 & $\mathrm{V} 1, \mathrm{~V} 2, \mathrm{~V} 3, \mathrm{~V} 4, \mathrm{~V} 5$ & & & & & & & erva & 35 \\
\hline Xyris sp.2 & $\mathrm{V} 1$ & & & & & & & erva & 65 \\
\hline Xyris sp.3 & $\mathrm{V} 3, \mathrm{~V} 4$ & & & & & & & erva & 73 \\
\hline Xyris sp.4 & V4, V5 & & & & & & & erva & 83 \\
\hline Xyris sp.5 & $\mathrm{V} 1$ & & & & & & & erva & 100 \\
\hline Xyris sp.6 & V4 & & & & & & & erva & 125 \\
\hline
\end{tabular}


Tabela 3: Ocorrência de espécies e gêneros do presente estudo em comparação com outras fitofisionomias de Cerrado. Onde $\mathrm{N}^{\circ}=\mathrm{Número,} \mathrm{EESGTO} \mathrm{=}$ Estação Ecológica Serra Geral do Tocantins, CSS = Cerrado sensu stricto, CS = Campo Sujo e CLU = Campo Limpo Úmido.

\begin{tabular}{|c|c|c|c|c|c|c|c|c|c|c|}
\hline & \multicolumn{2}{|c|}{ Veredas TO } & \multicolumn{2}{|c|}{ Veredas (TO, MG, MS e GO) } & \multicolumn{2}{|c|}{ CSS } & \multicolumn{2}{|c|}{ CS } & \multicolumn{2}{|c|}{ CLU } \\
\hline & Espécie & Gênero & Espécie & Gênero & Espécie & Gênero & Espécie & Gênero & Espécie & Gênero \\
\hline $\mathrm{N}^{\mathrm{o}}$ Total & 213 & 49 & 412 & 212 & 210 & 79 & 218 & 86 & 294 & 92 \\
\hline $\begin{array}{l}\mathrm{N}^{\circ} \text { de exclusivas por } \\
\text { fitofisionomia }\end{array}$ & 70 & 11 & 342 & 43 & 189 & 24 & 99 & 2 & 187 & 2 \\
\hline $\begin{array}{l}\mathrm{N}^{\circ} \text { de espécies e gêneros } \\
\text { que não ocorreram em } \\
\text { Veredas }\end{array}$ & - & - & - & - & 174 & 64 & 133 & 54 & 151 & 23 \\
\hline $\begin{array}{l}\mathrm{N}^{\mathrm{o}} \text { de ocorrências em } \\
\text { comum com a Vereda }\end{array}$ & - & - & - & - & 32 & 15 & 80 & 31 & 141 & 69 \\
\hline
\end{tabular}




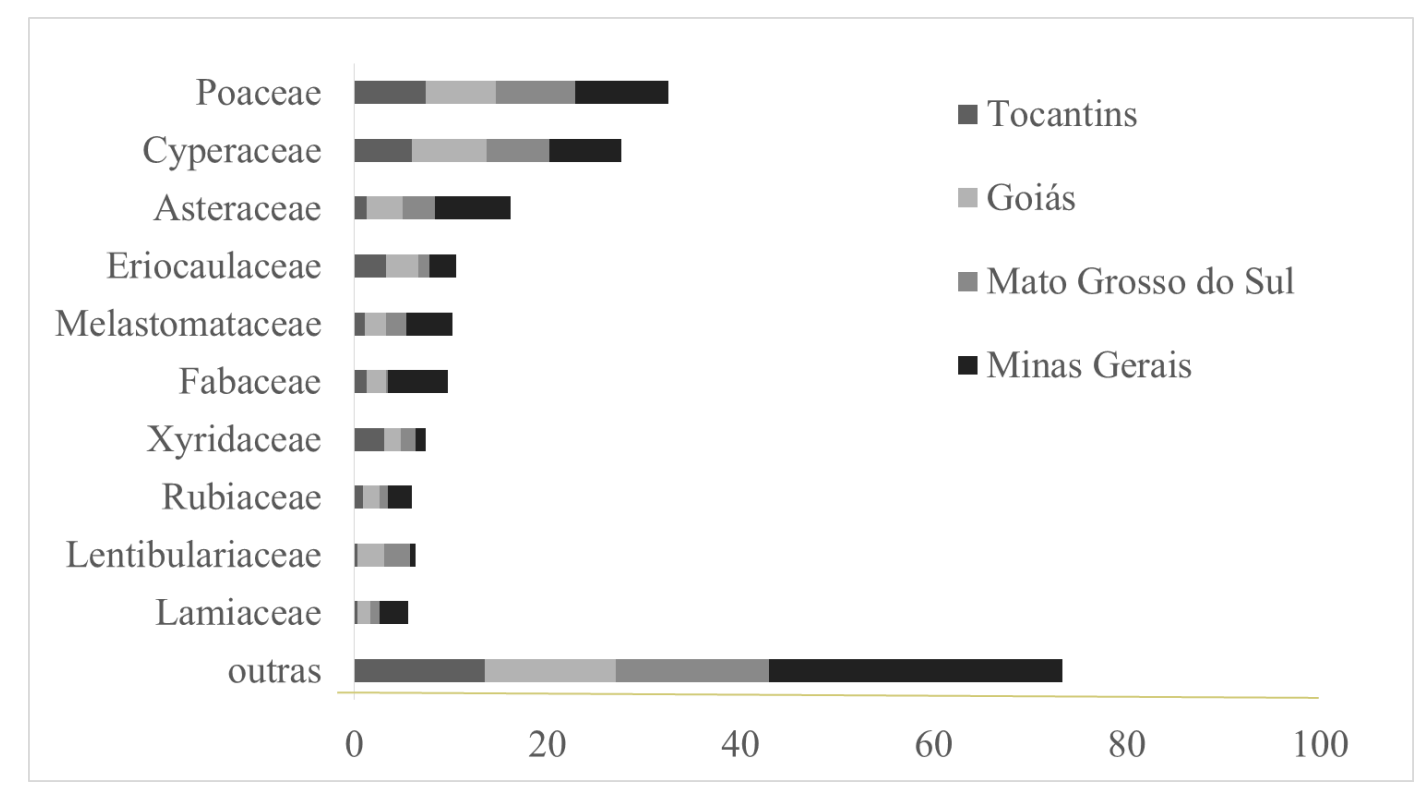

Figura 3: Ranque das dez famílias que apresentam maior número de espécies no levantamento florístico na Estação Ecológica Serra Geral do Tocantins, TO e nas veredas comparadas.

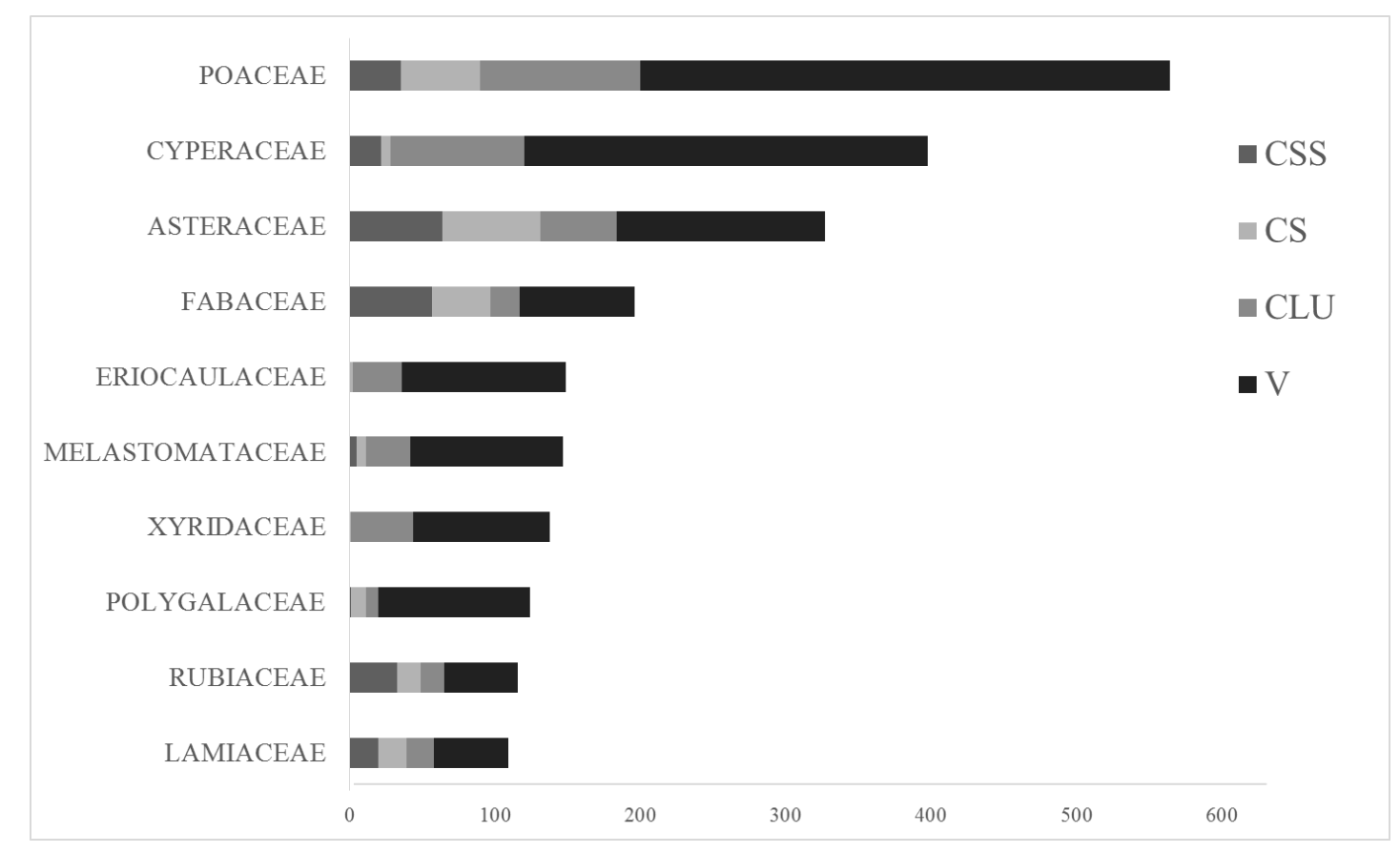

Figura 4: Ranque das famílias que apresentam maior número de espécies no levantamento florístico na Estação Ecológica Serra Geral do Tocantins, TO, nas veredas comparadas e nas fitofisionomias comparadas. 


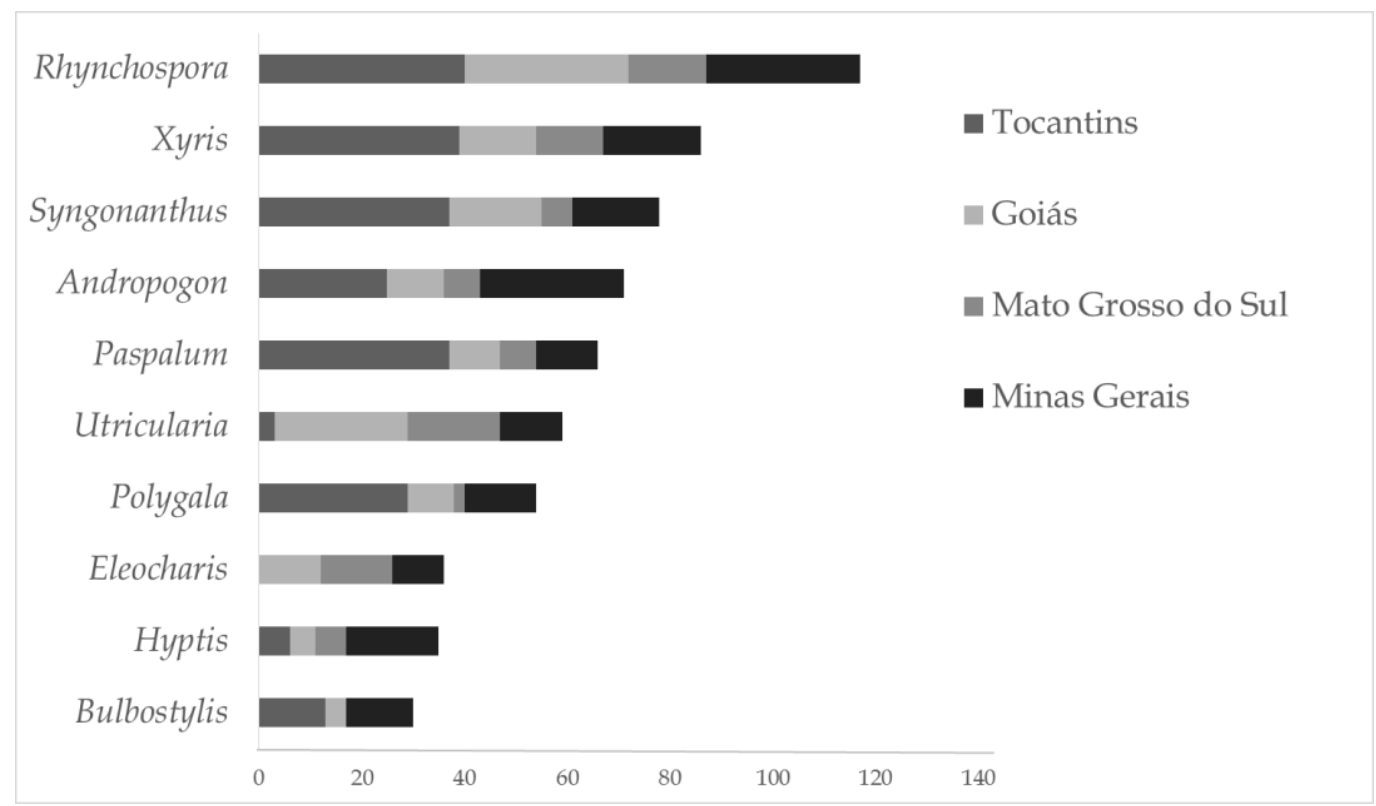

Figura 5: Ranque dos dez gêneros que apresentam maior número de espécies no levantamento florístico na Estação Ecológica Serra Geral do Tocantins, TO e nas veredas comparadas.

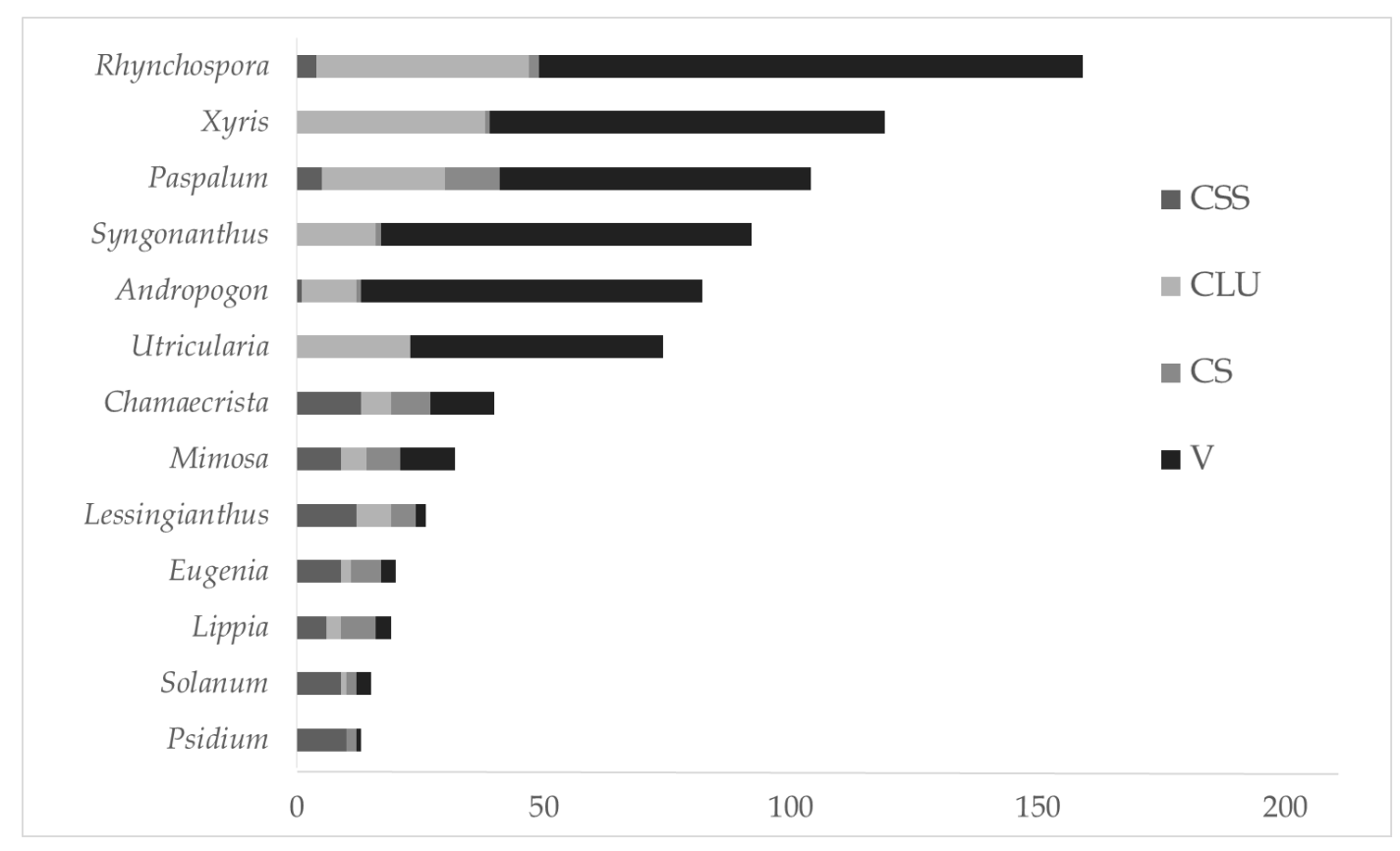

Figura 6: Ranque dos gêneros que apresentam maior número de espécies no levantamento florístico na Estação Ecológica Serra Geral do Tocantins, TO, nas veredas comparadas e nas fitofisionomias comparadas. 


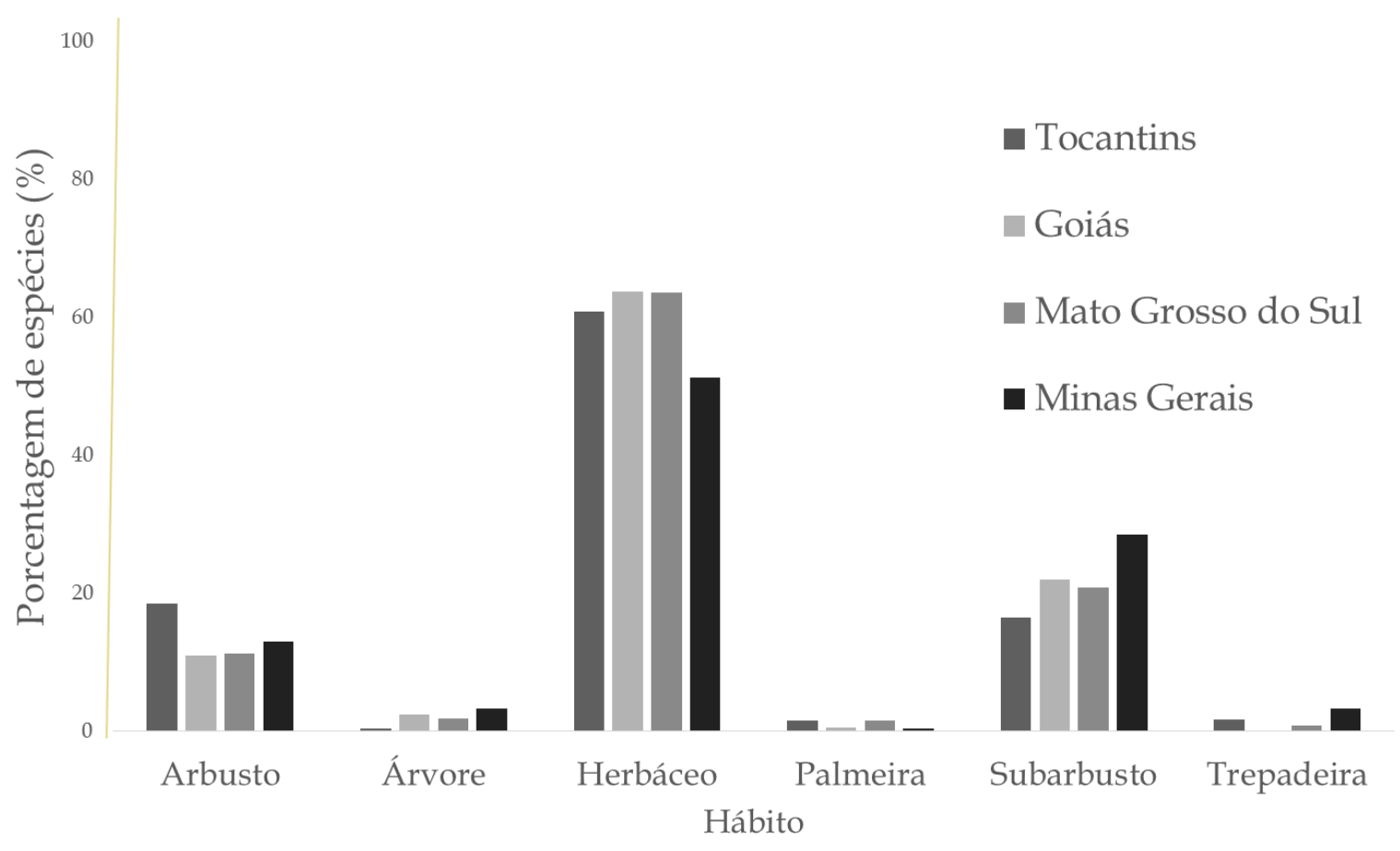

Figura 7: Porcentagem de distribuição de espécies de acordo com o hábito no estudo florístico na Estação Ecológica Serra Geral do Tocantins, TO, e nas veredas comparadas. 

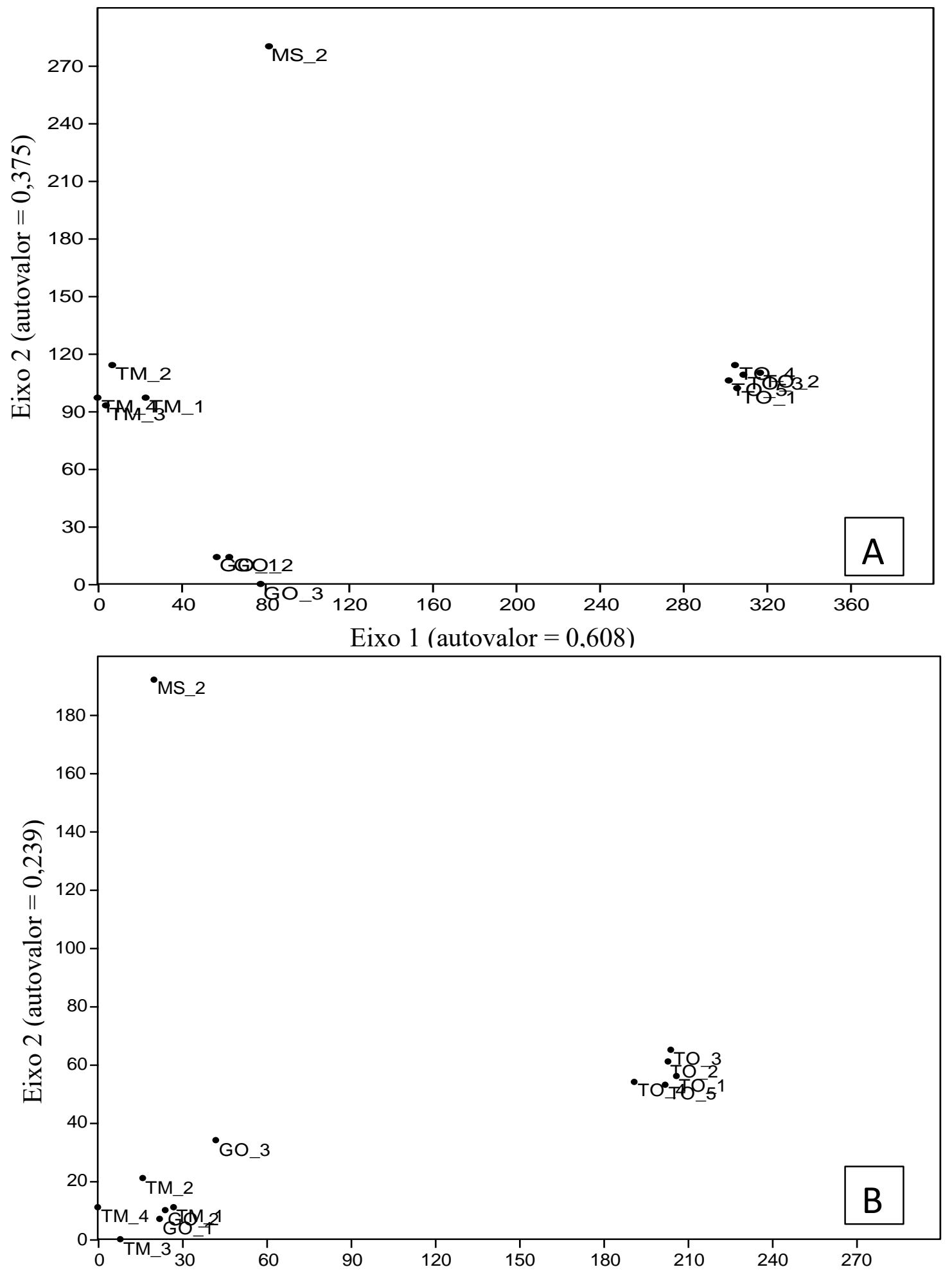

Eixo 1 (autovalor $=0,396)$

Figura 8: Posicionamento por eixos de ordenação (DCA) dos componentes herbáceos-arbustivos de 13 áreas de Veredas a nível específico (A) e genérico (B). MS_2, Vereda m Mato Grosso do Sul, GO_1, 2 e 3, Veredas em Goiás, TM_1, 2, 3 e 4, Veredas em Minas Gerais e TO_1, 2, 3, 4 e 5 = Veredas na EESGTO. 

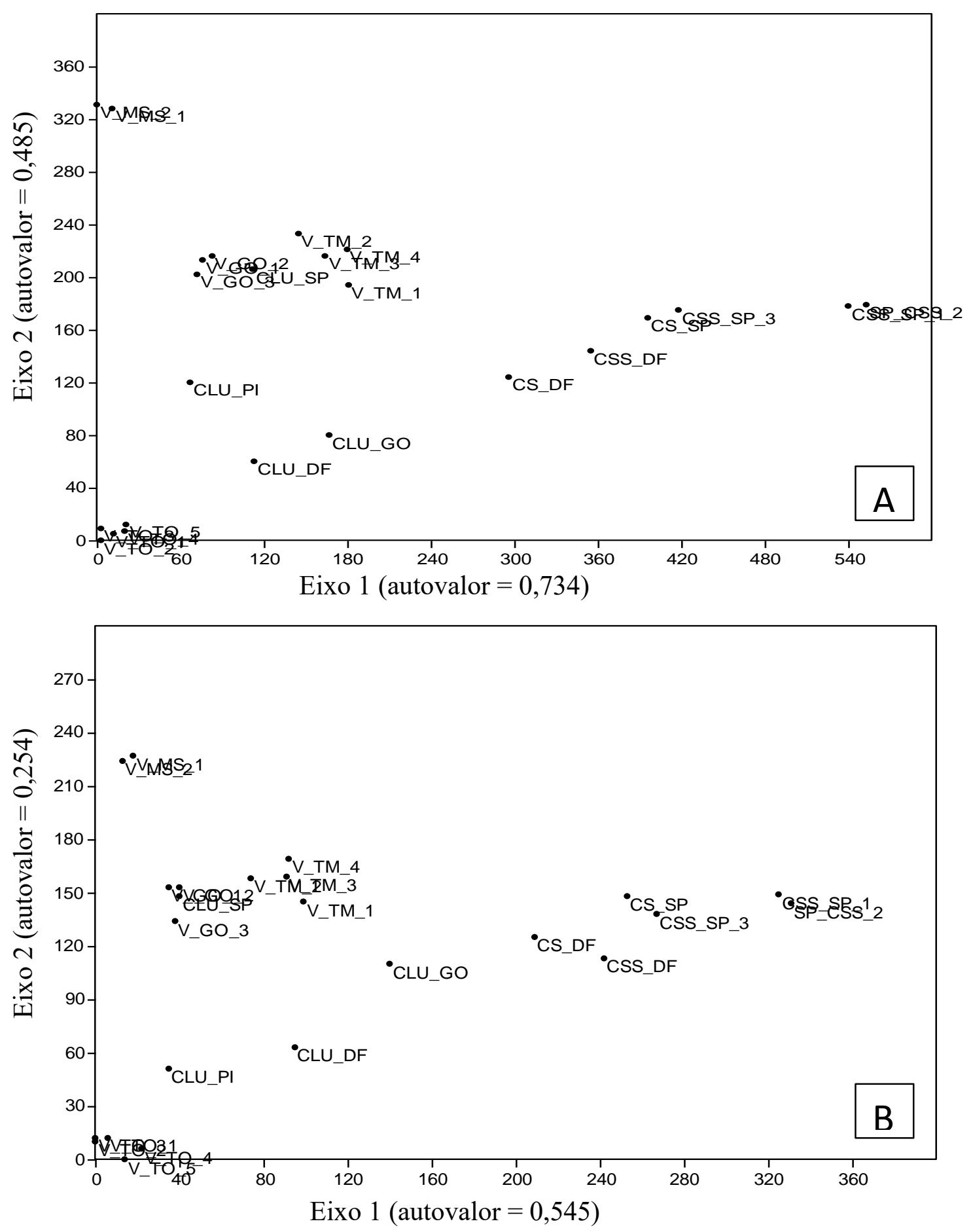

Figura 9: Posicionamento por eixos de ordenação (DCA) dos componentes herbáceos-arbustivos de 24 áreas em diferentes fitofisionomias de Cerrado a nível específico (A) e genérico (B). CSS_DF_, CSS_SP_1, 2 e 3 = Cerrado Sensu Stricto, CS_SP, CS_DF = Campo Sujo, CLU_DF, CLU_SP, CLU_GO, CLU_PI, V_MS_1 = Campo Limpo Úmido, V_MS_2, V_GO_1, 2 e 3, V_TM_1, 2, 3 e 4, V_TO_1, 2, 3, 4 e 5 = Veredas. 


\section{DISCUSSÃO}

Riqueza de espécies em Veredas na Estação Ecológica Serra Geral do Tocantins

As Veredas da EESGTO apresentaram elevada riqueza florística. As famílias que contribuíram com maior número de espécies nas Veredas da EESGTO foram Poaceae e Cyperaceae, também citadas como ricas em outros sítios de Veredas e campos úmidos (Araújo et al. 2002, Oliveira et al. 2003, Tannus \& Assis 2004). Os gêneros com maior número de espécies Rhynchospora e Xyris são comumente ricos em áreas úmidas de Cerrado (Araújo et al. 2002, Munhoz \& Felfili 2007, Resende et al. 2013).

O registro de 78 novas ocorrências de espécies para o estado do Tocantins contribui com a adição à listagem da flora vascular do Cerrado (Mendonça et al. 2008, Forzza et al. 2012). Sugerindo que a flora das Veredas no estado do Tocantins não foram ainda satisfatoriamente coletadas. A ocorrência de espécies na EESGTO até então registradas para a região Amazônica e Mata Atlântica, deve-se à escassez de estudos florísticos no estado do Tocantins e em Veredas (Meio et al. 2003). As espécies de Cerrado possuem grande alcance geográfico muitas vezes em mais de dois biomas, podendo ser registradas em diferentes fitofisionomias, (Françoso et al. 2015). Estudos apontam que a coincidência florística arbórea entre a floresta Atlântica e Amazônica com o Cerrado, para formações de Cerrado sensu stricto, pode ser superior a 49\%, sendo que, as espécies de Cerrado são majoritariamente compartilhadas com a Mata Atlântica, seguido pela Amazônia (Françoso et al. 2015). As hipóteses sobre a origem do bioma Cerrado remontam o início do período Cretáceo, onde as linhagens de espécies de Cerrado dariam origem à vegetação de outros biomas brasileiros (Ledru 2002, Pennington et al. 2004). Os limites do Cerrado são também portas de recrutamento de linhagens a partir de uma variedade de tipos de florestas de vegetações úmidas e secas (Simon et al. 2009). 


\section{Relações florísticas entre Veredas no domínio do Cerrado}

A análise de similaridade mostrou uma baixa sobreposição de espécies entre as 13 Veredas aqui comparadas, e maior semelhança florística entre as áreas com menor distância geográfica. Na família Poaceae, por exemplo, das 125 espécies que compuseram a matriz de análise, aproximadamente $27 \%$ ocorreram em apenas uma área, sendo que, somente seis espécies ocorreram nas 13 áreas. O endemismo de espécies para a flora herbáceo-arbustiva de Cerrado pode ser resultado da distribuição geográfica restrita de determinada espécie (Castro et al. 1999, Proença et al. 2010).

A análise de ordenação por DCA mostrou a formação de quatro grupos distintos, quando analisadas a nível de espécie. A nível genérico as áreas se aproximam floristicamente, formando três grupos, onde as Veredas de Minas Gerais se aproximam das de Goiás. A separação das veredas evidenciou a distinção regional entre as mesmas, que não possuem uma flora compartilhada, tanto ao nível especifico como genérico. O gradiente longitudinal determina variações em fatores ambientais, como a mudança no clima e características no solo, que estão relacionados a essa distribuição de espécies ao longo do bioma, o que reflete a mudança dinâmica nos padrões de distribuição de espécies no Cerrado (Castro et al. 1999, Ratter et al. 2003).

Compartilhamento florísticas entre Veredas e outras fitofisionomias no domínio do Cerrado

A análise de ordenação por DCA para espécies encontradas nas Veredas e demais fitofisionomias do Cerrado demonstrou não haver compartilhamento na composição florística entre as 24 áreas analisadas. Ocorreu a formação de grupos distintos relacionados à separação espacial dos sítios comparados. Também, evidenciou um gradiente de mudanças de composição florística das fitofisionomias mais úmidas para as mais secas. Entre as áreas mais úmidas, é possível notar a formação de um arranjo que vai dos campos úmidos para as Veredas, com o Campo Limpo Úmido do estado do Piauí, que se torna mais próximo às Veredas do Tocantins, mostrando maior 
coincidência florística quando comparados ao nível específico. Já quando comparados a nível genérico, há uma maior semelhança florística. As áreas de Cerrado sensu stricto e Campo Sujo do estado de São Paulo se aproximam das áreas do Distrito Federal, mostrando a relação entre sítios mais secos. A distância geográfica, reflexo da ampla variação latitudinal, entre as áreas comparadas pode ser o principal fator de influência na heterogeneidade florística no componente herbáceoarbustivo, uma vez que variações climáticas e edáficas entre as diferentes regiões podem determinar especiação e mudanças na flora em uma ampla região de Cerrado (Ratter et al. 2003, Simon et al. 2009).

Do total de espécies que compuseram a matriz com todas as fitofisionomias $47 \%$ são espécies que ocorreram exclusivamente nas Veredas. A flora herbáceo-arbustiva do Cerrado sensu stricto foi a que mais se distanciou das demais fitofisionomias, $85,7 \%$ das espécies registradas para esta fisionomia não ocorrem nas Veredas estudadas, sendo que esta flora compreendeu $29 \%$ do total de espécies da matriz. A partir da avaliação deste estudo, podemos supor que as Veredas são ambientes isolados. O solo úmido e com alto teor de matéria orgânica funcionaram como um filtro ambiental ao longo do tempo que selecionou grande parte das espécies. Nesse sentido, as Veredas podem ser consideradas como ilhas de savana úmida, assim como os campos limpos úmidos, que se encontram em meio a savanas de solo bem drenado, onde a flora é fracamente compartilhada. A exemplo de florestas úmidas que ocorrem no Brasil, consideradas uma unidade florística distinguível em função do isolamento em relação a outras formações vegetacionais (Kurtz et al. 2015).

A ocorrência da vegetação depende principalmente da sua história de formação e histórico de distúrbios ao longo do tempo (Ledru 2002; Schmidt et al. 2011). Sendo que a vegetação circunvizinha não possui influência direta na paisagem da Vereda. Áreas de campo limpo úmido associadas a nascentes compartilham cerca de 53\% de sua flora com Veredas, que por sua vez possuem uma flora 47\% distante floristicamente de qualquer outra fitofisionomia. Assim, esse ambiente, assim como 
cada Vereda, possui uma flora peculiar e distinta de demais formações vegetacionais, motivo pelo qual necessitam de um tratamento especial em relação a conservação (Moreira et al. 2015).

Estudos florísticos são importantes para conhecer as espécies que ocorrem nas Veredas do Jalapão que, no presente estudo mostraram elevada riqueza e com registro de novas ocorrências para o Cerrado, para o estado do Tocantins e provavelmente para a ciência, porém dentro dos limites normalmente encontrados para outras úmidas estudadas no Brasil Central (Araújo et al. 2002, Munhoz \& Felfili 2007). Com uma composição de espécies que se distância das demais em termos específicos e genéricos, é possível sugerir que ambientes de Vereda são do ponto de vista florístico ambientes prediletos para ocorrência de algumas espécies, o que torna as Veredas savanas distinguíveis de outras fitofisionomias de Cerrado. A baixa similaridade da vegetação de Veredas com outros ambientes de Cerrado serve como reforço para políticas públicas de conservação e gestão sustentável de Veredas, como uso na agronomia e pecuária. Sugere ainda a ampliação da área destinada à conservação nas Veredas, assim como os campos limpos úmidos como flora muito similar e tão exclusiva como as veredas, prevista no CONAMA (2012).

\section{AGRADECIMENTOS}

Agradecemos ao PNUD pelo apoio financeiro que permitiu viabilizar toda logística e infraestrutura necessária para execução deste estudo, ICMBio pelo apoio e auxílio no trabalho de campo. A CAPES pela bolsa de mestrado concedida para o primeiro autor. Pela identificação do material botânico os autores agradecem à M.V.S Alves (Cyperaceae), R.C. Oliveira (Poaceae), J.B. Bringel (Asteraceae), A.S. Silva (Poaceae), D.V. Segarra (várias famílias), J.E.Q. Faria Junior (várias famílias), M.R.V. Zanatta (Fabaceae), V.L. Rivera (Asteraceae), C.E.B. Proença (várias famílias), A.L.R. Oliveira (Eriocaulaceae). 


\section{REFERÊNCIAS BIBLIOGRÁFICAS}

Adámoli, J., Macedo, J., Azevedo, L. D., Netto, J. M. (1986). Caracterização da região dos Cerrados. Solos dos Cerrados: tecnologias e estratégias de manejo (ed. Goedert, WJ). Empresa Brasileira de Pesquisa Agropecuária/Nobel, p.33-74.

Byng, J. W. et al. (2016). An update of the Angiosperm Phylogeny Group classification for the orders and families of flowering plants: APG IV.BOTANICAL JOURNAL OF THE LINNEAN SOCIETY, 181: 1-20.

Araújo, G.M., Barbosa, A.A.A., Arantes, A.A., Amaral, A.F. (2002). Composição florística de Veredas no município de Uberlândia, MG. Revista Brasileira de Botânica 25: 475-493.

Borges, L. M., Antar, G. M. (2016). Four they are! Broadening the description of Mimosa flabellifolia (Leguminosae Mimosoideae), a rare species from the Brazilian Cerrado. Phytotaxa, 243: 155162.

Boulinier T, Nichols JD, Sauer JR, Hines JE, Pollock KH. (1998). Estimating species richness: the importance of heterogeneity in species detectability. Ecology 79: 1018-1028.

Brasil (2015). Presidência da República, Decreto № 8.447/2015, Casa Civil, Subchefia para Assuntos Jurídicos, 2015b, Disponível em: http://www.planalto.gov.br/ccivil_03/_Ato20152018/2015/Decreto/D8447.htm, Acesso: 07 março. 2016.

Carvalho, G. (2015). flora: Tools for Interacting with the Brazilian Flora Checklist. R package version 0.2.4. http://CRAN.R-project.org/package=flora

Castro, A.A.J.F., Martins, F.R., Tamashiro, J.Y., Shepherd, G.J. (1999). How rich is the flora of Brazilian cerrados? Annals of the Missouri Botanical Garden 86: 192-224.

Cifuentes, J. E. M. (2014). Agronegócio e acumulação por espoliação: o enclave da soja em Campos Lindos, TO. Sociedade e Estado 29: 303-304. 
EMPRESA BRASILEIRA DE PESQUISA AGROPECUÁRIA - EMBRAPA. (1999). Sistema Brasileiro de Classificação de Solos. Embrapa-SPI, Brasília. Embrapa Solos, p. 412.

Felfili, J. M., \& da Silva Jr, M. C. (1993). A Comparative Study of Cerrado (Sensu stricto) Vegetation in Central Brazil. Journal of Tropical Ecology, 9: 3, 277-289.

Ferreira, Laerte G. et al. (2009). Dinâmica agrícola e desmatamentos em áreas de cerrado: uma analise a partir de dados censitários e imagens de resolução moderada. Revista Brasileira de Cartografia, 61: 2, 117-127.

Filgueiras, T.S., Nogueira, P.E., Brochado, A.L. \& Guala II, G.F. (1994). Caminhamento: um método expedito para levantamentos florísticos qualitativos. Cadernos de Geociências 12: 39-43.

Flora do Brasil (2020) em construção. Jardim Botânico do Rio de Janeiro. Disponível em: <http://floradobrasil.jbrj.gov.br/ >. Acesso em: 24 Mai. 2016

Forzza, R.C., Baumgratz, J.F.A., Bicudo, C.E.M., et al. (2012). New Brazilian Floristic List Highlights Conservation Challenges. BioScience 62: 39-45. http://dx.doi.org/10.1525/bio.2012.62.1.8.

Françoso, R. D., Haidar, R. F., \& Machado, R. B. (2016). Tree species of South America central savanna: endemism, marginal areas and the relationship with other biomes. Acta Botanica Brasilica, 30:1, 78-86.

Guimarães, A.J.M., Araújo, G.M., Corrêa, G.F. (2002). Estrutura fitossociológica em área natural e antropizada de uma Vereda em Uberlândia, MG. Acta Botanica Brasilica 16: 317-329.

Klink, C.A., Machado, R.B. (2005). Conservation of the Brazilian Cerrado. Conservation biology, 19: 707-713.

Kurtz, B. C., Valentin, J. L., \& Scarano, F. R. (2015). ARE THE NEOTROPICAL SWAMP FORESTS A DISTINGUISHABLE FOREST TYPE? PATTERNS FROM SOUTHEAST AND SOUTHERN BRAZIL.Edinburgh Journal of Botany, 72:02, 191-208. 
Ledru, M. P. (2002). Late Quaternary history and evolution of the Cerrado as revealed by palynological records. In The Cerrados of Brazil p. 33-50.

MacArthur, R. H., \& Wilson, E. O. (2015). Theory of Island Biogeography. (MPB-1) (Vol. 1). Princeton University Press.

Mamede, F., Garcia, P.Q., Sousa Júnior, W.C. (2002). Análise da viabilidade sócio-econômicoambiental da transposição de águas da bacia do rio Tocantins para o rio São Francisco na região do Jalapão/TO. Caderno de política ambiental, 1. Brasília: Conservation Strategy Fund/Conservation International do Brasil/ Instituto Internacional de Educação do Brasil.

McCune, B., Grace, J. B., \& Urban, D. L. (2002). Analysis of ecological communities (Vol. 28). Gleneden Beach, OR: MjM software design.

Méio B. B, Freitas C. V, Jatobá L, Silva M. E. F, Ribeiro J. F, Henriques R. P. B. (2003). Influência da flora das florestas Amazônica e Atlântica na vegetação do cerrado sensu stricto. Revista Brasileira de Botânica 26: 437-444

Mendonça, R. C., Felfili, J.M.; Walter, B.M.T., Junior, M.C.S., Rezende, A.V., Filgueiras, T.S, Nogueira, P.E., Fagg, C.W. (2008). Flora vascular do bioma Cerrado. v. 2. In Sano, S. M.; Almeida, S. P., Ribeiro, J. F. (eds.). Cerrado: ecologia e flora. Brasília, Embrapa-Cerrados, Embrapa Informação Tecnológica, p. 1279.

Moreira, S. N., Eisenlohr, P. V., Pott, A., Pott, V. J., \& Oliveira-filho, A. T. (2015). Similar vegetation structure in protected and non-protected wetlands in Central Brazil: conservation significance. Environmental Conservation, 42: 356-362.

Munhoz, C. B. R., Felfili, J. M. (2005). Fenologia do estrato herbáceo-subarbustivo de uma comunidade decampo sujo na fazenda água limpa no Distrito Federal, Brasil. Acta Botânica Brasilica 19: 981-990.

Munhoz, C. B. R., Felfili, J. M. (2007). Florística do estrato herbáceo-subarbustivo de um campo limpo úmido em Brasília, Brasil. Biota Neotropica 7: 205-215. 
Oliveira, G.C., Araújo, G.M., Barbosa, A.A.A. (2003). Levantamento florístico em seis comunidades vegetais de Veredas no triângulo mineiro. Trabalho do VI Congresso de Ecologia do Brasil. Capítulo 3 - Cerrado. Resumos. Fortaleza, CE.

Oliveira, G.C.; Araújo, G.M., Barbosa, A.A.A. (2009). Florística e zonação de espécies vegetais em Veredas no Triângulo Mineiro, Brasil. Rodriguésia 60: 1077-1085.

Oliveira-Filho A. T, Ratter J. A. (2002). Vegetation Physiognomies and Woody Flora of the Cerrado Biome. In: Oliveira PS, Marquis RJ. (eds.) The Cerrados of Brazil: ecology and natural history of a neotropical savanna. New York, Columbia University Press. p. 93-120.

Oliveira-Filho, A. T., Shepherd, G. J., Martins, F. R., Stubblebine, W. H. (1989). Environmental factors affecting physiognomic and floristic variation in an area of cerrado in central Brazil. Journal of Tropical Ecology 5: 413-431.

Oksanen, J., Blanchet, F. G., Kindt, R., Legendre, P., et al. (2015). vegan: Community Ecology Package. R package version 2.0-10. http://CRAN.R-project.org/package=vegan

Pennington, R. T., Lavin, M., Prado, D. E., Pendry, C. A., Pell, S. K., Butterworth, C. A. (2004). Historical climate change and speciation: neotropical seasonally dry forest plants show patterns of both Tertiary and Quaternary diversification. Philosophical Transactions of the Royal Society of London B: Biological Sciences, 359: 515-538.

Proença, C.E.B., Farias-Singer, R., Gomes, B.M. (2007). Pleonotoma orientalis (Bignoniaceae Bignonieae): Expanded description, distribution and a new variety of a poorly known species. dinburgh Journal of Botany 64: 17-23. http://dx.doi.org/10.1017/S0960428606000680

R Development Core Team. (2015). R: a language and environment for statistical computing. R Foundation for Statistical Computing, Vienna. Available in <http:// www.R-project.org>. Access on 7 Março 2016. 
Ramos, M.V.V., Curi, N., Motta, P.E.F., Vitorino, A.C.T., Ferreira, M.M., Silva, M.L.N. (2006). Veredas do Triângulo Mineiro: solos, água e uso. Ciência e Agrotecnologia Lavras, 30: 283293.

Ratter, J.A., Bridgewater, S., Ribeiro, J.F. (2003). Analysis of the floristic composition of the Brazilian cerrado vegetation III: comparison of the woody vegetation of 376 areas. Edinburgh Journal of Botany 60: 57-109.

Resende, I. L. D. M., Chaves, L. J., Rizzo, J. Â. (2013). Floristic and phytosociological analysis of palm swamps in the central part of the Brazilian savanna. Acta Botanica Brasilica, 27: 205-225.

Ribeiro, J.F., Walter, B.M.T. (2008). As Principais Fitofisionomias do Bioma Cerrado. In Cerrado: Ecologia e Flora (S.M. Sano \& S.P. de Almeida, eds.). EMBRAPA, p. 153-212.

Rizzini CT. (1963). A flora do Cerrado. In: Ferri MG. (ed.) Simpósio sobre o Cerrado. Editora da Universidade de São Paulo. p. 127-177.

Rosolen, V., de Oliveira, D. A., \& Bueno, G. T. (2015). Vereda and Murundu wetlands and changes in Brazilian environmental laws: challenges to conservation. Wetlands Ecology and Management, 23: 285-292.

Schmidt, I.B.; Figueiredo, I.B., Scariot, A. (2007). Ethnobotany and effects of harvesting on the population ecology of Syngonanthus nitens (Bong.) Ruhland (Eriocaulaceae), a NTFP from Jalapão region, Central Brazil. Economic Botany 61: 73-85.

Schmidt, I.B. (2011). Effects of local ecological knowledge, harvest and fire on Golden-grass (Syngonanthusnitens, Eriocaulaceae), a non-timber forest product (NTFP) species from Brazilian savanna.Tese (Doutorado em Botânica, Ecologia, Evolução e Biologia da Conservação). University of Hawai'I at Manoa. p. 186.

Seplam. (2003a). Plano de Manejo do Parque Estadual do Jalapão. Palmas, TO.

Seplam. (2003b). Zoneamento Ecológico Econômico de Tocantins. www.seplan.to.gov.br 
Silva, J.M.C, Bates, J.M. (2002). Biogeographic Patterns and Conservation in the South American Cerrado: A Tropical Savanna Hotspot. BioScience, 52: 225-234.

Simon M. F Grether R, Queiroz L. P, et al. (2009). Recent assembly of the Cerrado, a neotropical plant diversity hotspot, by in situ evolution of adaptations to fire. Proceedings of the National Academy of Sciences of the United States of America 106: 20359-20364.

Sousa-Baena M. S, Garcia L. C, Peterson A. T. (2014). Completeness of digital accessible knowledge of the plants of Brazil and priorities for survey and inventory. Diversity and Distributions 20: 369-381.

Tannus, J. L., Assis, M. A. (2004). Composição de espécies vasculares de campo sujo e campo úmido em área de cerrado, Itirapina-SP, Brasil. Revista Brasileira de Botânica, 27: 489-506.

Villela, F.N.J, Nogueira, C. (2011). Geologia e geomorfologia da estação ecológica Serra Geral do Tocantins. Biota Neotropica, 11: 217-230. 


\section{CAPÍTULO 2}

\section{ESTRUTURA FITOSSOCIOLÓGICA EM VEREDAS NA ESTAÇÃO ECOLÓGICA SERRA GERAL DO TOCANTINS NO JALAPÃO, TOCANTINS}

\section{RESUMO:}

Na região do Cerrado, a Vereda é uma fitofisionomia savânica composta um estrato predominante herbáceo e um estrato arbóreo-arbustivo com a presença da palmeira Mauritia flexuosa. O gradiente de umidade do solo é um dos fatores determinantes na distribuição das espécies. Presentes na região do Jalapão, no estado do Tocantins, as Veredas tem sido alvo de estudos quali-quantitativos. Nesse sentido, o presente estudo teve por objetivo contribuir para o conhecimento da composição e diversidade da vegetação na Estação Ecológica Serra Geral do Tocantins. Os solos no Jalapão são Neossolo Quartizarênico, distróficos e álicos. O clima é caracterizado por forte sazonalidade, onde $90 \%$ das chuvas ocorrem de outubro a abril. A temperatura média na região é de $27^{\circ} \mathrm{C}$ e a precipitação anual média é de $1.700 \mathrm{~mm}$. Os estudos fitossociológicos da vegetação foram realizados em expedições no período chuvoso onde a maioria dos espécimes se encontravam em estágio reprodutivo. Foi utilizado o método de interseção na linha, tendo sido instaladas 15 linhas de 10m, em cada Vereda. A projeção das espécies foi anotada para cálculos das coberturas e frequências. Amostra de solo $(0-20 \mathrm{~cm})$ foram coletadas para análises químicas e texturais. Análise fitossociológica registrou 123 espécies em 69 gêneros e 33 famílias. Análises das variáveis ambientais, de agrupamento e ordenação, refletem a homogeneidade florística entre as áreas comparadas, o que está relacionado à baixa variação ambiental entre as mesmas. A distribuição das espécies na Estação Ecológica apresenta uma relação direta entre as Veredas, onde são formados mosaicos de vegetação, em função do gradiente de variáveis ambientais.

\section{(CAPES, ICMBio, PNUD)}

Palavras-chave: Vereda, estrato herbáceo, método de interseção na linha, variáveis ambientais. 


\section{INTRODUÇÃO}

No Brasil Central o bioma Cerrado é composto por um mosaico de formações campestres, savânicas e florestais, e é considerado o segundo maior bioma brasileiro, inferior apenas em relação à Amazônia (Klink \& Machado 2005, Ribeiro \& Walter 2008). Na região do Cerrado, existem fitofisionomias de solos bem drenados e ocorrência de áreas úmidas, entre elas as Veredas, que são comunidades hidrófilas formadas por um estrato herbáceo que ocupa maior parte da área e um estrato arbóreo-arbustivo com a presença da palmeira Mauritia flexuosa L.f. (Arecaceae), conhecida como buriti, com dossel entre 5\% e 10\% (Ribeiro \& Walter 2008).

É possível destacar a influência do gradiente de umidade do solo na distribuição das espécies com grupos característicos de ambientes secos, úmidos e grupos indiferentes (Moreira et al. 2011). As Veredas são áreas protegidas pela lei brasileira e consideradas áreas de proteção permanente (CONAMA 2012), são fundamentais na manutenção dos recursos hídricos, auxiliando na regularidade dos cursos d'água, funcionando também como filtros naturais e fornecendo água para os hábitats adjacentes e recarga para aquíferos e ainda produzindo alimentos que fazem parte da dieta humana (Pott et al. 2003, Moreira et al. 2011). No entanto, Rosolen et al. 2015, discute as incertezas em relação a área de proteção das Veredas, que seria insuficiente, pelos parâmetros do CONAMA de 2012.

Ambientes de Veredas foram caracterizados quanto à sua evolução (Boaventura 1978), características geomorfológicas (Augustin et al. 2009), características de solo (Ramos et al. 2006), composição florística (Araújo et al. 2002), estrutura da vegetação (Ribeiro \& Walter 2008) e o efeito da ação antrópica nos solos e na comunidade vegetal (Guimarães et al. 2002).

Os estudos desenvolvidos em Veredas procuram avaliar a composição quali-quantitativa de seu estrato herbáceo-arbustivo, sendo que trabalhos dessa natureza foram desenvolvidos para diversas regiões no Brasil Central (Oliveira et al. 2009, Tannus \& Assis 2004, Meirelles et al. 2004, Munhoz 
\& Felfili 2008 e Resende et al. 2013) de modo a compreender os fatores determinantes e a estrutura da comunidade vegetal (Felfili 1998, Giehl \& Budke 2011).

As Veredas estão presentes na região do Jalapão, no estado do Tocantins, onde se encontra a Estação Ecológica Serra Geral do Tocantins, que juntamente com o Parque Estadual do Jalapão e o Parque Nacional das Nascentes do Parnaíba formam a maior área continua de preservação integral do Cerrado (Silva \& Bates 2002, Françoso et al. 2015). Para esta região, bem como para ambientes onde predomina o estrato herbáceo, é possível observar uma considerável riqueza da flora e complexidade abaixo do solo, com raízes, bulbos, rizomas, biomassa, a diversidade funcional, índices de Carbono e a micro-fauna (Fidelis et al. 2013). De maneira geral os solos das Veredas apresentam altos níveis de matéria orgânica, e minerais como magnésio, fosforo, zinco, manganês, ferro e cálcio, o que promove a riqueza encontrada abaixo do solo (Ramos et al. 2014), no entanto são escassos os trabalhos na avaliação da composição e estrutura da vegetação (Naturatins 2003).

Na região do Jalapão, as Veredas são locais onde se encontram as principais espécies de plantas utilizadas pela população local, em diversas atividades, desde pastagem para gado à alimentação humana (Schmidt 2011). Neste contexto, o estudo fitossociologico das Veredas da região vem contribuindo para o conhecimento estrutural destes ambientes, o que pode conduzir a mudanças nas políticas públicas em relação ao perímetro de proteção permanente, hoje praticado.

Neste sentido, o objetivo deste estudo foi contribuir para o conhecimento da composição, diversidade e variação espacial em Veredas da Estação Ecológica Serra Geral do Tocantins, TO, ampliando conhecimento a respeito da estrutura da vegetação de Veredas na região do Jalapão. 


\section{MATERIAL E MÉTODOS}

\section{Área de Estudo}

O estudo foi desenvolvido na Estação Ecológica Serra Geral do Tocantins (EESGTO) situada no Jalapão a aproximadamente $260 \mathrm{~km}$ a sudeste de Palmas, Tocantins, entre as latitudes $10^{\circ} 25^{\prime}$ a $11^{\circ} 21^{\prime}$ S e longitudes $47^{\circ} 13^{\prime}$ a $45^{\circ} 50^{\prime}$ W (Villela \& Nogueira 2011), onde foram amostradas quatro Veredas (Figura 1), sendo a primeira (V_1) próxima ao município de Rio da Conceição, nas margens do rio Balsas $\left(10^{\circ} 57^{\prime} 09,02^{\prime \prime} \mathrm{S}\right.$ e $46^{\circ} 42^{\prime} 57,08^{\prime}$ W). A segunda e a terceira (V_2 e V_3) situam-se a aproximadamente 90 km de Rio da Conceição, nas margem direita (V_2, 10 51' 48, 4' S e 46 36' 55,1 " W) e a e esquerda do rio Novo (V_3, $10^{\circ} 52^{\prime}$ '09, 1" S e 46 $36^{\circ}$ '53, 6" W). A quarta Vereda (V_4) situa-se na região norte da EESGT, próxima ao município de Mateiros, na margem do rio Preto $\left(10^{\circ} 36^{\prime} 54\right.$ ' S e $46^{\circ} 31$ ' $\left.38^{\prime \prime} \mathrm{W}\right)$.

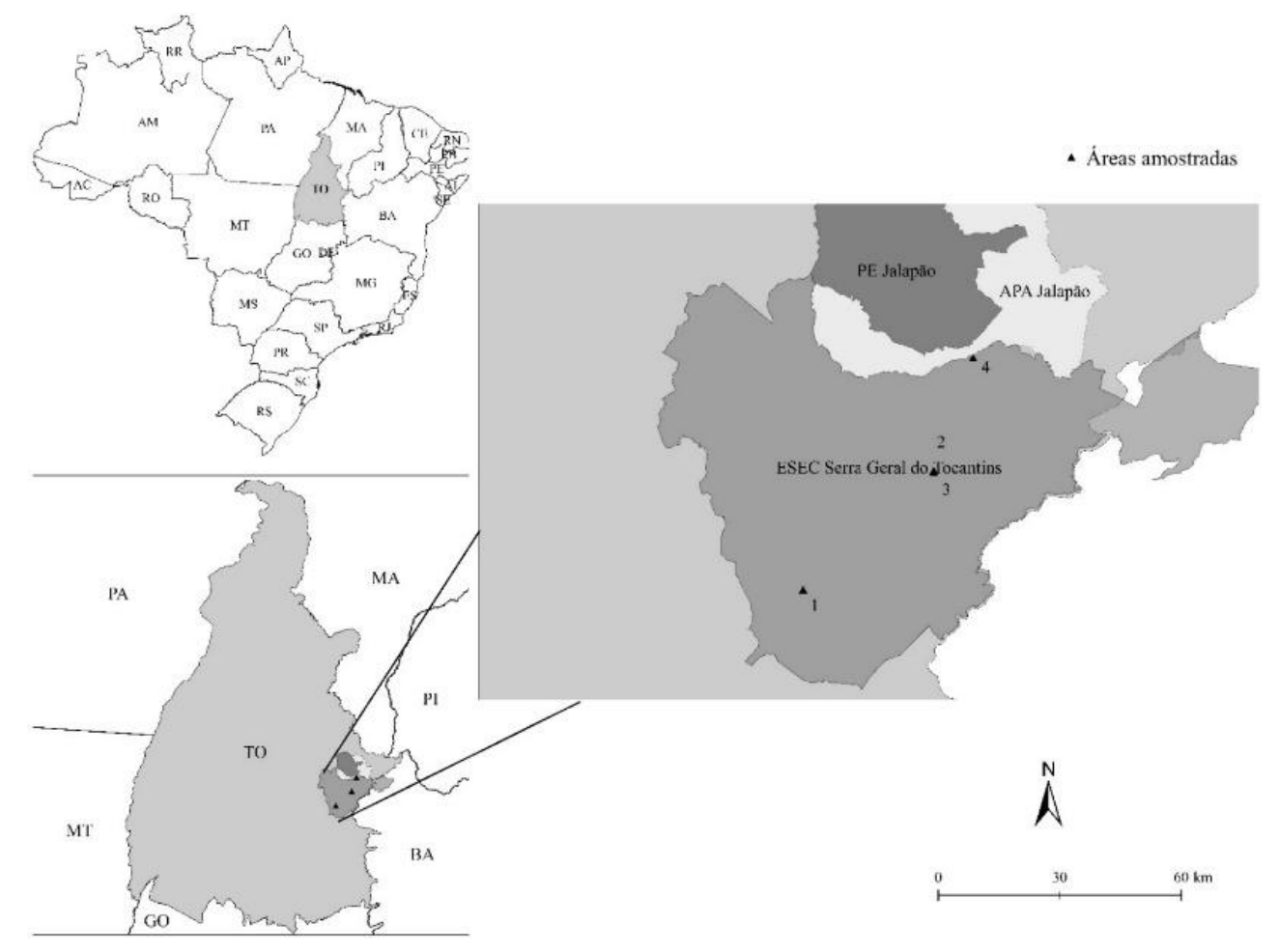

Figura 1. Localização das quatro Veredas estudadas na Estação Ecológica Serra Geral do Tocantins, Brasil. 


\section{Amostragem da Vegetação}

O levantamento da vegetação foi realizado em expedições de coleta no início da estação chuvosa (Novembro-Dezembro/2014) e no fim do período chuvoso (Maio/2015), período em que a maioria das espécies do estrato herbáceo-arbustivo encontram-se em estágio reprodutivo em ambientes úmidos (Munhoz \& Felfili 2005). As estimativas de cobertura das espécies foram feitas pelo método de interseção na linha (Canfield 1941; Meirelles et al. 2002; Munhoz \& Felfili 2008). Foram traçadas de 3 a 4 transecções, paralelas e distantes 100 m entre si, ao longo da extensão perpendicular da linha de buritis nas Veredas. Nas transecções a cada $50 \mathrm{~m}$ foi instalado perpendicularmente uma linha de $10 \mathrm{~m}$, sendo ao todo 15 linhas por Vereda (unidade amostral), totalizando $150 \mathrm{~m}$ lineares. Nas linhas realizamos a visualização da projeção horizontal das espécies, considerando todos os indivíduos com hábito herbáceo, subarbustivo e arbustivo.

Os cálculos de cobertura absoluta e relativa, frequência absoluta e relativa, e ainda o valor de importância (VI), que representa a soma da cobertura e frequência relativa, foram calculados de acordo com Munhoz \& Felfili (2006). Para identificação e nomenclatura botânica das famílias e espécies, seguiu-se a classificação do Angiosperm Phylogeny Group APG IV (Byng et al. 2016).

\section{Coleta e Análise do Solo}

Foram realizadas coletas de solo na porção central de cada linha, as amostras foram coletadas na profundidade de 0-20 cm (EMBRAPA 1997). As análises incluíram as seguintes variáveis: pH; Capacidade de troca Catiônica (CTC), B, S, Ca, Mg, Al, H+Al, K, P, Na, Zn, Cu, Fe e Mn; N total, saturação de bases; saturação de alumínio; matéria orgânica; e teores de argila, silte e areia, as análises químicas e texturais foram realizadas segundo o protocolo da EMBRAPA (1997). 


\section{Análise dos Dados}

\section{Análise de Agrupamentos}

Para avaliar a similaridade florística ao nível de espécie entre as diferentes áreas, serão feitas análises de agrupamento. Em uma primeira análise, foi utilizada uma matriz de espécies (o VI de cada espécie) por área. Em outra análise, foi utilizada uma matriz de VI das famílias (soma do VI de todas as espécies de cada família) por área e como medida de distância o Índice de Sørensen (Bray-Curtis).

\section{Variáveis Ambientais}

Os valores encontrados para as variáveis de solo, foram comparadas entre as áreas amostradas, para verificar a significância das diferenças encontradas. Foi realizado o teste de Kruskal Wallis $(\mathrm{P}<0,05)$, seguido pelo teste Dunn, $\alpha=0,05$ (Zar 1999). As variáveis foram padronizadas pela média e desvio padrão, que permite que comparações entre variáveis desuniformes sejam possíveis (Felfili et al. 2011), em seguida submetidas a uma PCA, buscando sumarizar as variáveis a poucos componentes principais e identificar as principais tendências ambientais do conjunto de dados. As variáveis principais foram as utilizadas nas análises de ordenação.

\section{Análise de Ordenação}

As relações entre as espécies e as variáveis ambientais foram avaliadas através da Análise de Redundância (RDA), técnica de análise direta de gradientes que permite calcular a quantidade de variância em um conjunto de variáveis que é explicada por uma combinação linear (Felfili et al. 2011). Essa abordagem foi empregada para discriminar a proporção da variação total dos dados das espécies que foi explicada pelas variáveis ambientais, bem como a proporção da variação remanescente que não pode ser explicada por este conjunto de dados. Para testar a significância dos autovalores dos eixos da RDA foi empregada como teste de aleatorização e estatística F uma análise de variância (ANOVA). O nível de significância foi testado a $5 \%(\mathrm{p}<0,05)$. 


\section{RESULTADOS}

Foi encontrado um total de 123 espécies, distribuídas em 33 famílias e 69 gêneros para as Veredas da EESGTO (Tabela 1), sendo que $60 \%$ das famílias e $84 \%$ dos gêneros foram representados por apenas uma espécie. As famílias com maior número de espécies foram Poaceae (27), Cyperaceae (24), Eriocaulaceae (14) e Xyridaceae (12) somando 62\% das espécies amostradas. Os gêneros mais frequentes foram Paspalum (Poaceae), Rhynchospora (Cyperaceae) e Xyris (Xyridaceae), contudo o número de espécie nestes gêneros foi variável de uma área para outra.

As espécies que obtiveram valor de cobertura igual ou superior a 10\%, ocorrendo apenas em uma das Veredas foram Agenium villosum (35,2\%), Juncus effusus (34,6\%), Rhynchospora emaciata (44,8\%), Rhynchospora hirta (10,7\%), Syngonanthus fischerianus (10,7\%) e Xyris hymenachne (26,7\%). Apenas três espécies, Paspalum dedeccae (Poaceae), Rhynchospora globosa (Cyperaceae) e Trachypogon spicatus (Poaceae), obtiveram alto valor de cobertura nas quatro Veredas amostradas. Algumas espécies, variam entre as Veredas, com maior porcentagem de cobertura e frequência em duas Veredas, ou três.

A análise de agrupamento (UPGMA) (Figura 2) para avaliar a similaridade florística ao nível de espécies nas quatro Veredas da EESGTO, formou três grupos, sugeridos pelas variáveis ambientais. A umidade do solo nas Veredas da EESGTO, sugere a modificação na composição das espécies nas diferentes áreas. Assim, é possível ressaltar que, as espécies mais abundantes, toleram uma amplitude de variáveis, sem comprometer sua abundância.

Para as quatro Veredas da EESGTO, as análises químicas e texturais do solo evidenciam um solo predominante arenoso, entre 8,5 a $9 \%$, seguido pelos teores de argila e silte que somados variam de 1 a 3\%. As variáveis químicas caracterizam os solos das Veredas estudadas com elevados teores de Ferro. A capacidade de troca catiônica (CTC), a presença de matéria orgânica, aliadas as demais variáveis, caracterizam os solos das Veredas por apresentarem baixa fertilidade. 
O teste de Kruskal Wallis mostra a baixa similaridade florística entre as linhas de amostragem de uma mesma área, que se assemelham a linhas de outras áreas, o que sugere linhas em grupos com composição de espécies similares e diferenciadas entre si. A análise de componentes principais mostrou que as quatro Veredas da EESGTO não sofrem grandes alterações em função das variáveis ambientais (79\%). A afinidade entre as áreas se dá, principalmente, pelos valores das variáveis, magnésio, matéria orgânica, saturação de alumínio, saturação de bases e percentagem de Argila e Silte. Valores de zinco, ferro, cobre, boro, enxofre e fosforo foram os menos redundantes $(1,15 \%)$, portanto retirados das análises de ordenação.

A análise de redundância (RDA) (Figura 3) mostrou que as variáveis ambientais relacionadas a RDA1, foram responsáveis por 37,7\% (anova $0,001 * *$ ) do total da variação, a RDA2 foi responsável por $21,6 \%$, no entanto, os autovalores foram significativos para ambos os eixos $(>0,05)$. Os padrões de solo, são altamente coincidentes com os resultados da RDA. 
Tabela 1. Espécies com maior cobertura absoluta potencial em quatro Veredas (V_1, V_2, V_3 e V_4) na Estação Ecológica Serra Geral do Tocantins, onde $\mathrm{CA}=$ Cobertura Absoluta, $\mathrm{CR}=$ Cobertura Relativa, $\mathrm{FA}=$ Frequência Absoluta e FR= Frequência Relativa. Em negrito os valores de CA, CR, FA e FR acima de $10 \%$.

\begin{tabular}{|c|c|c|c|c|c|c|c|c|c|c|c|c|c|c|c|c|}
\hline \multirow{2}{*}{ Espécie } & \multicolumn{4}{|c|}{ V_1 } & \multicolumn{4}{|c|}{ V_2 } & \multicolumn{4}{|c|}{ V_3 } & \multicolumn{4}{|c|}{ V_4 } \\
\hline & $\mathrm{CA}$ & $\mathrm{CR}$ & FA & FR & $\mathrm{CA}$ & $\mathrm{CR}$ & FA & FR & $\mathrm{CA}$ & $\mathrm{CR}$ & FA & FR & $\mathrm{CA}$ & $\mathrm{CR}$ & FA & FR \\
\hline Abolboda poarchon Seub. & 0.86 & 0.20 & 6.00 & 0.19 & - & - & - & - & 3.12 & 0.95 & 47.33 & 1.57 & - & - & - & - \\
\hline Abolboda pulchella Humb. & - & - & - & - & - & - & - & - & 0.80 & 0.24 & 23.33 & 0.77 & - & - & - & - \\
\hline Aeschynomene paniculata Willd. ex Vogel & - & - & - & - & 0.41 & 0.15 & 18.00 & 0.77 & 0.81 & 0.25 & 18.00 & 0.60 & - & - & - & - \\
\hline Agenium villosum (Nees) Pilg. & - & - & - & - & 35.22 & 13.31 & 198.67 & 8.48 & 1.82 & 0.55 & 11.33 & 0.38 & 3.86 & 0.99 & 26.67 & 0.88 \\
\hline Andropogon bicornis $\mathrm{L}$. & 1.50 & 0.36 & 15.33 & 0.48 & - & - & - & - & - & - & - & - & - & - & - & - \\
\hline Andropogon carinatus Nees & 2.12 & 0.50 & 11.33 & 0.36 & - & - & - & - & - & - & - & - & 0.33 & 0.08 & 2.00 & 0.07 \\
\hline Andropogon lateralis Ness & 0.66 & 0.16 & 3.33 & 0.11 & 10.45 & 3.95 & 62.67 & 2.67 & - & - & - & - & - & - & - & - \\
\hline Andropogon leucostachyus Kunth & - & - & - & - & - & - & - & - & - & - & - & - & 2.64 & 0.67 & 16.67 & 0.55 \\
\hline Andropogon selloanus (Hack.) Hack. & 1.15 & 0.27 & 7.33 & 0.23 & - & - & - & - & - & - & - & - & - & - & - & - \\
\hline Andropogon virgatus Desv. & 24.48 & 5.82 & 108.00 & 3.40 & - & - & - & - & - & - & - & - & 2.46 & 0.63 & 28.00 & 0.93 \\
\hline Aniseia martinicensis (Jacq.) Choisy & - & - & - & - & 0.40 & 0.15 & 12.67 & 0.54 & - & - & - & - & - & - & - & - \\
\hline Ascolepis brasiliensis (Kunth) Benth. ex C.B.Clarke & 0.11 & 0.03 & 0.67 & 0.02 & 3.00 & 1.13 & 37.33 & 1.59 & - & - & - & - & 0.53 & 0.14 & 10.67 & 0.35 \\
\hline Axonopus brasiliensis (Spreng.) Kuhlm. & - & - & 0.00 & - & - & - & - & - & - & - & - & - & 0.34 & 0.09 & 11.33 & 0.38 \\
\hline Axonopus comans (Trin. ex Döll) Kuhlm. & 2.49 & 0.59 & 17.33 & 0.55 & - & - & - & - & 0.19 & 0.06 & 9.33 & 0.31 & 4.06 & 1.04 & 46.67 & 1.55 \\
\hline Axonopus fastigiatus (Nees ex Trin.) Kuhlm. & - & - & - & - & - & - & - & - & 1.47 & 0.45 & 27.33 & 0.91 & - & - & - & - \\
\hline Axonopus pellitus (Nees ex Trin.) Hitchc. \& Chase & - & - & - & - & 7.93 & 3.00 & 38.67 & 1.65 & - & - & - & - & - & - & - & - \\
\hline Axonopus sp.1 & - & - & - & - & 4.51 & 1.70 & 36.67 & 1.56 & - & - & - & - & - & - & - & - \\
\hline Bisboeckelera sp.1 & - & - & - & - & - & - & - & - & 1.11 & 0.34 & 24.00 & 0.79 & - & - & - & - \\
\hline Blechnum serrulatum Rich. & - & - & - & - & - & - & - & - & - & - & - & - & 0.89 & 0.23 & 22.67 & 0.75 \\
\hline Bulbostylis conifera (Kunth) C.B.Clarke & 0.20 & 0.05 & 2.00 & 0.06 & 1.15 & 0.43 & 12.00 & 0.51 & - & - & - & - & - & - & - & - \\
\hline Bulbostylis consanguinea (Kunth) C.B.Clarke & - & - & - & - & - & - & - & - & 3.49 & 1.06 & 39.33 & 1.30 & - & - & - & - \\
\hline Bulbostylis emmerichiae T.Koyama & - & - & - & - & - & - & - & - & 1.04 & 0.32 & 8.00 & 0.26 & 0.14 & 0.04 & 11.33 & 0.38 \\
\hline Bulbostylis junciformis (Kunth) C.B.Clarke & - & - & - & - & - & - & - & - & 3.26 & 0.99 & 33.33 & 1.10 & - & - & - & - \\
\hline Bulbostylis sellowiana (Kunth) Palla & 3.23 & 0.77 & 58.00 & 1.83 & 0.40 & 0.15 & 10.00 & 0.43 & 0.67 & 0.20 & 5.33 & 0.18 & - & - & - & - \\
\hline Byrsonima subterranea Brade \& Markgr. & - & - & - & - & - & - & - & - & - & - & - & - & 1.75 & 0.45 & 10.00 & 0.33 \\
\hline Calyptrocarya glomerulata (Brongn.) Urb. & 0.41 & 0.10 & 10.00 & 0.32 & - & - & - & - & - & - & - & - & - & - & - & - \\
\hline
\end{tabular}




\begin{tabular}{|c|c|c|c|c|c|c|c|c|c|c|c|c|c|c|c|c|}
\hline \multirow{2}{*}{ Espécie } & \multicolumn{4}{|c|}{ V_1 } & \multicolumn{4}{|c|}{ V_2 } & \multicolumn{4}{|c|}{ V_3 } & \multicolumn{4}{|c|}{ V_4 } \\
\hline & $\mathrm{CA}$ & $\mathrm{CR}$ & FA & FR & CA & $\mathrm{CR}$ & FA & FR & CA & $\mathrm{CR}$ & FA & FR & CA & $\mathrm{CR}$ & FA & FR \\
\hline Cassytha filiformis $\mathrm{L}$. & 2.16 & 0.51 & 35.33 & 1.11 & 0.08 & 0.03 & 3.33 & 0.14 & 1.64 & 0.50 & 16.67 & 0.55 & 0.56 & 0.14 & 16.00 & 0.53 \\
\hline Cecropia pachystachya Trécul & - & - & - & - & 0.85 & 0.32 & 12.67 & 0.54 & - & - & - & - & - & - & - & - \\
\hline Chamaecrista desvauxii (Collad.) Killip & 0.23 & 0.05 & 13.33 & 0.42 & 1.14 & 0.43 & 22.67 & 0.97 & - & - & - & - & 1.32 & 0.34 & 38.00 & 1.26 \\
\hline $\begin{array}{l}\text { Comanthera xeranthemoides (Bong.) L.R.Parra \& } \\
\text { Giul. }\end{array}$ & 16.89 & 4.01 & 158.67 & 5.00 & 0.54 & 0.20 & 10.00 & 0.43 & 2.52 & 0.76 & 42.00 & 1.39 & 7.74 & 1.98 & 150.67 & 4.99 \\
\hline Costus spiralis (Jacq.) Roscoe & - & - & - & - & 1.58 & 0.60 & $\mathbf{1 7 . 3 3}$ & 0.74 & 0.66 & 0.20 & 8.67 & 0.29 & 4.02 & 1.03 & 43.33 & 1.44 \\
\hline Cryptangium verticillatum (Spreng.) Vitta & 0.95 & 0.23 & 24.67 & 0.78 & - & - & - & - & 3.01 & 0.91 & 34.00 & 1.13 & - & - & - & - \\
\hline Cuphea antisyphilitica Kunth & 33.07 & 7.86 & 211.33 & 6.66 & 3.72 & 1.41 & 105.33 & 4.50 & 4.55 & 1.38 & 78.00 & 2.58 & 20.20 & 5.16 & 120.67 & 4.00 \\
\hline Curtia tenuifolia (Aubl.) Knobl. & 0.02 & - & 3.33 & 0.11 & - & - & - & - & 0.05 & 0.02 & 4.67 & 0.15 & - & - & - & - \\
\hline Cyperus haspan $\mathrm{L}$. & 1.22 & 0.29 & 6.00 & 0.19 & - & - & - & - & - & - & - & - & - & - & - & - \\
\hline Cyrtopodium fowliei L.C.Menezes & - & - & 0.00 & - & - & - & - & - & 0.18 & 0.05 & 6.67 & 0.22 & - & - & - & - \\
\hline Desmoscelis villosa (Aubl.) Naudin & - & - & - & - & 0.19 & 0.07 & 7.33 & 0.31 & - & - & - & - & 1.16 & 0.30 & 35.33 & 1.17 \\
\hline Drosera comunis A.St.-Hil. & - & - & - & - & - & - & - & - & 4.06 & 1.23 & 102.67 & 3.40 & - & - & - & - \\
\hline Echinolaena inflexa (Poir.) Chase & 2.21 & 0.53 & 46.67 & 1.47 & 0.10 & 0.04 & 2.00 & 0.09 & 0.48 & 0.15 & 5.33 & 0.18 & 0.21 & 0.05 & 6.67 & 0.22 \\
\hline Eriocaulon humboldtii Kunth & - & - & - & - & - & - & - & - & 1.83 & 0.55 & 16.67 & 0.55 & - & - & - & - \\
\hline Exochogyne amazonica C.B.Clarke & - & - & - & - & 0.10 & 0.04 & 9.33 & 0.40 & 1.97 & 0.60 & 32.00 & 1.06 & - & - & - & - \\
\hline Gymnopogon foliosus (Willd.) Nees & - & - & - & - & - & - & - & - & - & - & - & - & 14.81 & 3.78 & 112.00 & 3.71 \\
\hline Habenaria schwackei Barb.Rodr. & - & - & - & - & - & - & - & - & - & - & - & - & 0.30 & 0.08 & 0.67 & 0.02 \\
\hline Hyptis linarioides Pohl ex Benth. & - & - & - & - & 4.95 & 1.87 & 31.33 & 1.34 & - & - & - & - & - & - & - & - \\
\hline Ichnanthus procurrens (Nees ex Trin.) Swallen & - & - & - & - & - & - & - & - & 0.06 & 0.02 & 1.33 & 0.04 & 0.31 & 0.08 & 4.67 & 0.15 \\
\hline Juncus effusus $\mathrm{L}$. & 34.66 & 8.24 & 161.33 & 5.09 & - & - & - & - & - & - & - & - & - & - & - & - \\
\hline Justicia sericographis V.A.W.Graham. & - & - & - & - & 1.08 & 0.41 & 8.00 & 0.34 & - & - & - & - & - & - & - & - \\
\hline Lagenocarpus rigidus Nees & 40.62 & 9.65 & 230.00 & 7.25 & 7.55 & 2.85 & 54.67 & 2.33 & 22.14 & 6.71 & 134.00 & 4.44 & 41.23 & 10.53 & 306.67 & 10.16 \\
\hline Leiothrix flavescens (Bong.) Ruhland & - & - & - & - & 0.22 & 0.08 & 16.00 & 0.68 & 3.85 & 1.17 & 48.00 & 1.59 & - & - & - & - \\
\hline Ludwigia nervosa (Poir.) H.Hara & 2.55 & 0.61 & 17.33 & 0.55 & 0.69 & 0.26 & 10.00 & 0.43 & - & - & - & - & - & - & - & - \\
\hline Lycopodiella alopecuroides (L.) Cranfill & - & - & - & - & - & - & - & - & 0.88 & 0.27 & 10.67 & 0.35 & - & - & - & - \\
\hline
\end{tabular}




\begin{tabular}{|c|c|c|c|c|c|c|c|c|c|c|c|c|c|c|c|c|}
\hline \multirow{2}{*}{ Espécie } & \multicolumn{4}{|c|}{ V_1 } & \multicolumn{4}{|c|}{ V_2 } & \multicolumn{4}{|c|}{ V_3 } & \multicolumn{4}{|c|}{ V_4 } \\
\hline & $\mathrm{CA}$ & $\mathrm{CR}$ & FA & FR & $\mathrm{CA}$ & $\mathrm{CR}$ & FA & FR & $\mathrm{CA}$ & $\mathrm{CR}$ & FA & FR & $\mathrm{CA}$ & $\mathrm{CR}$ & FA & FR \\
\hline Mauritia flexuosa L.f. & 2.62 & 0.62 & 14.67 & 0.46 & 6.91 & 2.61 & 14.67 & 0.63 & - & - & - & - & 0.83 & 0.21 & 12.67 & 0.42 \\
\hline Mauritiella armata (Mart.) Burret & - & - & - & - & 0.78 & 0.29 & 14.00 & 0.60 & - & - & - & - & 3.13 & 0.80 & 22.67 & 0.75 \\
\hline Mesosetum penicillatum $\mathrm{Mez}$ & 6.32 & 1.50 & 44.67 & 1.41 & - & - & - & - & - & - & - & - & - & - & - & - \\
\hline Miconia chamissois Naudin & 0.17 & 0.04 & 2.00 & 0.06 & - & - & - & - & - & - & - & - & 1.06 & 0.27 & 2.00 & 0.07 \\
\hline Microlicia viminalis (DC.) Triana & - & - & - & - & - & - & - & - & 1.35 & 0.41 & 24.67 & 0.82 & 2.37 & 0.61 & 32.67 & 1.08 \\
\hline Microstachys bidentata (Mart.\& Zucc.) Esser & - & - & - & - & 1.46 & 0.55 & 6.67 & 0.28 & - & - & - & - & - & - & - & - \\
\hline Mikania officinalis Mart. & - & - & - & - & 0.02 & 0.01 & 5.33 & 0.23 & - & - & - & - & - & - & - & - \\
\hline Nephradenia acerosa Decne. & 0.76 & 0.18 & 1.33 & 0.04 & - & - & - & - & - & - & - & - & - & - & - & - \\
\hline Paepalanthus chiquitensis Herzog & - & - & - & - & - & - & - & - & 0.49 & 0.15 & 20.67 & 0.68 & - & - & - & - \\
\hline Paepalanthus elongatulus Ruhland & 6.17 & 1.47 & 54.67 & 1.72 & - & - & - & - & - & - & - & - & - & - & - & - \\
\hline Paepalanthus polytrichoides Kunth & - & - & - & - & 2.12 & 0.80 & 25.33 & 1.08 & - & - & - & - & - & - & - & - \\
\hline Palhinhaea cernua (L.) Franco \& Vasc. & - & - & - & - & - & - & - & - & 2.83 & 0.86 & 24.67 & 0.82 & - & - & - & - \\
\hline Panicum campestre Nees ex Trin. & - & - & - & - & - & - & - & - & 18.92 & 5.74 & 75.33 & 2.49 & 0.10 & 0.03 & 2.00 & 0.07 \\
\hline Paspalum approximatum Döll & - & - & - & - & 0.04 & 0.02 & 0.67 & 0.03 & - & 0.00 & - & - & - & - & - & - \\
\hline Paspalum dedeccae Quarín & 17.98 & 4.27 & 122.00 & 3.85 & 30.44 & 11.50 & 191.33 & 8.17 & 74.12 & 22.47 & 418.00 & 13.84 & 39.41 & 10.06 & 239.33 & 7.93 \\
\hline Paspalum hyalinum Ness ex Trin. & - & - & - & - & 9.88 & 3.73 & 56.67 & 2.42 & - & - & - & - & - & - & - & - \\
\hline Paspalum lanciflorum Nees ex Steud. & - & - & - & - & 0.30 & 0.11 & 10.00 & 0.43 & - & - & - & - & - & - & - & - \\
\hline Paspalum lineare Trin. & 1.07 & 0.25 & 4.00 & 0.13 & 27.30 & 10.31 & 132.67 & 5.66 & 8.19 & 2.48 & 40.67 & 1.35 & 29.88 & 7.63 & 243.33 & 8.06 \\
\hline Paspalum maculosum Trin. & - & - & - & - & 1.65 & 0.62 & 10.67 & 0.46 & - & - & - & - & 0.69 & 0.18 & 3.33 & 0.11 \\
\hline Paspalum polyphyllum Ness & - & - & - & - & - & - & - & - & - & - & - & - & 0.96 & 0.25 & 18.00 & 0.60 \\
\hline Perama hirsuta Aubl. & - & - & - & - & 0.15 & 0.06 & 10.00 & 0.43 & - & - & - & - & 0.03 & 0.01 & 3.33 & 0.11 \\
\hline Pfaffia jubata Mart. & 0.02 & - & 6.00 & 0.19 & - & - & - & - & - & - & - & - & - & - & - & - \\
\hline Philodendron dardanianum Mayo & 0.10 & 0.02 & 6.00 & 0.19 & - & - & - & - & - & - & - & - & - & - & - & - \\
\hline Phyllanthus niruri $\mathrm{L}$. & 0.96 & 0.23 & 25.33 & 0.80 & 0.27 & 0.10 & 4.67 & 0.20 & - & - & - & - & 0.97 & 0.25 & 24.00 & 0.79 \\
\hline Piper fuligineum Kunth & - & - & - & - & 0.20 & 0.08 & 6.00 & 0.26 & - & - & - & - & - & - & - & - \\
\hline Polygala adenophora DC. & - & - & - & - & 0.46 & 0.17 & 0.67 & 0.03 & 0.01 & - & 2.67 & 0.09 & - & - & - & - \\
\hline Polygala celosioides A.W. Benn. & - & - & - & - & 1.11 & 0.42 & 4.00 & 0.17 & 0.14 & 0.04 & 8.00 & 0.26 & 0.04 & 0.01 & 0.67 & 0.02 \\
\hline
\end{tabular}




\begin{tabular}{|c|c|c|c|c|c|c|c|c|c|c|c|c|c|c|c|c|}
\hline \multirow{2}{*}{ Espécie } & \multicolumn{4}{|c|}{ V_1 } & \multicolumn{4}{|c|}{ V_2 } & \multicolumn{4}{|c|}{ V_3 } & \multicolumn{4}{|c|}{ V_4 } \\
\hline & $\mathrm{CA}$ & $\mathrm{CR}$ & FA & FR & $\mathrm{CA}$ & $\mathrm{CR}$ & FA & FR & $\mathrm{CA}$ & $\mathrm{CR}$ & FA & FR & $\mathrm{CA}$ & $\mathrm{CR}$ & FA & FR \\
\hline Polygala gracilis Kunth & - & - & - & - & 0.14 & 0.05 & 2.67 & 0.11 & 0.08 & 0.02 & 0.67 & 0.02 & - & - & - & - \\
\hline Polygala longicaulis Kunth & - & - & - & - & 0.26 & 0.10 & 2.67 & 0.11 & 0.05 & 0.02 & 0.67 & 0.02 & - & - & - & - \\
\hline Pterolepis repanda (DC.) Triana & - & - & - & - & 0.02 & 0.01 & 4.67 & 0.20 & - & - & - & - & - & - & - & - \\
\hline Rhynchospora ferruginea Roem. \& Schult. & 0.74 & 0.18 & 22.00 & 0.69 & 3.64 & 1.38 & 66.67 & 2.85 & 0.56 & 0.17 & 11.33 & 0.38 & 1.56 & 0.40 & 40.67 & 1.35 \\
\hline Rhynchospora asperula (Nees) Steud. & 4.21 & 1.00 & 72.67 & 2.29 & - & - & - & - & 2.09 & 0.63 & 38.00 & 1.26 & - & - & - & - \\
\hline Rhynchospora barbata (Vahl) Kunth & - & - & - & - & 5.58 & 2.11 & 63.33 & 2.70 & - & - & - & - & - & - & - & - \\
\hline Rhynchospora brasiliensis Boeckeler & - & - & - & - & - & - & - & - & 0.32 & 0.10 & 13.33 & 0.44 & - & - & - & - \\
\hline Rhynchospora brevirostris Griseb. & 0.45 & 0.11 & 4.67 & 0.15 & - & - & - & - & - & - & - & - & - & - & - & - \\
\hline Rhynchospora consanguinea (Kunth) Boeckeler & 5.52 & 1.31 & 51.33 & 1.62 & 2.22 & 0.84 & 22.00 & 0.94 & 4.67 & 1.42 & 72.67 & 2.41 & 4.69 & 1.20 & 74.00 & 2.45 \\
\hline Rhynchospora elatior Kunth & - & - & - & - & - & - & - & - & 3.15 & 0.96 & 40.67 & 1.35 & - & - & - & - \\
\hline Rhynchospora emaciata (Nees) Boeckeler & 44.84 & 10.66 & 298.00 & 9.39 & - & - & - & - & 1.93 & 0.59 & 22.67 & 0.75 & 7.82 & 2.00 & 68.00 & 2.25 \\
\hline Rhynchospora globosa (Kunth) Roem. \& Schult. & 51.12 & 12.15 & 335.33 & 10.57 & 46.54 & $\mathbf{1 7 . 5 8}$ & 411.33 & $\mathbf{1 7 . 5 6}$ & 68.99 & 20.92 & 511.33 & 16.93 & 75.46 & 19.26 & 479.33 & 15.88 \\
\hline Rhynchospora hirta (Nees) Boeckeler & 10.79 & 2.56 & 110.67 & 3.49 & 2.83 & 1.07 & 36.67 & 1.56 & 0.54 & 0.16 & 14.67 & 0.49 & 0.70 & 0.18 & 17.33 & 0.57 \\
\hline Rhynchospora marisculus Lindl. \& Nees & - & - & - & - & 0.25 & 0.09 & 12.67 & 0.54 & - & - & - & - & 0.51 & 0.13 & 12.67 & 0.42 \\
\hline Rhynchospora sp.3 & - & - & - & - & - & - & - & - & - & - & - & - & 0.80 & 0.20 & 7.33 & 0.24 \\
\hline Sauvagesia linearifolia A.St.-Hil. & - & - & - & - & 0.34 & 0.13 & 16.67 & 0.71 & - & - & - & - & - & - & - & - \\
\hline Schultesia heterophylla Miq. & 0.46 & 0.11 & 3.33 & 0.11 & - & - & - & - & - & - & - & - & - & - & - & - \\
\hline Scleria hirtella Sw. & - & - & - & - & 0.55 & 0.21 & 0.67 & 0.03 & - & - & - & - & 0.02 & 0.01 & 4.00 & 0.13 \\
\hline Sisyrinchium vaginatum Spreng. & - & - & - & - & 0.06 & 0.02 & 7.33 & 0.31 & 0.02 & 0.01 & 2.00 & 0.07 & - & - & - & - \\
\hline Stylosanthes sp.1 & - & - & - & - & 0.92 & 0.35 & 26.00 & 1.11 & 1.25 & 0.38 & 20.00 & 0.66 & - & - & - & - \\
\hline Stylosanthes sp.2 & - & - & - & - & 0.01 & - & 2.67 & 0.11 & - & - & - & - & - & - & - & - \\
\hline Syngonanthus anthemiflorus (Bong.) Ruhland & 0.51 & 0.12 & 2.00 & 0.06 & - & - & - & - & - & - & - & - & - & - & - & - \\
\hline Syngonanthus bisumbellatus (Steud.) Ruhland & - & - & - & - & 1.38 & 0.52 & 28.67 & 1.22 & - & - & - & - & - & - & - & - \\
\hline Syngonanthus densiflorus (Körn.) Ruhland & 0.27 & 0.06 & 0.67 & 0.02 & - & - & - & - & - & - & - & - & - & - & - & - \\
\hline Syngonanthus fischerianus (Bong.) Ruhland & 10.71 & 2.54 & 100.00 & 3.15 & 0.14 & 0.05 & 12.67 & 0.54 & - & - & - & - & - & - & - & - \\
\hline Syngonanthus gracilis (Bong.) Ruhland & - & - & - & - & 0.70 & 0.26 & 14.00 & 0.60 & 0.38 & 0.12 & 11.33 & 0.38 & - & - & - & - \\
\hline Syngonanthus humboldtii (Kunth) Ruhland & - & - & - & - & - & - & - & - & - & - & - & - & 0.97 & 0.25 & 22.00 & 0.73 \\
\hline Syngonanthus nitens Ruhland & 7.75 & 1.84 & 157.33 & 4.96 & 2.41 & 0.91 & 48.00 & 2.05 & 15.36 & 4.66 & 292.00 & 9.67 & 1.58 & 0.40 & 74.00 & 2.45 \\
\hline
\end{tabular}




\begin{tabular}{|c|c|c|c|c|c|c|c|c|c|c|c|c|c|c|c|c|}
\hline \multirow{2}{*}{ Espécie } & \multicolumn{4}{|c|}{ V_1 } & \multicolumn{4}{|c|}{ V_2 } & \multicolumn{4}{|c|}{$\mathrm{V} \_3$} & \multicolumn{4}{|c|}{ V_4 } \\
\hline & CA & $\mathrm{CR}$ & FA & FR & CA & $\mathrm{CR}$ & FA & FR & CA & $\mathrm{CR}$ & FA & FR & $\mathrm{CA}$ & $\mathrm{CR}$ & FA & FR \\
\hline Syngonanthus verticillatus (Bong.) Ruhland & - & - & - & - & - & - & - & - & 1.25 & 0.38 & 12.00 & 0.40 & - & - & - & - \\
\hline Syngonanthus widgrenianus (Körn.) Ruhland & 1.00 & 0.24 & 12.00 & 0.38 & - & - & - & - & - & - & - & - & - & - & - & - \\
\hline Tococa nitens (Benth.) Triana & - & - & - & - & 0.80 & 0.30 & 6.00 & 0.26 & 0.97 & 0.29 & 10.00 & 0.33 & 0.42 & 0.11 & 7.33 & 0.24 \\
\hline Trachypogon spicatus (L.f.) Kuntze & 46.38 & 11.02 & 248.67 & 7.84 & 18.18 & 6.87 & 191.33 & 8.17 & 39.93 & 12.11 & 234.00 & 7.75 & 78.81 & 20.12 & 340.67 & 11.28 \\
\hline $\begin{array}{l}\text { Trichanthecium cyanescens (Nees ex Trin.) Zuloaga } \\
\& \text { Morrone }\end{array}$ & 4.12 & 0.98 & 35.33 & 1.11 & 0.78 & 0.29 & 3.33 & 0.14 & 0.20 & 0.06 & 1.33 & 0.04 & - & - & - & - \\
\hline Trimezia juncifolia (Klatt) Benth. \& Hook. & - & - & - & - & 0.27 & 0.10 & 16.00 & 0.68 & 0.24 & 0.07 & 6.00 & 0.20 & 0.30 & 0.08 & 10.00 & 0.33 \\
\hline Urospatha sagittifolia (Rudge) Schott & - & - & - & - & 2.60 & 0.98 & 39.33 & 1.68 & - & - & - & - & - & - & - & - \\
\hline Xyris dawsonii L.B.Sm. \& Downs & 0.74 & 0.18 & 27.33 & 0.86 & - & - & - & - & - & - & - & - & - & - & - & - \\
\hline Xyris blanchetiana Malme & - & - & - & - & - & - & - & - & 0.09 & 0.03 & 0.67 & 0.02 & - & - & - & - \\
\hline Xyris fallax Malme & - & - & - & - & - & - & - & - & 0.98 & 0.30 & 36.67 & 1.21 & - & - & - & - \\
\hline Xyris hymenachne Mart. & 6.52 & 1.55 & 77.33 & 2.44 & 0.63 & 0.24 & 27.33 & 1.17 & 1.46 & 0.44 & 16.67 & 0.55 & 26.74 & 6.83 & 168.00 & 5.56 \\
\hline Xyris macrocephala Vahl & 2.34 & 0.56 & 17.33 & 0.55 & - & - & - & - & 0.18 & 0.05 & 2.67 & 0.09 & - & - & - & - \\
\hline Xyris paraensis Poepp. ex Kunth & - & - & - & - & 3.23 & 1.22 & 32.67 & 1.39 & 0.05 & 0.02 & 1.33 & 0.04 & - & - & - & - \\
\hline Xyris pterygoblephara Steud. & - & - & - & - & - & - & - & - & - & - & - & - & 1.62 & 0.41 & 29.33 & 0.97 \\
\hline Xyris savanensis Miq. & - & - & - & - & - & - & - & - & 6.35 & 1.93 & 123.33 & 4.08 & - & - & - & - \\
\hline Xyris seubertii L.A.Nilsson & 7.18 & 1.71 & 79.33 & 2.50 & - & - & - & - & 2.98 & 0.90 & $\mathbf{5 3 . 3 3}$ & 1.77 & - & - & - & - \\
\hline Xyris tortula Mart. & 3.78 & 0.90 & $\mathbf{5 9 . 3 3}$ & 1.87 & 0.86 & 0.32 & 18.00 & 0.77 & 4.04 & 1.22 & 68.67 & 2.27 & 1.37 & 0.35 & 40.00 & 1.32 \\
\hline Total Geral & 420.83 & 100 & 3172.67 & 100 & 264.69 & 100 & 2343.33 & 100 & 329.82 & 100 & 3020.67 & 100 & 391.70 & 100 & 3019.33 & 100 \\
\hline
\end{tabular}




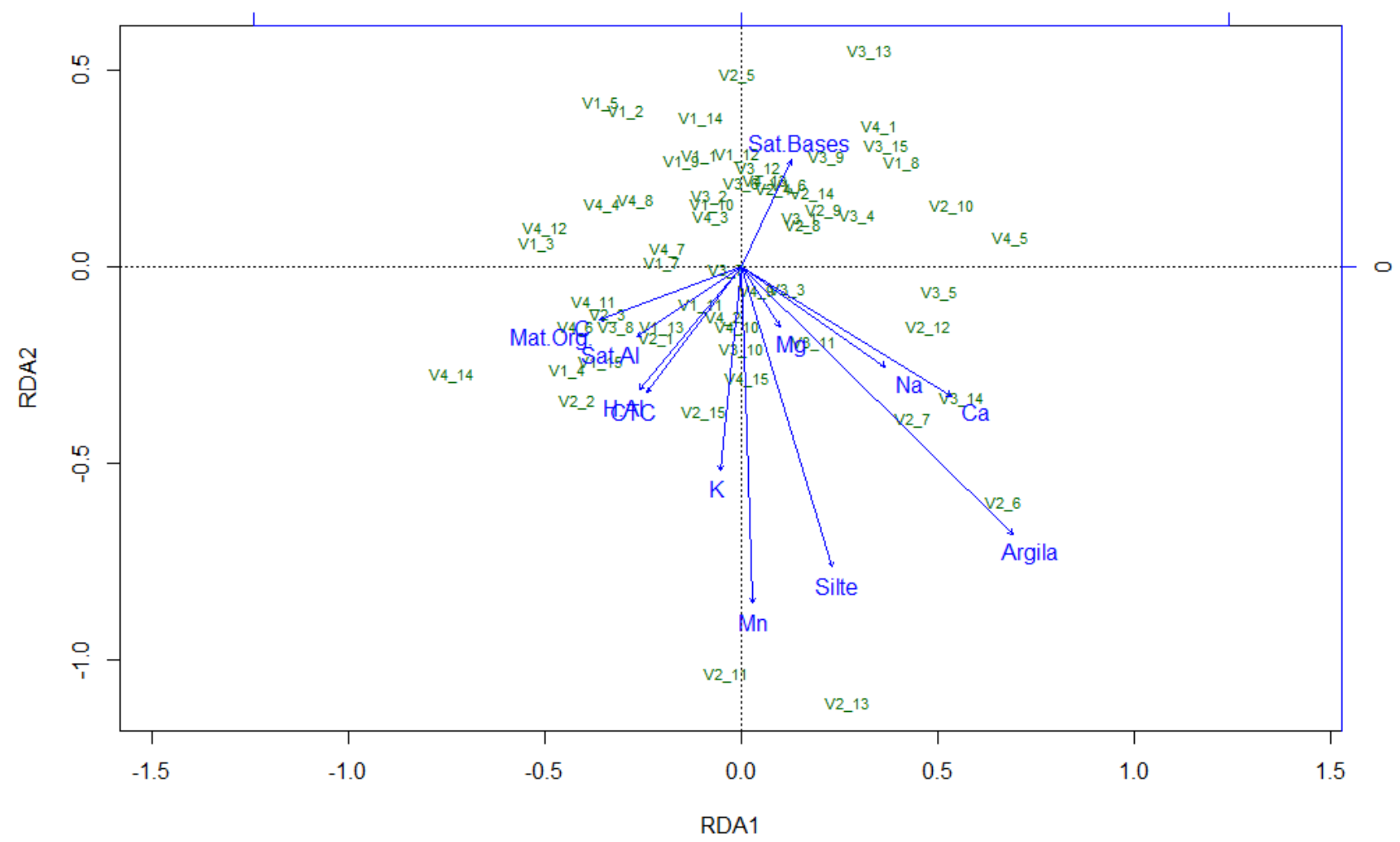

Figura 3. Análise de redundância (RDA) para as 60 linhas e variáveis ambientais nas Veredas da Estação Ecológica Serra Geral do Tocantins. 


\section{DISCUSSÃO}

As Veredas da EESGTO apresentam elevada riqueza florística, semelhante à encontrada em outros estudos de estrutura fitossociológica do componente herbáceo-subarbustivo (Guimarães et al. 2002, Oliveira et al. 2009). A família Poaceae com as espécies Paspalum dedeccae e Trachypogon spicatus, as Cyperaceae, Lagenocarpus rigidus, Rhynchospora globosa e a Eriocaulaceae Syngonanthys nitens, apresentam a maior frequência relativa nas Veredas da EESGTO, as Poaceae e Cyperaceae citadas, são também encontradas para outras localidades com valor elevado de frequência relativa (Araújo et al. 2002, Resende et al. 2013). O Syngonanthus nitens, espécie conhecida na região do Jalapão por sua importância econômica (Schmidt 2007), a pesar do tamanho médio de sua roseta de $1,5 \mathrm{~cm}$ de diâmetro, se torna bastante representativo quantitativamente.

A análise de agrupamento (UPGMA) formou três grupos, especulados a partir das linhas estabelecidas nas Veredas, com base nas variáveis ambientais. Houve o agrupamento de linhas em solo com maior umidade, e solos mais bem drenados, na Vereda um, que mostrou a maior quantidade de linhas em solo úmido, em função da matéria orgânica ali presente. As linhas dessa área mostraram similaridade com as linhas da Vereda quatro, no primeiro grupo. No segundo grupo, houve predominância das linhas da Vereda três, cuja quantidade de matéria orgânica é inferior as demais Veredas, o que reflete um solo mais bem drenado, onde as linhas das Veredas um e quatro de solo mais seco, tornam-se mais semelhantes as linhas da Vereda três. No terceiro grupo, linhas das Veredas dois e um foram predominantes, mesclando linhas de solo majoritariamente úmido.

Logo, a diferença na composição entre as Veredas está diretamente ligada a disponibilidade da umidade na área. As assembléias de uma Vereda, estão relacionadas com as de outra, mesmo que não seja relacionada com a vegetação de sua área de ocorrência. Não houve diferença relevante na quantidade de espécies nas diferentes Veredas analisadas. As Veredas mostram uma homogeneidade florística entre si. 
Nas linhas em solo mais seco, ocorreram espécies, como Echinolaena inflexa, conhecida como indicadora de ambientes inundáveis, assim como, Andropogonn virgatus, que mostrou altos valores de cobertura para Vereda um e quatro, o que indica Veredas de solo mais úmido, em relação as Veredas dois e três, em solo relativamente mais bem drenado.

Os padrões de solos encontrados nas Veredas da EESGTO, foram semelhantes aos padrões já encontrados em outras áreas de Vereda do Triangulo Mineiro, como baixos valores de $\mathrm{pH}$ e altos teores de cálcio, magnésio, manganês, ferro e matéria orgânica (Ramos et al. 2006). A diferença no teor de alguns elementos entre as quatro Veredas no Jalapão, como a saturação de bases, Carbono e a capacidade de troca iônica, não foram suficientes para evidenciar uma heterogeneidade edáfica entre as Veredas. As Veredas um e quatro, apresentam os maiores teores de matéria orgânica, ferro e alumínio, respectivamente, são aquelas onde foram registrados os maiores potenciais de riqueza em espécies.

As áreas mais secas e as áreas mais úmidas, evidenciam modificações na composição das espécies e na estrutura da vegetação. A ocorrência de espécies da família Fabaceae, pouco frequente para campos úmidos, pode revelar o futuro empobrecimento na fertilidade das Veredas da EESGTO, principalmente, devido aos teores elevados de fósforo (Amorin \& Batalha 2007). A matéria orgânica, está diretamente relacionada com a umidade no solo determinante e pode determinar a estrutura da vegetação, uma vez que, a umidade pode interferir nos processos de decomposição, aumentando a quantidade de matéria orgânica no solo, favorecendo determinadas espécies nos ambientes de maior umidade (Gopal \& Masing 1990, Crawley 1997).

A análise de componentes principais, proporcionou a retirada de elementos como boro e ferro, por serem menos redundantes. Assim, a análise de redundância entre as espécies das quatro Veredas, mostrou associação entre a vegetação e as variáveis ambientais, onde houve a evidencia da uniformidade na distribuição das espécies ao longo das linhas nas Veredas. Os teores de saturação de base, se relacionaram principalmente com a Vereda dois, e fracamente com as Veredas três e quatro. 
Os níveis de matéria orgânica, saturação de alumínio, capacidade de troca iônica e carbono, explicam o maior número de ocorrência das espécies na Vereda um e grande parte das linhas da Vereda quatro. Houve um grupo formado pelas linhas 2, 3, 5, 7, 9 e 14 da Vereda um, linhas 3, 4, 7, 8 e 12 da Vereda quatro, onde não há associação com os elementos contidos nas análises. Dessa forma, a pouca variação nas propriedades químicas do solo, mostra a baixa fertilidade do solo em

A presença de unidades de conservação como a Estação Ecológica Serra Geral do Tocantins e o Parque Estadual do Jalapão, reforçam as estratégias de conservação da diversidade biológica, do ponto de vista da estrutura e relações com as variáveis ambientais.

\section{AGRADECIMENTOS}

Agradecemos ao PNUD pelo apoio financeiro. ICMBio pelo apoio e auxílio no trabalho de campo. A CAPES pela bolsa de mestrado concedida para o primeiro autor. Aos especialistas das diversas famílias que contribuíram na identificação do material botânico. À Aryanne Amaral e Natália Bijos pela contribuição nos trabalhos de campo. 


\section{REFERÊNCIAS BIBLIOGRÁFICAS}

Amorim, P. K., \& Batalha, M. A. 2007. Soil-vegetation relationships in hyperseasonal cerrado, seasonal cerrado, and wet grassland in Emas National Park (central Brazil). Acta ecologica, 32(3): 319-327.

Araújo, G.M., Barbosa, A.A.A., Arantes, A.A., Amaral, A.F. 2002. Composição florística de Veredas no município de Uberlândia, MG. Revista Brasileira de Botânica 25(4): 475-493.

Augustin, C. H., de Melo, D. R., Aranha, P. R. A. 2009. Aspectos geomorfológicos de Veredas: um ecossistema do bioma do Cerrado, Brasil. Revista Brasileira de Geomorfologia 10:1.

Boaventura, R.S. 1978. Contribuição aos estudos sobre evolução das Veredas. In Encontro Nacional de Geógrafos, 3. Fortaleza: AGB/UFC.

Byng, J. W. et al. 2016. An update of the Angiosperm Phylogeny Group classification for the orders and families of flowering plants: APG IV. BOTANICAL JOURNAL OF THE LINNEAN SOCIETY, 181: 1-20.

Canfield, R. 1941. Application of line interception in sampling range vegetation. Journal of Forestry 39: 388-394.

CONAMA 2012. Lei no. 12.651, de 25 de maio de 2012. Conselho Nacional do Meio Ambiente, Brasília, Brazil [www document]. URL http://www.planalto.gov.br/ccivil_03/_ato2011$\underline{2014 / 2012 / \text { lei/112651.htm }}$

Crawley, M.J. The structure of plant communities. 1997. Plant ecology. 2ed. Blackwell, Oxford. 
EMPRESA BRASILEIRA DE PESQUISA AGROPECUÁRIA - EMBRAPA. 1997. Serviço Nacional de Levantamento e Conservação do Solo. Manual de análises de solo. 2.ed. Rio de Janeiro, p. 212.

Felfili, J.M. 1998. Determinação de padrões de distribuição de espécies em uma mata de galeria no Brasil Central com a utilização de técnicas de análise multivariada. Boletim do Herbário Ezechias Paulo Heringer 2: 35-48.

Felfili, J.M., Carvalho, F.A., Libano, A.M., Venturoli, F., Pereira, B.A.S., Machado, E.L.M. 2011. Análise multivariada: princípios e métodos em estudos de vegetação. In Fitossociologia no Brasil: métodos e estudos de casos (J.M. Felfili, P.V. Eisenlohr, M.M.R.F. Melo, L.A. Andrade \& J.A.A.M. Neto, eds.) Editora UFV, Viçosa, p. 211-230.

Fidelis, A., Lyra, M. F. D. S., Pivello, V. R. 2013. Above-and below-ground biomass and carbon dynamics in Brazilian Cerrado wet grasslands. Journal of Vegetation Science, 24: 356-364.

Françoso, R. D., Brandão, R., Nogueira, C. C., Salmona, Y. B., Machado, R. B., Colli, G. R. 2015. Habitat loss and the effectiveness of protected areas in the Cerrado Biodiversity Hotspot. Natureza \& Conservação 13: 35-40.

Giehl, E.L.H., Budke, J.C., Oliveira-Filho, A.T., Jarenkow, J.A. 2011. Variações florísticas e relação com variáveis geográficas e climáticas em florestas ribeirinhas do sudeste da América do Sul. In Fitossociologia no Brasil: métodos e estudos de casos (J.M. Felfili, P.V. Eisenlohr, M.M.R.F. Melo, L.A. Andrade \& J.A.A.M. Neto, eds.) Fitossociologia no Brasil: métodos e estudos de caso. Viçosa: Editora UFV, 1: 504-519.

Gopal, B. \& Masing, V. 1990. Biology and ecology. In: Patten, B.C. Wetlands and Shallow Continental Water Bodies. SPB Academic Publishing, The Hague. p. 91-239. 
Guimarães, A.J.M., Araújo, G.M., Corrêa, G.F. 2002. Estrutura fitossociológica em área natural e antropizada de uma Vereda em Uberlândia, MG. Acta Botanica Brasilica 16: 317-329.

Klink, C.A., Machado, R.B. 2005. Conservation of the Brazilian Cerrado. Conservation biology, 19: 707-713.

Meirelles, M.L.; Oliveira, R.C.; Ribeiro, J.F.; Vivaldi, L.J.; Rodrigues, L.A., Silva, G.P. 2002. Utilização do método de interseção na linha em levantamento quantitativo do estrato herbáceo do cerrado. Boletim do Herbário Ezechias Paulo Heringer 9: 60-68.

Meirelles, M.L.; Guimarães, A.J.M.; Oliveira, C.O.; Araújo, G.M., Walter, J.F. 2004. Impactos sobre o estrato herbáceo de áreas úmidas do cerrado. In: Aguiar, L.M.S. \& Camargo, A.J.A. (eds.). Cerrado: ecologia e caracterização. Embrapa Cerrados, Brasília. p. 41-68.

Moreira, S. N., Pott, A., Pott, V. J., Damasceno-Junior, G. A. 2011. Structure of pond vegetation of a Vereda in the Brazilian Cerrado / Estrutura da vegetação de lagoa associada à Vereda no Cerrado brasileiro. Rodriguésia 64: 721-729.

Munhoz, C. B. R., Felfili, J. M. 2005. Fenologia do estrato herbáceo-subarbustivo de uma comunidade decampo sujo na fazenda água limpa no Distrito Federal, Brasil. Acta Botânica Brasilica 19: 981-990.

Munhoz, C. B. R., Felfili, J. M. 2006. Fitossociologia do estrato herbáceo-subarbustivo de uma área de campo sujo no Distrito Federal, Brasil. Acta Botânica Brasilica 20: 671-685.

Munhoz, C.B.R., Felfili, J.M. 2008. Fitossociologia do estrato herbáceo subarbustivo em campo limpo úmido no Distrito Federal, Brasil. Acta Botanica Brasilica, 22: 905-913.

Naturatins 2003. Instituto Natureza do Tocantins. Seplan - Secretária do Planejamento e Meio Ambiente. Governo de Tocantins. Palmas. 
Oliveira, G.C.; Araújo, G.M., Barbosa, A.A.A. 2009. Florística e zonação de espécies vegetais em Veredas no Triângulo Mineiro, Brasil. Rodriguesia 60: 1077-1085.

Pott, V.J., Pott, A. 2003. Dinâmica da vegetação aquática do Pantanal. In: Thomaz, S. M. \& Bini, L.M. (eds.). Ecologia e manejo de macrófitas aquáticas. EDUEM, Maringá. p. 145-162.

R Development Core Team. 2015. R: a language and environment for statistical computing. R Foundation for Statistical Computing, Vienna. Available in <http:// www.R-project.org $>$ Access on 7 Março 2016.

Ramos, M.V.V.; Cury, N.; Mota, P.E.F.; Vitorino, A.C.T.; Ferreira, M.N., Silva, M.L.N. 2006. Veredas do Triângulo Mineiro: Solos, água e uso. Ciência Agrotécnica 30: 283-293.

Ramos, M. V. V., Haridasan, M., de Araújo, G. M. 2014. Caracterização dos Solos e da Estrutura Fitossociológica da Vegetação de Veredas da Chapada no Triângulo Mineiro. FronteirasJournal of Social, Technological and Environmental Science, 3: 180-a.

Ribeiro, J.F., Walter, B.M.T. 2008. As Principais Fitofisionomias do Bioma Cerrado. In Cerrado: Ecologia e Flora (S.M. Sano \& S.P. de Almeida, eds.). EMBRAPA, p. 153-212.

Resende, I. L. D. M., Chaves, L. J., Rizzo, J. Â. 2013. Floristic and phytosociological analysis of palm swamps in the central part of the Brazilian savanna. Acta Botanica Brasilica, 27: 205-225.

Ribeiro, J.F., Walter, B.M.T. 2008. As Principais Fitofisionomias do Bioma Cerrado. In Cerrado: Ecologia e Flora (S.M. Sano \& S.P. de Almeida, eds.). EMBRAPA, Planaltina, p. 153-212.

Rosolen, V., de Oliveira, D. A., \& Bueno, G. T. 2015. Vereda and Murundu wetlands and changes in Brazilian environmental laws: challenges to conservation. Wetlands Ecology and Management, 23: 285-292. 
Schmidt, I.B.; Figueiredo, I.B., Scariot, A. 2007. Ethnobotany and effects of harvesting on the population ecology of Syngonanthus nitens (Bong.) Ruhland (Eriocaulaceae), a NTFP from Jalapão region, Central Brazil. Economic Botany 61: 73-85.

Schmidt, I.B. 2011. Effects of local ecological knowledge, harvest and fire on Golden-grass (Syngonanthusnitens, Eriocaulaceae), a non-timber forest product (NTFP) species from Brazilian savanna.Tese (Doutorado em Botânica, Ecologia, Evolução e Biologia da Conservação). University of Hawai'I at Manoa. p. 186.

Silva, J.M.C, Bates, J.M. 2002. Biogeographic Patterns and Conservation in the South American Cerrado: A Tropical Savanna Hotspot. BioScience 52: 225-234.

Tannus, J.L.S., Assis, M.A. 2004. Composição de espécies vasculares de campo sujo e campo úmido em área de cerrado, Itirapina - SP, Brasil. Revista Brasileira de Botânica 27: 489-506.

Villela, F.N.J, Nogueira, C. 2011. Geologia e geomorfologia da estação ecológica Serra Geral do Tocantins. Biota Neotropica, 11: 217-230.

Zar, J. H. 1999. Biostatistical analysis. Pearson Education India. 